\title{
The Long Term Effects of Forcible Assimilation Policy: The Case of Indian Boarding Schools
}

\author{
Donna Feir \\ Department of Economics, University of Victoria \\ Victoria, B.C., Canada V8W $2 Y 2$
}

November, 2013

\begin{abstract}
For decades in North America and Australia, indigenous children were forcibly removed from their homes and placed in boarding schools. These schools had the stated goal of cultural assimilation and are perceived to have been an educational failure. I offer the first causal evidence on the long run effects of these schools using the interaction of changes in Canadian national policy and variation in the power of the Catholic Church. I find that the average boarding school had substantial effects on both cultural and economic assimilation. However, I find suggestive evidence that highly abusive schools only affected cultural connection.
\end{abstract}

Keywords: $\quad$ Assimilation, Boarding Schools, North American Indians

JEL Classifications: I20, I24, I25, I28, I38, J01, J15, J18, Z00 


\section{Introduction}

There are 370 million indigenous people throughout the world (UN 2009), and despite their diversity they often live in more difficult economic and social circumstances than the average people in their countries. In the United States, for example, American Indians on reservation earn 39 percent less than the average American (Cornell and Kalt 2010), while in Canada registered Indians earn 45 percent less the average Canadian (MacDonald and Wilson 2010). Similar disparities exists in Australia (Altman, Biddle and Hunter 2008), New Zealand (Maani 2004), Latin America (Hall and Patrinos 2006), the Arctic and Northern Europe (Andersen, Kruse and Poppel 2002) and Asia and Africa (Hall and Patrinos 2012). Yet only a handful of economists have contributed to the discussion on the causes of this disparity..$^{1}$ This paper examines the long run consequences of a policy often held responsible for devastating consequences for Indigenous people across the world: the forcible removal of children from their homes and their placement in Indian boarding (residential) schools. These institutions are now illegal under international law (United Nations Declaration of the Rights of Indigenous people 2007) and have captured international attention (BBC News 2008; Smith 2009; The Economist 2000).

For decades, numerous governments throughout the world put residential schooling policies in place with the help of various religious organizations. These policies aimed not only to educate Indigenous children, but also to immerse them in a European way of life $:^{2}$ Hundreds of thousands of children in the United States, Canada,

\footnotetext{
${ }^{1}$ The literature that exists includes the work by Cornell and Kalt (2000), Evans and Topoleski (2002), Kuhn and Sweetman (2002), Akee (2009), Dippel (2012), and Sunde, Jorgensen, and Akee (2012).

${ }^{2}$ See Miller (1996), Milloy (1999), Smith (2009), Glenn (2011), Dawson (2012).
} 
and Australia were affected by child removal and residential schools, and in all three countries there have been calls for compensation and federal government apologies ${ }^{3}$ In Canada and Australia, these policies have been subject to scathing public inquiries (RCAP 1991, Commonwealth of Australia 1997) and, in Canada, they resulted in the largest class action settlement in Canadian history (Reimer 2010) and are notorious for physical and sexual abuse..$^{4}$ However, despite the widespread nature of these institutions and the numerous individual accounts of the negative impact of residential schools (Haig-Brown 1991; Fournier and Crey 1997; Grant 1996), there does not exist any rigorous statistical research on the schools' long run consequences $5^{5}$ I fill this gap and study residential schooling's long-run consequences for both economic and cultural assimilation using several novel sources of Canadian data. 6

I overcome the fact that the Canadian federal government systematically selected children to attend residential schools by leveraging the conflicting objectives of the Catholic Church, the federal government, and the Aboriginal people. Specifically, when the federal government started to shut down the residential schooling system, the Catholic Church differentially resisted school closures based on the local availability of alternative religious infrastructure. I take advantage of this

\footnotetext{
${ }^{3}$ See Gover (2000), Rudd (2008), Harper (2008), BSHP (2008-2011), and Cassidy (2009).

${ }^{4}$ See a short list of references include Miller (1996), Milloy (1999), The Economist (2000), Smith (2009), and The Truth and Reconciliation Commission of Canada (2012).

${ }^{5}$ The few statistics that exist are compiled by the Nuu-Chah-Nulth Tribal Council (1996), the Cariboo Tribal Council (1991); and Commonwealth of Australia (1997).

${ }^{6}$ The Canadian experience is similar in many respects to the American one (Smith 2009; Glenn 2011). In fact the Canadian system was based off of the American one (Milloy 1999, Miller 1996). While examining the American case would be interesting, there is no equivalent data I am aware of to address it. I measure economic assimilation by the probability of high school graduation, employment and the receiving social assistance while cultural assimilation is measured by the likelihood of leaving traditional communities, speaking an Aboriginal language at home and participating in traditional activities.
} 
variation within communities and cohorts by interacting the concentration of nonindigenous Catholics surrounding an Aboriginal community in 1941 with the national trend in residential school enrollment. Consequently, identification is based on the assumption that the interaction between the initial regional variation in the non-indigenous religious composition and national changes in residential school enrollment is not correlated with changes in outcomes within cohorts and Aboriginal communities. 7 In additional specifications, I use school opening, closure, and proximity to schools as identifying variation following in the spirit of Duflo (2004), Card (1995), Tyler (1994), and Neal (1997).

While many academics have argued that residential schooling produced a culturally stranded, uneducated, and impoverished population, others believe that the institutions generated a culturally connected, educated elite that spent their careers fighting for Indigenous rights..$^{8}$ Which depiction (if either) is correct has substantial implications for the economic development of Aboriginal communities. For example, a large body of literature suggests that accumulation of formal education is a driver of economic development, 9 and research on the economic conditions of American Indian reservations suggests that formal institutions which are rooted in traditional culture are the most successful (Dippel 2011; Cornell and Kalt 2000). The broader literature on the long term effects of historical trauma, such as the slave trade (Nunn 2008) and the holocaust (Acemoglu, Hassan, and Robinson 2011), would also suggest that residential schooling could have far reaching

\footnotetext{
${ }^{7}$ This is not unlike the strategies used in the local labor market literature that interacts initial regional variation with national trends (Blanchard and Katz 1992; Bartik 1993).

${ }^{8}$ Those that argue the former include Adams (1999), Milloy (1999), and Miller (2001). Those that argue the later include Gresko (1979), Reyhner and Eder (2004), Szaz (2006), and Glenn (2011).

${ }^{9}$ This literature is extensive. See Aghion and Howitt (2009) for a literature review.
} 
consequences.

I find evidence that attendance at a residential school results in both economic and cultural assimilation. Once selection into residential school attendance is accounted for, I find the increase in economic assimilation is substantial. Even conditional on reaching high school, residential schooling increases the likelihood of graduation by 17 percent. Residential schooling also reduces the likelihood of relying on government transfers by 16 percent and increases the probability of being employed in the labor market by approximately 15 percent and in addition, raises wages. The loss in traditional skills and cultural connection is also significant: individuals are 16 percent more likely to live outside Aboriginal communities, 10 percent less likely to participate in traditional activities and 8 percent less likely to speak an Aboriginal language in the home. These effects are substantial, For example, less than 20 percent of Aboriginal people in the sample speak an Aboriginal language at home. 10

I also find that even though residential schools actively, and at times aggressively, tried to eliminate cultural connection, the extreme assimilation policy within the schools did not drive cultural loss. Segregating indigenous children from nonindigenous children in residential schools may have actually preserved cultural connectedness into adulthood relative to alternatives that also removed them from the

\footnotetext{
${ }^{10}$ While these findings are consistent with the work done by Curto and Fryer (2013) on urban boarding schools for the poor, residential schools are unique in a number of dimensions. First, attendance at an urban boarding school is voluntary. Over the period I investigate, attendance at a residential school was not. Second, urban boarding schools remove children from their families and communities for five days out of the week. Residential schools removed children from their families and communities for most of the year and sometimes removed them for years at a time. Finally, residential schools existed purely for the Aboriginal population, were religious and intended to assimilate. In addition, unlike in Curto and Fryer (2013), the results presented here are not driven by females.
} 
home. Those children that lived with and went to school with predominately nonindigenous people were, if anything, more economically and culturally assimilated than those who attended residential schools with their indigenous peers. The results suggest that culture is transmitted through knowledgeable reference groups rather than through force. This speaks to the broader notion that individuals are most naturally assimilated when they are removed from their traditional reference group, especially during youth. This assumption is embedded in the research on identity and assimilation and inherent in government policies that attempt to break up ethnic communities or restrict the locations of immigrant settlement ${ }^{11}$ As far as I am aware, my research that demonstrates this empirically. My results also demonstrate that while externally attempting to impose culture without the full removal of a traditional reference group is not the most effective assimilation policy, partial removal can still have a substantial impact.

Residential schools are notorious for the abuses children suffered while attending. I address this by examining whether the effects of attending a residential school differ based on the abusiveness of the environment. To measure the abusiveness of the environment, I construct a ratio of filed abuse claims to the number of children that attended a given residential school over a given decade. I also examine whether the effect of residential schooling differs by the religion of the school. While I find the religion of the school matters little, relatively extreme ratios of abuse claims to enrollments are negatively related to economic and social outcomes.

Section 2 gives a brief description of residential schooling, its alternatives and the main actors in the system in order to put it into context. Section 3 discusses

\footnotetext{
${ }^{11}$ See Akerlof and Kraton (2000), Fryer and Levitt (2004), Austen-Smith and Fryer (2005), Fryer and Torelli (2010), and Akerlof and Kraton (2010) for the literature on identity.
} 
the main data sources used, the basic patterns in the data and explains how the selective process on the part of the federal government results in an identification problem. Section 4 formalizes the intuition given in Section 3 by laying out an empirical model of the residential schooling system in order to be precise about the nature of the identification problem. This section also clarifies how leveraging the disjoint objectives of the church, the federal government, and the Aboriginal people provides a solution to the identification problem. Section 6 presents the main results and extensions.

\section{Brief Background}

The history of Aboriginal education in Canada is not a simple one: it is often muddled with other broader and sensitive issues. I discuss here only the elements of the system necessary for understanding what follows. For more on the historical details of the system, see the first section of the online historical appendix.

A total of 139 residential schools existed and operated in every province and territory except Newfoundland and Prince Edward Island. Approximately 150,000 Aboriginal children attended these schools with more than half of these former students still living today (TRC 2012). Figure 1 shows the distribution of residential schools across the country during the peak of the system in 1930. The flags represent the locations of residential schools and the dots indicate the centroid of Aboriginal communities included in the 1991 Census.

The system involved three main actors: the missionaries (who opened, closed and operated the schools for most of their history); the federal government (who 
funded, regulated and enforced attendance); and the Aboriginal families (whose children could be compelled to attend these schools). The federal government's formal involvement began shortly after confederation in 1867 and was inspired by a complementary report by Nicholas F. Davin, who after visiting industrial schools in the United States, saw promise in the residential school model (The Davin Report 1879). For most of the system's history, the federal government had very little direct involvement in the operation of the residential schools themselves and relied on missionary participation. The federal government provided per capita grants and funds to establish schools, but the missionaries were the ones to propose the schools' location and their desire to offer a school was essential in determining whether a residential school was constructed. This religious involvement with residential schooling would continue until 1969 when the government and various religious denominations would end their partnership (Milloy 1999).

In addition to providing funding, and eventually regulations, for the residential schooling system, the federal government also enforced attendance at residential schools. In 1920, an amendment to the Indian Act made school attendance mandatory for all Indian children between the ages of seven and fifteen. Section A10(1) of the 1920 Indian Act states that "every Indian child between the ages of seven and fifteen years who is physically able shall attend such day, industrial or boarding school as may be designated by the Superintendent General...Provided, however, that such school shall be the nearest available school of the kind required," (Indian Act 1920, Emphasis added). The Act did not clearly define what determines the type of school that is "of the kind required" and left a substantial amount of discretion to the Superintendent General for student selection. This discretion resulted 
in residential schools being operated for "orphan children, children from broken homes and those who because of isolation or the migratory way of life of their families, are unable to attend day schools," (The Administration of Indian Affairs 1964, 44). After 1951, the welfare role of the residential schools became even more predominant as provinces began to provide child welfare services on reserves and to use residential schools as a resource. A successive series of confidential reports by Indian Affairs suggests that from the 1950s to mid-1960s 40 to 75 percent of children in residential schools were categorized as neglected (Milloy 1999). It should be noted that many children that were perceived to be neglected may actually have been well cared for and their removal was a consequence of cultural misunderstanding (Johnston 1983; Jacobs and White 1992).

If no other schooling options were available, children were forced to attend residential schools in order to comply with federal legislation. How strictly this legislation was enforced came down to the discretion of the government agent on reserve (the Indian Agent). If the Indian Agent desired to enforce the law to its full extent, children could be forcefully removed from their home by truancy officers and their parents subject to fines or imprisonment (Indian Act 1920). Some attempted to fight the system but were punished or threatened into submission (Haig-Brown 1991, 95-96; Haig-Brown 1991, 109) or, after 1945, would loose a substantial monthly income supplement (Milloy 1999, 205). if they did not comply with provincially legislated schooling ages. If Aboriginal children wanted to attend high school, the only option was often to attend a residential school or to board in a residential school while attending public school in a non-aboriginal community. 12

\footnotetext{
${ }^{12}$ For a more detailed discussion of the exact content of the admission regulations, please see the online historical appendix.
} 
The federal government's enforcement of attendance at residential schools varied over time. In 1945, government policy began to shift away from the residential schooling system after harsh critiques presented by Aboriginal peoples and members of the Indian Affairs department during Canada's review of its affairs after the Second World War (Leslie 2002). The federal government began to view residential schooling as a relic of the past. The government promoted the system's closure and started integrating children into public day schools with the assistance of the provinces. Figure 2 shows this sharp change in government enforcement of attendance at residential schools. While residential schools accounted for over 50 percent of enrollments in schools in 1945, they accounted for less than 20 percent by 1965 . Later, the federal government began to tighten the grounds for admission to residential schools and to put more stringent specifications on when removal of children from their homes was warranted. This further decreased the proportion of children attending residential schools (Milloy 1999, 219).

Aboriginal families were another important actor in the residential schooling system. There is significant evidence that Aboriginal people desired education, though demanding education in the form of residential schools was not the common pattern. Parents are frequently described as resistant to the residential schooling system, attempting to prevent their children from attending these schools both indirectly and overtly (Furniss 1995). Not until the late 1960s and early 1970s did Aboriginal parents have any active choice in the education of their children. Before then, "Indians took no part in the processes of education," (Hawthorn 1967, 40).

Residential schools were located both within Aboriginal communities and as far as hundreds of kilometers away. Although children were permitted to return home 
for summer vacation, children were often taken extraordinary distances to attend a residential school and many didn't see their family for years (Miller 1996, 311-312; Aboriginal Healing Foundation, 2002; McFarlane 1999). Unlike schools attended only during the day (day schools) the residential schooling system operated on a half day system for much of its history. Half the day was spent in academics and religion and the other half in skills such as shoe-making and other trades. However, by 1910 , the half day system did not involve as much instruction in trades as it did manual labour (Gresko 1986, 94). Although the half day system officially ended in 1951 (Milloy 1999, 227) it was abolished in Anglican schools in the mid-1940s and it continued in some schools until the late 1950s (Miller 1996, 530). Regimes at these schools tended to be much more regulated than a student's life at home (Gresko 1986, 33). Schooling also involved cultural learning such as ethics, music, differences between white and Indian ways of life, and gender roles. Children were only permitted to speak English and were either punished for speaking their native language or rewarded for not. Some of these punishments were severe. Examples of severe punishment include beatings to the point of permanent scarring (Crey and Fournier 1998, 62) and the insertion of needles into tongues (Aboriginal Healing Foundation 2002, 6).

Not all principals and teachers submitted to government preferences regarding English language usage and the restriction of parental visits (Barman 1986; Gresko 1986). Although the quality of education received at the residential schools has been questioned repeatedly over the history of the system, the small amount of academic literature on early federal day schools suggests education received at these schools was also poor (Hamilton 1986,17-18). In fact, day schools in Aboriginal 
communities were often operated by the same religious denominations that ran the residential schools and suffered many of the same challenges. Both types of institutions suffered from significant staff turn-over, were chronically underfunded, and employed unqualified teachers (The Department of Citizenship and Immigration 1965).

As the decades progressed children were integrated into public schools. By 1967, approximately 50 percent of Indian children attended public schools (Hawthorn 1967). Whether public schools offered a better learning environment than residential schools is not obvious. Socioeconomic and cultural misunderstandings between parents and teachers were prevalent. Children were often sent home because they were "dirty" or "improperly dressed" which was difficult to remedy due to the lack of bathing facilities in many Aboriginal homes common to many non-aboriginal ones. In addition, many Aboriginal students did not speak English or French as their first language and this resulted in communication barriers with their teachers at public schools (Hawthorn 1967). In addition, those children that could attend a public school from home could face bus commutes as long as two hours each way (Educational Task Force 1975, 33). Some children were simply too far from public schools to commute, so they would have to leave their homes to attend high school. If they did not stay in a residential school with other Aboriginal children, they stayed in private, predominately white boarding homes. These became a prevailing option after the closure of residential schools (Educational Task Force 1975).

The final fundamental actor in the residential schooling system was the missionary organizations that ran, organized and lobbied for the system. Of the total denominational residential schools established approximately 60 percent were 
Catholic, 30 percent Anglican with the remainder divided between various other Protestant groups (AANDC 2012). Missionaries had been setting up residential schools as education and conversion effort since the 1600s in New France, but only started to establish long lasting institutions in the 1830s in British Canada with the financial assistance of the Federal government (Miller 1996). Missionary organizations proposed the school's location and their willingness and initiative was essential in determining whether a residential school was constructed (Milloy 1999). The missionaries' perceptions were often paternalistic: some seemed to believe that they were more capable of determine an Aboriginal community's needs than the community itself. For example, the Anglican Church believed that "the Church represents in many of these developing areas the appropriate voice of peoples slowly emerging into community consciousness," (Anglican Church of Canada, Joint Committee, 1960, 796). These sorts of attitudes and the lack of involvement and control of Aboriginal people suggest that the existence of residential schools was due to supply, rather than demand concerns. The government showed surprising lack of direction and control in the construction and location of residential schools and rarely ever rejected a missionary's request for school funding (Milloy 1999, 56-58). The "battle for the souls" between various religious denominations often led to the quick establishment of residential schools and played a pivotal role in the operation of the system (Miller 2001). In fact, church political influence and passion extended the system far past the date the government believed it was optimal policy. The federal government at times faced fierce religious opposition to residential school closure, most notably on the part of the Catholic Church in Western Canada (Hawthorn 1967, Milloy 1999). 
Interestingly, it is this struggle and the conflicting goals of the Church, the federal government, and Aboriginal families that allows for identification of the impact of residential schooling on long term outcomes. The next section presents the main source of data used in this paper and presents the basic patterns. I argue that these patterns may be explained by the selective process that sorted children into schools, rather than the effect of residential school attendance itself.

\section{Data Source, Basic Patterns and the Identification Problem}

The main body of this analysis uses the confidential 1991 Aboriginal Peoples Survey (APS) Adult Retrieval file. The APS sample was derived from the Canadian census population that answered the long form questionnaire and claimed Aboriginal ancestry and/or individuals who were registered under the Indian Act. It is important to note that the survey does not include the institutional population (such as those in prisons) nor does it include the homeless. To the extent that residential schooling increases incarceration rates or homelessness, the results here will be biased. This issue is explored further in the online data appendix.

The APS 1991 includes a substantial fraction of individuals who were between the ages of seven and fifteen during the peak of the residential schooling system were largely still living and of working age. The oldest people who answered residential schooling questions were 65 years of age, thus would have been born in 1926 and been of the mandatory schooling age by 1933. I restrict my sample to include those individuals who are registered under the Indian Act, are members of an identified band, live in the western provinces (British Columbia, Alberta, Man- 
itoba and Saskatchewan) and are aged 20 to 65. I limit my sample to those who are registered under the Indian Act and are members of a band since these are the individuals that the residential schooling system was designed for.

Table 1 shows summary statistics of the dependent and independent variables of interest by whether or not a child attended a residential school. This includes all people independent of the time their closest residential school ceased operation. Individuals who attended residential schools are more likely to be female, tend to have solely Aboriginal ethnic origins and are on average ten years older than those who did not attend residential school. They are also located closer to their nearest major city.

Interestingly, the means comparison also reveals that children who attended a residential school are equally likely to have graduated high school as those who attended a day school. While many have claimed residential schooling was of low quality (Milloy 1999; RCAP 1996), these results suggest that they were no less successful than the alternative options for increasing high school graduation. Despite this educational equivalence, Aboriginal people who attended a residential school are more likely to receive government transfers and less likely to be employed. This falls in line with earlier suggestions that the system did not economically benefit the children who attended residential schools (Miller 1996). On the other hand, Aboriginal peoples who attended residential schools are more likely to speak an Aboriginal language at home and to participate in traditional activities. This is contrary to the claim these schools were culturally destructive. While it is possible these patterns are due to some causal relationship it is equally plausible that children that were selected to attend residential school were from relatively more traditional homes 
and more likely to abide by these traditions as adults. The next section lays out a framework to empirically distinguish between these two possibilities.

\section{The Empirical Framework}

The first possibility would be to use the large change in government policy around 1945 to identify the effect of residential schooling. The enforcement of residential school attendance by the federal government varied over time as a consequence of shifting public opinion and culminated in a sudden change in government policy as discussed above and as demonstrated in Figure 2, This figure explains why those who attended a residential school are much older than those who did not attend a residential school. However, this sharp change in policy coincided with a rising demand for education in Canada in general (Milloy 1999). At the same time, Aboriginal languages were in decline. As a consequence, subsequent generations are more likely have formal education and less likely to participate in cultural activities than the older generation are due to trends unrelated to residential school attendance. In this environment, it is clearly important to account for cohort effects which can not be seperated from national changes in government policy. It is also likely not credible to use regional variation in residential school attendance because of varying treaty obligations and geographic circumstances of the band are likely to influence both residential school attendance and other adult outcomes.

What is left is the variation within communities over time, net of national cohort trends. While this may seem like a promising source of variation, it is not robust to the selective enforcement of residential school attendance within communities and 
cohorts by the government. For example, if a community had slower than average economic integration, then the federal government (based on the historical discussion above) would likely reduce pressure to attend residential schools more slowly than in areas with faster than average economic integration. If this is related to outcome differences between cohorts within communities, this source of variation will also be invalid.

Given the above discussion, it is useful to be more formal about the actions and decisions of the government, Aboriginal families, and the missionaries. In this section I lay out a simple framework based on the historical accounts of the residential schooling system. I model the federal government as an enforcement agent who desires to assimilate and educate Aboriginal children. Aboriginal families are concerned with their children's well-being and choose how much to resist their children being taken to residential school. Together, the decision rules of the government and Aboriginal families determine the demand for residential schools. Missionary organizations are assumed to care only about converting Aboriginal children and choose the supply and location of residential schools on that basis. This framework is obviously a highly stylized, but its simplicity allows me to be precise about the nature of the endogeneity concerns and assists me in clarifying my identification strategy and its plausibility.

First, assume the government attempts to educate and assimilate Aboriginal children by selectively enforcing the provision that allows the state to remove children from their homes. The level of enforcement the government chooses to implement is child specific and given by $E_{i j t}$, where $i$ indexes children, $j$ a given child's community and $t$ their cohort. Enforcement should be thought of as the cost the gov- 
ernment imposes on parents if the child is not sent to residential school. Second, assume that a person's well-being is determined by their adult skills, specifically, their skills that are valued in the market and skills that are valued their traditional community. For the sake of comparability with the rest of the economics literature I will call skills that are valued in the labour market human capital and skills that are valued in a traditional community cultural capital. Aboriginal families care about whether their child attends a residential school or a day school because it has different consequences for their child's final accumulation of these skills. Aboriginal families choose some "level of resistance" regarding their child being taken to residential school based on these preferences and the other options available to their children. Parent's optimal amount of resistance is given by $\psi_{i j t}^{*} \sqrt[13]{13}$ A child attends a residential school if the amount of resistance chosen by their parent is less than government enforcement, $E_{i j t}>\psi_{i j t}^{*}$. This can be represented as:

$$
A_{i j t}=\left\{\begin{array}{ccc}
1 & \text { if } & E_{i j t}>\psi_{i j t}^{*} \\
0 & \text { if } & \text { otherwise }
\end{array},\right.
$$

where $A_{i j t}$ indicates attendance at a residential school.

We saw in section 2 that government enforcement varied along several dimensions. First, government enforcement varies by cohort due to changes in policy over time (demonstrated in Figure 2). The cohort-dependent level of enforcement is given by $C_{t}$. Enforcement also varies by community: the community specific level of enforcement is given by $B_{j}$ in the model ${ }^{14}$ This allows government preferences

\footnotetext{
${ }^{13}$ Examples of parental resistance include hiding their children, physically resisting the Indian Agent, or paying fines.

${ }^{14}$ I use $B_{j}$ to represent band which is not the same necessarily the same as geographic community.
} 
to vary over fixed community characteristics such as treaty region or proximity to the closest city. The government enforcement level also depends on the cost of sending a child to a residential school. The cost of enforcement for a cohort and community depends on the local supply of residential schools, given by $e\left(z_{j t}, \delta_{j}\right)$ where $\delta_{j}$ is the distance of the closest residential school to community $j$, and $z_{j t}$ indicates whether the school is open when cohort $t$ is of schooling age. ${ }^{15}$

Government enforcement is assumed to also depend on unobservable, individual specific, idiosyncratic endowments of market and cultural skill (which are given by $h_{i j t}$ and $\kappa_{i j t}$ respectively). The initial idiosyncratic endowments of cultural and market skill children receive will also determine their adult stocks of these skills independent of parental decisions. The government is assumed to care about these endowments since families with more adherence to traditional cultural norms were targeted historically. Adherence to traditional cultural norms is assumed to be correlated with fewer market skills because of the naturally limited time available to dedicate to each of these activities, but not perfectly so. Thus, the effect of cultural capital on the enforcement level, $\rho_{\kappa}$, is positive while the effect of human capital, $\rho_{h}$, is negative. I also allow the selection of individuals to depend on their gender and whether they have non-aboriginal ancestry, which is given by the vector $x_{i j t}$. There is also another unobservable idiosyncratic term that varies by cohort, community and individual, $v_{i j t} \sqrt{16}$ Thus the enforcement level for each individual is given by:

However, frequently they are and a set of fixed effects can be used for band or communities with no consequential effects on the empirical results.

${ }^{15}$ This can also be thought of as representing an existing contract with a religious group to operate the school for a specific band or group of bands.

${ }^{16}$ This is meant to represent Indian Agent specific preferences for residential school attendance for a particular child. Since Indian agents vary by time and place, $v$ also indexed by $j$ and $t$. 


$$
E_{i j t}=\lambda x_{i j t}^{\prime}+C_{t}+B_{j}-e\left(z_{j t}, \delta_{j}\right)+\varepsilon_{i j t} .
$$

where $\lambda$ is a parameter vector and $\varepsilon_{i j t}=\rho_{\kappa} \kappa_{i j t}+\rho_{h} h_{i j t}+v_{i j t}$.

Aboriginal parents know that the government will enforce attendance according to Equation 2, but do not observe $v_{i j t}$. Let $\bar{\kappa}_{i j t}$ represent total cultural capital and $\bar{h}_{i j t}$ total human capital. Human capital accumulates for each child according to the total amount of time they spend in school, given by $\tau_{s}$, where $s$ indexes the type of school ( $s=d$ for day school and $s=b$ for residential school), multiplied by the quality of the schooling given by $q$. Note that the time in boardings school will be greater than the time spent in a day school so $\tau_{b}>\tau_{d}$. The amount of cultural capital accumulated is given by the amount of time a child spends with their family over the course of their schooling years. This is given by $\bar{\tau}-\tau_{s}$ where $\bar{\tau}$ is the total time available during their schooling years. The accumulation rate of cultural capital is given by $\boldsymbol{l}$. The human and cultural capital accumulation equations are given respectively as $\bar{h}_{i j t}=q \tau_{s}+h_{i j t}$ and $\bar{\kappa}_{i j t}=\imath\left(\bar{\tau}-\tau_{s}\right)+\kappa_{i j t}$. Parent's utility is assumed to be given by the some linear combination of $\bar{h}_{i j t}$ and $\bar{\kappa}_{i j t}$ and parents choose their optimal level of resistance, $\psi^{*}$, accordingly. To solve the parental decision problem I assume that $\varepsilon_{i j t}$ is normally distributed with mean zero and variance equal to one.

To construct the outcome equations assume there exists a set of cultural outcomes, each given by $\kappa_{i j t k}$ and market outcomes, $e_{i j t m}$, whose return is given by $\alpha_{k} \bar{\kappa}_{i j t}+\tilde{B}_{j k}+\tilde{C}_{t k}+\alpha_{k 2}^{\prime} x_{i j t}$ and $\alpha_{m} \bar{h}_{i j t}+\tilde{B}_{j m}+\tilde{C}_{t m}+\alpha_{m 2}^{\prime} x_{i j t}$ respectively. ${ }^{17}$ The subscript $m$ indexes market outcomes and $k$ indexes cultural outcomes. The factors

\footnotetext{
${ }^{17}$ Given that most of the outcomes I have access to are binary I focus on zero/one outcomes here, but a similar intuition follows for continuous variables.
} 
$\tilde{B}_{j k}, \tilde{C}_{t k}$, and $\alpha_{k 2}^{\prime} x_{i j t}$, allow the return to a given cultural activity $k$ to vary by community, birth cohort and a set of individual characteristics such as gender and ethnic origins. Parameters specific to market activities are defined similarly. Whether an individual chooses to engage in each type of activity will depend on their return to that activity. If the return to that activity is positive they will engage in it, and if negative they won't. Substituting for $\bar{h}_{i j t}$ in the return to market activity $m$ will give the decision rule for engaging in market activities and substituting in for $\bar{\kappa}_{i j t}$ in the returns to cultural activity $k$ gives the cultural activity decision rule. Solving the parent's decision problem yields 18

\footnotetext{
${ }^{18}$ The parents decision problem and the outcome equations is repeated and expanded on in ap-
} pendix A. 


$$
\begin{gathered}
A_{i j t}=\left\{\begin{array}{ccc}
1 & \text { if } & \beta_{1}+\beta_{2}^{\prime} x_{i j t}-e\left(z_{j t}, \delta_{j}\right)+B_{j}+C_{t}+\varepsilon_{i j t}>0 \\
0 & \text { if } & \text { otherwise }
\end{array}\right. \\
e_{i j t m}=\left\{\begin{array}{ccc}
1 & \text { if } & \alpha_{m 1}+\alpha_{m 2}^{\prime} x_{i j t}+\alpha_{m 3} A_{i j t}+\tilde{B}_{j m}+\tilde{C}_{t m}+\eta_{m i j t}>0, \\
0 & \text { if } & \text { otherwise }
\end{array}\right. \\
\kappa_{i j t k}=\left\{\begin{array}{ccc}
1 & \text { if } & \alpha_{k 1}+\alpha_{k 2}^{\prime} x_{i j t}+\alpha_{k 3} A_{i j t}+\tilde{B}_{j k}+\tilde{C}_{t k}+\eta_{k i j t}>0, \\
0 & \text { if } & \text { otherwise }
\end{array}\right. \\
\eta_{k i j t}, \eta_{m i j t}, \varepsilon_{i j t} \sim N(\mu, \sigma), \mu=\left[\begin{array}{l}
0 \\
0 \\
0
\end{array}\right], \sigma=\left[\begin{array}{ccc}
1 & 0 & \rho_{1} \\
0 & 1 & \rho_{2} \\
\rho_{1} & \rho_{2} & 1
\end{array}\right]
\end{gathered}
$$

where $\kappa_{i j t k}$ represents a set of $k$ cultural outcomes and $e_{i j t m}$ a set of $m$ market outcomes, $\eta_{k i j t}=\alpha_{k} \kappa_{i j t}, \eta_{k i j t}=\alpha_{k} \kappa_{i j t}, i=1, \ldots N, j=1, \ldots, J, t=1, \ldots, T$, and $\rho_{1}=\alpha_{k} \rho_{k}$ and $\rho_{2}=\alpha_{m} \rho_{h} \cdot{ }^{19}$ The parameters $\tilde{B}_{j k}, \tilde{C}_{t k}$, and $\alpha_{k 2}^{\prime} x_{i j t}$, allow the return to a given cultural activity $k$ to vary by community, birth cohort and a set of individual characteristics such as gender. Parameters specific to market activities are defined similarly.

As a result of government selection being based on children's initial unobserv-

\footnotetext{
${ }^{19}$ Given that most of the outcomes I have access to are binary I focus on zero/one outcomes here, but a similar intuition follows for continuous variables.
} 
able endowments of human and cultural capital the outcome and attendance equations are correlated through their error terms. To evaluate the causal effect of residential school attendance on outcomes, an additional parameter - the correlation of the errors terms - must be estimated 20 For the model above to be identified independent of functional form restrictions there must be at least one variable that varies over both cohorts and communities and affects residential school attendance but not adult outcomes.

Note that in this framework, the cost of government enforcement depends on the time varying local supply of residential schools. This supply depended heavily (and does exclusively in this framework) on the decisions of the missionaries. If the geographic supply of residential schools is driven primarily by religious objectives rather than the selective process of the federal government, one could imagine using a community's distance from the closest residential school, $\delta_{j}$, and the process of the school's opening and closing, $z_{j t}$, as exogenous variation (i.e. I could impose that $e\left(z_{j t}, \delta_{j}\right)=\beta_{3} z_{j t}+\beta_{4} z_{j t} \delta_{j}$ in estimation).

However, thinking about the missionary's decision problem makes clear the strong restrictions required to use distance and school opening and closing as exogenous variation. Consider the decision of a missionary that is distance $\delta$ from community $j$. The missionary gets utility from educating and converting Aboriginal children. The missionary's indirect utility function can be given by:

$$
v_{\delta_{j}}=z_{j t} \gamma_{j t}^{1} \mathrm{E}\left[\sum_{i=1}^{N_{t j}} A_{i j t}\right]+\left(1-z_{j t}\right) \gamma_{j t}^{2} N_{j t}
$$

\footnotetext{
${ }^{20}$ Note that $\eta_{k i j t}$ and $\eta_{m i j t}$ do not have to be uncorrelated for the results to be consistent since this restriction is not imposed in estimation.
} 
where $A_{i j t}$ is equal to one when a child in community $j$ and time $t$ attends a residential school and zero otherwise. The expected number of children who will attend the residential school is given by $\mathrm{E}\left[\sum_{i=1}^{N_{t j}} A_{i j t}\right]$ and the proportion of those children who will be converted and educated is given by $\gamma_{j t}^{1}$ per dollar spent. The expectation is taken over the sum of the attendance equation in 3 for all individuals in a cohort and community. The per dollar fraction of the community that will be educated and converted if the missionary does not open a residential school given by $\gamma_{j t}^{2} N_{j t}$ where $N_{j t}$ is the number of Aboriginal people within a community. The variable $z_{j t}=1$ if the missionary opens the school and $z_{j t}=0$ otherwise. A similar intuition follows if the school is already open at aiven $t$ and $j$ and the missionary must decide to keep the school open or close it (although $\gamma_{j t}^{1}$ and $\gamma_{j t}^{2}$ will be different). Thus missionary decisions to open or close a residential will depend on $\mathrm{E}\left[\sum_{i=1}^{N_{t j}} A_{i j t}^{*}\right], N_{t j}, \gamma_{j t}^{2}$ and $\gamma_{j t}^{1}$ (the average attendance at a residential school, size of the Aboriginal population, and the relative cost effectiveness of conversion).

To use distance and the opening and closing of schools as exogenous variation, variations in $\mathrm{E}\left[\sum_{i=1}^{N_{t j}} A_{i j t}^{*}\right], N_{t j}, \gamma_{j t}^{2}$ and $\gamma_{j t}^{1}$ from their community and cohort averages must vary independently from human and cultural capital endowments $\kappa_{i j t}$ and $h_{i j t}$. In other words, if openings and closings are to be used directly as a source of exogenous variation, missionaries must only make decisions based on persistent impressions of a given community's residential school attendance given the selection process. This restriction is rather strong. For example, it assumes that missionaries cannot have rational expectations regarding student residential school attendance. In this framework, if one cohort in a community has relatively low market skill endowments then the government will select many children from this cohort to attend 
a nearby residential school. Consequentially, nearby missionaries may choose to open a school and keep it open. However, if successive cohorts in this community have higher market skill endowments, fewer children will successively be selected to attend a residential school. As a consequence, missionaries nearby may choose to close their school. If this story was systematically true, then the opening and closing of schools may be correlated with student outcomes through their human capital endowments and could not be used as exogenous variation.

Fortunately, this framework also suggests capitalizing on a cleaner source of variation. What the framework makes clear is that there is at least one factor that influences the supply of residential schools that does not enter demand. Specifically, the likelihood of conversion per dollar which enters the objective function of the missionaries (who control the supply of residential schools) but does not enter the decisions of the Aboriginal people or the federal government (whose joint decisions determine the demand for residential schools). Thus, the perceived effectiveness of religious alternatives available to the Aboriginal people could be used to directly determine the effect of residential school attendance. In the model, the size of $\gamma_{j t}^{1}$ relative to $\gamma_{j t}^{2}$ represents the per dollar likelihood of conversion through residential schooling relative to the likelihood of conversion using the existing religious infrastructure. Differing amounts of religious infrastructure imply differing returns from a residential school and thus differing levels of resistance to school closure on the part of the missionaries when the federal government attempted to reduce enrollments rates. If there were fewer options for non-secular education - or more competition from other religious organizations - missionaries would be less likely to close their residential school, which would reduce the cost of enforcement and thus 
kept enrollment rates higher for longer periods than in areas where there were more options for non-secular education or less competition from other religious organizations. Conditional on fixed geographic characteristics (such as distance from the closest major city), this sort of community-cohort variation in residential school attendance is a useful source of variation since it is plausibly exogenous from changes within communities and cohorts in adult outcomes.

The general religiosity of the non-aboriginal population surrounding an Aboriginal community should be highly correlated with the presence of a non-indigenous denominational school nearby and general religious infrastructure. Thus, historic variation in geographic religious composition should influence the trends in enrollments within communities over time. To capture this, I multiply the 1941 religious composition (specifically the Catholic proportion) surrounding an Aboriginal community with the deviation in national enrollment rates from their peak in the 1930s. Let $\gamma_{j t}^{2} / \gamma_{j t}^{1}=\gamma_{t} w_{j t=1941}$ where $w_{j t=1941}$ indicates the Catholic proportion in a census division surrounding an Aboriginal community in 1941 and $\gamma_{t}$ is the proportion of children nationally that attended a residential school in each cohort. Since $\gamma_{t} w_{j t=1941}$ is plausibly independent of variations in $N_{j t}$ and $h_{j t}$ and $\kappa_{t j}$, this proposed source of variation will not suffer from the same challenges as using $z_{j t}$ and $\delta_{j t}$ directly.

Given that I control for cohort effects and geographic fixed effects, I need the following assumption for identification: how the historic non-aboriginal religious composition in a given area interacts with the overall government-determined trend in residential school enrollment is conditionally independent of unobserved changes in outcomes between cohorts within communities. If this assumption holds and the 
variable just described is significantly correlated with attendance at a residential school, then the model is identified independent of functional form restrictions. An example of a phenomenon that might violate this restriction would be if the proportion of Catholic individuals (of the non-aboriginal population) influenced rate of change in discrimination against the Aboriginal population in proportion to the change in residential school attendance at the national level. So, for example, if the opportunities for employment of Aboriginal peoples increase when there is less discrimination, and in areas with a higher proportion of Catholic people decrease discrimination more quickly than those with a lower proportion of Catholic people, this estimation strategy would be biased toward finding positive economic effects of residential schooling.

From the above framework, the missionaries' choice of $\delta_{j}$ is a function of $\gamma_{j t}^{1}, \gamma_{j t}^{2}, \mathrm{E}\left[\sum_{i=1}^{N_{t j}} A_{i j t}^{*}\right]$, and $N_{j t}$. As a consequence, $e\left(z_{j t}, \delta_{j}\right)=e\left(\gamma_{j t}^{1}, \gamma_{j t}^{2}, \mathrm{E}\left[\sum_{i=1}^{N_{t j}} A_{i j t}^{*}\right], N_{j t}\right)$ where $\mathrm{E}\left[\sum_{i=1}^{N_{t j}} A_{i j t}^{*}\right]$ may depend on $N_{t j}, h_{j t}$, and $\kappa_{t j}$. If $\gamma_{j t}^{2} / \gamma_{j t}^{1}$ is an additively separable, linear component of this function, $e\left(z_{j t}, \delta_{j}\right)=\tilde{\beta}_{3} \gamma_{t} w_{j t=1941}+\tilde{f}\left(N_{t j}, h_{i j t}, \kappa_{i j t}\right)$, it implies that the error term, $\varepsilon_{i j t}$, in Equation 3 becomes $\tilde{\varepsilon}_{i j t}=\tilde{f}\left(N_{t j}, h_{i j t}, \kappa_{i j t}\right)+$ $\rho_{h} h_{i j t}+\rho_{\kappa} \kappa_{i j t}+v_{i j t}$. Assuming $\tilde{\varepsilon}_{i j t}$ is normally distributed with mean zero and variance one, both these models can be estimated by quasi-maximum likelihood (using a bivariate probit). The model's likelihoods are given in appendix $\mathrm{C}$.

The results of estimating the specifications given by Equation 3 can be found in section 6.1. This model allows me to estimate the causal effect of attending a residential school for all children (also known as the average treatment effect or ATE) and, perhaps more plausibly, the effect of attending a residential school for the children who actually attended (also known as the average treatment effect on 
the treated or ATET).

\subsection{Historical Plausibility}

The importance of religious entitlement in the operation and persistence of the residential schooling system cannot be underestimated nor can "the bitterness of the sectarian environment in which educational and evangelical experiment in Indian schooling was initiated," (Miller 2001, p.141). The sense of the religious competition between various denominations can even be felt entrenched in the legislation of the 1920 Indian Act: “... no Protestant child shall be assigned to a Roman Catholic school or a school conducted under Roman Catholic auspices, and no Roman Catholic child shall be assigned to a Protestant school or a school conducted under Protestant auspices," (Indian Act 1920, Section 10(1)). When the Act allowed for this section to be over-ridden by "written directive of the parent," the Anglican Church argued that it would be wiser to omit this clause from the legislation thus demonstrating possessiveness over the souls of Aboriginal children that superseded the value placed on parental rights (Anglican Church of Canada, Joint Committee, 1960, 800).

When the federal government began attempting to shut down the residential schools in favor of integrating children into the public education system "the churches would have their say and would make their influence felt," (Milloy 1999, 219). Especially intense feelings were expressed on the part of the Catholic Church. "The Roman Catholic Church regarded itself as the 'one true faith' and did very little to disguise its view that Protestantism... was at best an error and at worst dangerous heresy," (Miller 2001, 141) and non-secular education was looked at with particular 
disdain. For example, in 1965, an Oblate Father said this to his parishioners: "Satan and his legion, making a review of their positions came to the conclusion that they were losing ground the world over and the Indian population was not exempt; therefore, they changed their strategy...What is this strategy? Or, to put in modern words, what is this policy? To them religion must be done away with in all schools. A formula must be found to lure away the Indians from denominational schools. . ." (Hawthorn 1967, 57).

Although the differential resistance by the Catholic Church within western Canada to residential school closure to this point has not been quantitatively documented, the anecdotal evidence is suggestive. Specifically, there was major opposition to public integration and the closure of residential schools from the Catholic Church in western Canada where the provinces did not provide for public Catholic schools, but in Ontario and Quebec, where children could be easily integrated into Catholic day-schools, there was no opposition mounted (Milloy 1990, 220). Certain areas in western Canada were "hives of evangelism" - fractionalized amongst various religious groups and were political hot spots where religious control of education was particularly contentious and arguably there was an incentive for the Catholic church to hold as much ground as possible with the Aboriginal population (Miller 2001, 143). After extensively reviewing Indian Affairs department files acquired through the Freedom of Information Act, the preeminent historian on residential schooling in Canada concluded that "it was not study, nor quiet rational consideration and discussion, that dominated the discourse on the western schools over the next decade but political struggles over the fate of each school...the Department saw the church's hand behind every incident of opposition" and the fight took on a greater 
character of "who would control Indian communities"; there was even a suspicion in the Indian Affairs department that the various religious denominations and sympathetic officials were admitting children to residential schools who were not even perceived to be neglected in any sense in order to simply to keep the schools open (Milloy 1999, 231, 219).

The religious battle for souls and the political strength of the Catholic church is cited as one of the major reasons the residential schooling system took over 40 years to shut down once it was determined the system was no longer desirable (Milloy 1999). Perhaps this view is best expressed in one of the most extensive reviews of Aboriginal affairs in Canadian history:

"An examination of the attitudes of the denominational groups throws a light on the opposition experienced by the Indian Affairs Branch in its search for viable solutions. These attitudes act as a brake on the development of Indian education through the stress they place on their own privileges and on the dangers which school integration presents to faith and morals," (Hawthorn 1967, 62).

\footnotetext{
Although none of this historical discussion clearly demonstrates the mechanism for identification I propose, I view it as highly suggestive. After discussing the additional data collected to identify the effect of residential schooling, I go on to present empirical evidence for this channel of identification.
} 


\section{Additional Data}

In addition to the APS, I use several other data sources to construct the variables discussed in Section 4. The variables I construct include the distance of a community to the closest residential school, $\delta_{j}$, an indicator of whether the closest residential school was open when an individual was of schooling age, $z_{j t}$, the proportion of Catholics surrounding a community in $1941, w_{j t=1941}$, and the national residential school enrollment rates $\gamma_{t}$. I use information from the Aboriginal Healing Foundation on the dates of closure, opening and location of different residential schools across the country. ${ }^{21}$ At total of sixty-two schools are included in the main analysis. This is approximately half of all the residential schools that existed. The other schools are not used either because they were in the territories or the eastern provinces, closed before the time the individuals in my sample were of schooling age, many schools often listed separately are in fact geographic and religious continuations of each other and thus I do not count them as different entities, and, finally, at times schools of different religious affiliations existed in the same area and I choose only the closest school. The sample of schools is further restricted beyond the sixty-two schools because I limit attention to those communities with residential schools that closed before $19652^{22}$ In addition in specifications that in-

\footnotetext{
${ }^{21}$ These dates and locations can be found at http://wherearethechildren.ca/en/about/ahf.html. Last Retrieved September 29, 2012. These are not the only dates that could be used. For a discussion

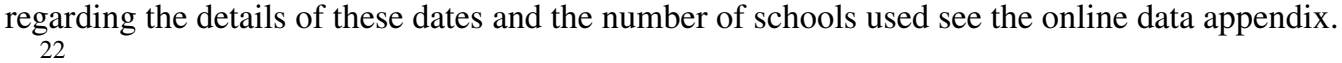

Past 1965 the federal government began to take over residential schools from the churches and the Aboriginal people began to acquire more authority in the education of their children and residential schools began to become more ambiguous in nature with some acting solely as hostels rather than schools. Restricting the analysis to schools that closed pre-1966 makes understanding what it means to attend residential school more straight forward and does not have a qualitative impact on the results.
} 
clude band (community) fixed effects, all bands with sample sizes less than 40 are excluded to ensure credible estimation.

To construct $z_{j t}$ and $\delta_{j}$ I combining data on the coordinates of Aboriginal communities provided by the Environmental Systems Institute with several provincial data sets from the Canadian Atlas Map Bundle on Canadian cities and towns which allows schools to be matched with communities. Residential schools are matched to cities/towns and then ARC GIS is used to locate the closest residential school to a given community ${ }^{23}$ Then, the closest residential school to each community is chosen using "as the crow flies" distance from the center of the community. This distance is used as the main distance measure $\delta_{j}$. By construction, all communities are tied to some residential school. For each cohort in each community $z_{j t}=1$ if a school was open when a given cohort would have been affected by the compulsory school attendance laws. Otherwise, $z_{j t}=024$

It is important to understand what the closure of the closest residential school implies. If the closest school to a community closes $-z_{j t}$ changes from one to zero - it implies that the cost of enforcement has increased for the federal government. This implies the government will have a weaker incentive to enforce attendance at

The only schools included in the match are those that existed in 1928 or later since it is the meaningful time frame for my sample. Using these files, the latitude and distance from the closest city are also calculated.

\footnotetext{
${ }^{24}$ Before 1945, the mandatory school attendance ages for Aboriginal children were defined through the Indian Act. In 1920, the mandatory ages for school attendance were seven to fifteen. In 1930, there was an amendment to the Indian Act to extend the mandatory ages to sixteen. To be eligible for the Family Allowance implemented in 1945, parents had to comply with provincial schooling laws. Thus, mandatory ages are defined to comply with both federal and provincial legislation after 1945. The provincial schooling ages and their changes over time after 1945 is taken from Riddell and Song (2011). Riddell and Song (2011) expand upon the initial data collected by Oreopoulos (2006).
} 
residential school and thus fewer children will attend. However, their still may be a subset of children who are forced to attend residential school despite its increased cost to the government. These children will attend a residential school further away. In addition, if the closest residential school was Catholic and a child's parents were Anglican, the closure of the closest residential school would not affect their attendance. As a consequence, the closure of the closest residential school does not induce attendance to drop to zero. Tests for a structural break in residential school attendance suggests the decrease in attendance after closure is 21.4 percent with a standard error of 6 percent. Tests indicate that there is no statistical trend in attendance before school closure, with the pre-closure slope coefficient of attendance equal to -0.01 with a standard error of 0.01 .

To construct a measure of historic religious infrastructure surrounding an Aboriginal community, I visually match 1941 census divisions and sub-divisions to their 1991 counterparts using the division maps from the 1941 and 1991 Census. At times this involves reconstructing the 1991 divisions using subdivisions in the 1941 data. Once comparable geographic regions are constructed, I use the 1941 census population counts to construct the proportion of non-aboriginal people in a division that are Catholic in 1941. This gives $w_{j t=1941}$. To estimate changes in national policy, $\gamma_{t}$, I use the national downward trend in residential school attendance from 1928 to 1966 from the Canada Year Book (1940-1970) and past 1966 I construct this measure using the proportion in each cohort that attended a residential school in the 1991 APS. Specifically for each year I use the proportion of children who would have been seven in that year minus the proportion who attended a residential school at the system's peak in 1934. Using historic geographical variation combined with 
national trends as exogenous variation is reminiscent of strategies used in the local labour market literature, specifically based on the work of Bartik (1991) and Blanchard and Katz (1992). Figure 3 illustrates how trends in residential school enrollment rates vary based on geographic religious composition. If there is a greater proportion Catholic in a region, the decline in residential school attendance is more dramatic as predicted by the logic above. This suggests using the non-aboriginal proportion Catholic in a region in 1941 could be a plausible proxy for either alternative religious infrastructure or religious competition.

The process of mapping individuals outside of Aboriginal communities to their "origin" community is more involved. Although the APS does not specify where an individual was born, it does specify what band an individual belongs to. More than half of these bands have a legally defined land base. A large fraction of these land bases link uniquely to one or two CSDs. Using Aboriginal Affairs and Northern Development Canada's (AANDC) legal-linkage files of bands to CSDs, I can reconstruct individuals" "origin" communities. If a band is linked to more than one possible sub-division, I use the 1991 Confidential Long Form Census files to estimate the probability of being from each of these CSDs. I then match individuals who currently reside outside one of the previously specified CSDs to the relevant area using the estimated probability distributions. A more thorough discussion of this process is given in the .

Although the APS is intended to be a representative sample of all Aboriginal communities, it will inherently have more noise for small communities than large ones. The Confidential Long Form 1991 Census files partially overcomes this problem and includes non-aboriginal people in the sample. It is not used for the main 
analysis since it does not have information on residential school attendance. Use of this sample allows me to compute the intent to treat for a larger set of Aboriginal communities and also allows me to construct a falsification test discussed in Section 6.1 .

\section{Results}

\subsection{Main Results}

One standard piece of evidence often provided in favor of random assignment is to show balance in observable covariates. Assuming observable variables are randomly drawn from a sample of total characteristics, observable variables being uncorrelated with the instrument is suggestive evidence that unobservable variables are also uncorrelated with the instrument and thus assignment to treatment is effectively random. Since the argument presented here requires conditional exogeneity, I regress the variables used as exogenous variation on a set of observable characteristics conditional on cohort and band fixed effects. The results from this exercise can be found in Table 2. While there is some evidence that the observables are correlated with opening and closure, there is far less evidence that they are correlated with the Bartik style instrument once band fixed effects are accounted for. This provides some suggestive evidence that the 1941 Proportion of Catholic multiplied by the national trend in residential school attendance, $\gamma_{t} w_{j t=1941}$, is not significantly correlated with unobservables. Of course, this is far from proof of the exclusion restriction, but it is at least reassuring. In addition, it should be noted that the pro- 
portion of Catholics in 1941 multiplied by the national trend in attendance enters the probability of being open $\left(z_{j t}\right)$ negatively as predicted by the model: if there is a higher proportion of Catholic individuals in a region, there will be more religious infrastructure; thus, the value of a residential school to the Catholic Church is lower, and the school is more likely to close.

Table 3 reports the results from the bivariate probit model described by Equation 3 using high school graduation as the outcome equation. The first panel uses the indicator of the school being open when the individual was of schooling age $\left(z_{j t}\right.$ and $z_{t j} \delta_{j}$ ) as the exclusion restriction. The second panel uses the Bartik style variation, $\gamma_{t} w_{j t=1941}$, as the exclusion restriction. The first column in each panel reports the estimated coefficients from the high school graduation determination equation (the $\alpha^{\prime} s$ in Equation 3), and the second column contains the results from the residential school attendance equation (the $\beta^{\prime} s$ in Equation 3). All the specifications include all bands over sample size 40 with 108 band fixed effect. The reason for these restrictions with the various geographic controls is due to convergence of the likelihood function and credible estimation of the time invariant effects ${ }^{25}$ First, the effect of residential school attendance on high school graduation is large, positive, and statistically significant in all specifications. Being female is positively associated with high school graduation, while distance from a major city and latitude are negatively correlated. The second panel presents the results from the attendance equation. Conditional on distance to the closest major city, latitude, solely Aboriginal ethnic origin, gender, birth cohort, and geographic fixed effects, the excluded instruments are significantly correlated with residential school attendance. In the

\footnotetext{
${ }^{25}$ The incidental parameters problem is not encountered in this context since the asymptotics are taken to be with respect to large $N$ rather than large $J$ or $T$ (Neyman and Scott 1948).
} 
online appendix tables, table 3 reports the first stage in a linear probability model. The F-statistics for the instruments are all above ten controlling for band fixed effects. If I include the full sample rather than just communities whose schools closed before 1965, then the F-statistics meet the more stringent criteria of Stock and Yogo (2003). However, it should be noted that the conditions for valid estimate in a bivariate probit specification are not necessarily the same as in linear IV regression. This is suggestive evidence that the model is well identified in the absence of functional form restrictions.

Table 4 reports the average treatment effect (ATE) and effect of the treatment on the treated (ATET) for a set of human and cultural capital outcomes and contains the main results of this paper. The treatment is whether or not an individual attended a residential school. I calculate the ATE by first predicting the probability that individuals in the sample would have a particular outcome if they were and were not to attend a residential school. I then average the predicted outcome probabilities if individuals were to attend a residential school and if they were to not attend a residential school. Finally, I subtract one from the other, which yields the ATE. The ATET is calculated similarly, but the sample is limited to only those individuals who actually attended a residential school.

All estimations include the same control variables as in Table 3 and band fixed effects. 26 The first panel contains the results from the specification that uses the Bartik style instrument as exogenous variation, while the second panel uses the open indicator and its interaction with distance. The first column reports an estimate of the ATE that does not account for selection into residential school attendance (i.e.

\footnotetext{
${ }^{26}$ The results are very similar if the model is estimated with the full sample and with province fixed effects.
} 
assuming $\rho=0$ ). The second column reports an estimate of the ATE that takes into account selection into residential school attendance. The third column reports the ATET, and the final column reports the correlation between residential school attendance and the outcome listed on the left most column $(\rho)$.

The first thing to note is that estimates of the ATE in the first and second column are notably different. In fact, the estimate of the ATE is actually of the opposite sign in the two columns. This implies accounting for the selection of children into residential school attendance is of substantial importance. If one were not to account for selection into attendance (as in the first column), one would conclude that residential schooling had little or positive effects on cultural outcomes, and generally negative effects on economic outcomes. The correlation coefficients reported in the fourth row in each panel clearly demonstrate that the selection of children into residential school is positively correlated with cultural outcomes, but negatively correlated with economic outcomes. In addition, the effects of residential school attendance are large. The more conservative specification suggests residential school decreased the likelihood of receiving government transfers by nearly 15 percent for those who attended. Given the proportion of individuals receiving government transfers in this group, this implies residential schools decreased government transfer receipts by 40 percent. Attendance at a residential school also dramatically increases the likelihood of high school graduation and employment.

However, this table also highlights the cultural implications of residential schooling. Conservative estimates suggest the the percentage of people who speak an Aboriginal language at home was reduced by nearly 30 percent due to residential schools. I arrive at this number since approximately 20 percent of individuals who 
attended a residential school currently speak an Aboriginal language at home. The most conservative estimates show this would have been at least 27.6 percent according to estimates of the ATET in Table 4. The reduction in participation in traditional activities due to residential schooling was about 12 percent for those who attended. This implies that the proportion of people in this group who participated in traditional activities would have been nearly double were it not for residential school.

While the results above are interesting, there are a few concerns about their interpretation. First, individuals may not honestly report whether they attended a residential school, and, even if they do, the residential schooling question is inconsistent between cohorts, which may bias estimates of the ATE and ATET. Second, although the APS was designed be a representative sample of all Aboriginal communities, the cost of running this extensive survey in remote areas may result in their under-representation. Third, spill-overs from individuals attending residential schools will bias the estimates of the ATE and the ATET. To overcome these problems, I use the 1991 Confidential Long Form Census files and estimate the effect of the intention to treat. Specially, I measure the effect of having an individual's closest residential school open during his or her schooling years. I then adjust this effect for how far away this residential school is. This larger data set includes more Aboriginal communities and this methodology captures any spill-over effects that residential schooling may have, while avoiding problems with non-random measurement error in residential school attendance.

Table 5 presents the results of this exercise. The row labeled "open" contains my measure of the intention to treat for each outcome listed in the top row. The intent to treat is measured in this context by the effect of a community's closest res- 
idential school being open when an individual was between the legally mandated schooling ages $\left(z_{j t}\right)$. The row labeled "open $\times$ distance" shows the decrease in this effect for every ten kilometers of distance between the residential school and the center of the community of interest $\left(z_{j t} \delta_{j}\right)$. The impact on high school graduation and employment is positive and significant, and impact on the likelihood of receiving government transfers is negative and significant, as before. There is also a 14 percent log point increase in the average log wage, but the impact on total weeks worked is insignificant. On the other hand, there is a negative impact on both the likelihood of living on reserve or speaking an Aboriginal language at home. Information on participation in traditional activities is unavailable in the census. To obtain an estimate of the ATE from the intention to treat, one merely divides the intention to treat by the percentage of individuals induced to attend residential school via the instrument (the compliers). This is approximately 20 percent. Doing this yields a larger estimate of the ATE than those calculated in Table 4 which suggests one of several things. First, there may be spill-over effects from individuals attending a residential school. Second, smaller Aboriginal communities missed in the APS may be more intensely impacted by residential schools. Finally, there may be misreporting of residential school attendance which biases the estimated effect toward zero. These results reinforce the findings of Table 4; residential schools increased economic integration at the expense of cultural connection.

To offer further support of the exclusion restriction we can perform this same exercise for geographically adjacent non-indigenous cohorts. If opening and closing are not correlated with changes in local conditions reflected in the outcomes of non-indigenous people (such as employment conditions or educational opportuni- 
ties) then we should observe no effect of an "intention to treat" as measured above on non-indigenous people. Table 6 estimates the intent to treat for non-aboriginal people who lived in the census divisions where the Aboriginal communities of interests are located. In nearly all specifications, estimates of the intent to treat are small and insignificant. In the one case it is significant the effect is of the opposite sign to that in Table 5. This supports the conclusion that, to the extent changing conditions among the non-aboriginal and Aboriginal people are correlated, changing local conditions are not driving the findings in Table 5 .

Another concern regarding the results above regards the matching procedure. Those off reserve had to be matched back to their "origin communities" using information on band membership and the geographical association of bands. There is necessarily error in this matching process due to changes in band names over time and misreporting of band information. Consequently, both of the instruments may be more weakly associated with the off reserve population than the on-reserve population. To address this Table 7 splits the sample by those who had to be matched back to an origin community and those who already lived in one. Table 7 demonstrates that the effect of residential schools is similar both on and off reserve although the estimates for the off reserve population are less precise. This implies that the economic effects of residential schools were not driven by leaving the reservation: an individual can still retain traditional cultural connections (as represented by living on reserve) and engage in the labor market. This suggests that although residential schooling did result in migration off reservations, communities could still potentially benefit from the formal educational consequences of the schools. While Table 7 only reports the results using the Bartik style instrument as a source of 
identifying variation, qualitatively the same results are found using openings, closing and distance from the closest residential school. These are reported in online appendix in Table 14 .

\subsection{Mechanisms}

Obviously, the treatment effects discussed above is really bundled effect of several treatments. For example, the "effect" of attending a residential school is relative to a number of counterfactuals: attending a federal Indian day school, a provincial non-Indian school, not attending school, and living at home versus not living at home. As a consequence it is difficult to draw general economic lessons from the estimates above. I narrow down the possible channels by restricting the sample to exclude alternative counterfactuals. I first investigate whether the increase in high school graduation was purely a mechanical phenomenon due to access. Second, I examine the extent to which the effects of residential school were due to the culturally oppressive environment versus the removal from the home and community into a non-indigenous environment.

In the first exercise, I limit my sample to individuals who have a grade ten education at minimum. By definition, all members of this subgroup had access to high school. If the effect of residential school on high school graduation is still found it implies that the effect was not solely due to access. Table 8 demonstrates that residential schools' impact on high school graduation was not purely mechanical. Panel (1) includes the full sample, all the control variables as in previous specifications and provincial fixed effects. Panel (2) includes all individuals in bands that have a sample size greater than 40 and all the control variables in previous spec- 
ifications and band fixed effects. It becomes immediately apparent that the effect of residential school attendance on those who attended is not due to access alone. In the preferred specification (with full band fixed effects and the Bartik style instrument), none of the effect of residential schooling is accounted for through this channel.

In the second exercise, I leverage information available in the APS on where an individual lived during school in order to determine whether some particular environmental characteristic within the residential school drove the results presented in the last section, or if it were more plausibly due to removal from the community. Those under the age of forty-nine were asked whether they lived at a residential school, at home, with an Aboriginal family other than their own, a non-aboriginal family, or "somewhere else." Given the historical context, "somewhere else" was likely a de-segregated foster or boarding home. The objective is to isolate the effect of the residential school environment from the effect of an individual being removed from their community or family. To do this I restrict the sample to only individuals who attended school while away from their families. As a consequence of the sixties sweep, and the binding nature of capacity constraints on either residential school enrollment or the Children Aid societies, there was a sizable proportion of children that were removed from their communities and that where both in residential schools and not in residential schools, but still away from their homes. Limiting the sample to only those people who attended school while staying away from home (with a non-aboriginal family, "somewhere else", or a residential school), and reestimating the model, will net out any effect of home removal from the results.

In addition, since children who stayed at home to attend school, and those who 
went away to attend school and did not go to a residential school, were extremely likely to receive the same form of high school education, I can infer that the difference between these results and in the full sample of those under forty-nine is due to removal from the home. Figure 4 supports the argument that those who did not attend a residential school where very likely to have the same quality of schooling. It demonstrates that high school education was either provided by provincial public schools or residential schools during this time period: graphically this is indicated in Figure 4 by the dotted "Federal High School" line almost overlapping the "Residential High School" line ${ }^{27}$ Table 9 shows the results from estimating the model within this sub-sample. In this sub-sample, residential schools played a relatively minor role in high school graduation rates, increased the likelihood of receiving government transfers, increased the likelihood of living on reserve and increased the likelihood of speaking an Aboriginal language. These results suggest that residential schools' primary effect was through removal from the home or community environment.

\subsubsection{Religion and Abuse}

If there is heterogeneity in student treatment over time and by school, the effect of residential schooling will differ. In this section I explore whether the religion of the residential school attended mattered for long-run outcomes and also whether students who attended schools that had relatively abusive environments in certain decades were affected differently than students who attended in less abusive eras.

To explore the issue of abuse I construct a measure of the abusiveness for each

\footnotetext{
${ }^{27}$ Note that it must also be true that are not extreme differences in the ease of access to high schools between children.
} 
school and decade I am able to obtain information for. To do this, I construct the proportion of students who were abused in each school and decade using data from Aboriginal Affairs and Northern Development Canada on the number of individuals who attended each residential school in each decade and data from the Indian Residential School Adjudication Secretariat on the number of approved abuse claims by school and decade. If a school in a given decade had five or fewer cases of abuse, the Adjudication Secretariat suppressed the observation. I assume all decades and schools not in the sample had five individuals who were abused to account for this censoring. Then I scale up the number of abuse cases reported in each schooldecade to account for the fact the sample I have access to represents only about 30 percent of the total expected abuse claims. 28 I then divided this number by the total number of children who attended a school in a given decade. This gives an estimate of the expected proportion of children abused by school and decade. Although the levels of abuse calculated here are obviously an underestimate, the Adjudication Secretariat believes this sample is representative of the final distribution of abuse cases. See online appendix, section $\mathrm{B} .4$ for a further discussion of this data and its possible limitations.

Table 11 contains descriptive statistics for the proportion of students abused from these data. The first column contains the proportion of students who have successfully filed an abuse claim over the total proportion of students who attended that school in that decade. The second reports the scaled estimates. The table reports the mean, median, 95th percentile, and maximum proportion of individuals who have filed successful abuse claim or who are expected to do so. The table indicates that

\footnotetext{
${ }^{28}$ The number of approved cases I have access to is 8,960 and a total of 29,000 is expected.
} 
abuse outcomes are highly skewed. The vast majority of schools in most decades have five or fewer cases of abuse. However, the results from some decades are dramatic, with the greatest proportion of children who have filed successful abuse claims reaching 44 percent.

I link the information on the proportion of students abused in each school and decade to individual observations in the APS by the decade an individual was seven years of age and the closest residential school. Merging the data on abuse with the APS results in some loss of information. I do not include all schools in all decades for the reasons discussed in the data section. In addition, in the original analysis I included schools that were not covered under the Independent Assessment Process. ${ }^{29}$ I then construct two indicators of whether a school had an "abusive environment" in a given decade. I count a school-decade as having an abusive environment if the school-decade was in the 95th or 99th percentile of school-decade abuse proportions. This corresponds to proportions between 8 and 14 percent.

Table 12 reports the marginal effects of residential school attendance (given in the row labeled "attendance"), whether the school had an abusive environment (the two different percentiles interacted with attendance) and the school's religion (Anglican, Methodist or Presbyterian - Catholic schools are used as the comparison group). Opening, closing, and distance are used as exclusion restrictions and all specifications include latitude, gender, distance from closest city, an indicator for only Aboriginal ancestry, birth cohort and provincial fixed effects. All previous conclusions regarding the effects of residential school attendance are unchanged. Presbyterian schools perform worse than Catholic schools in economic outcomes,

\footnotetext{
${ }^{29}$ Only those decades in which the federal government had involvement with a school are covered under this process.
} 
but are more likely to have their former students marry. Methodists and Anglican schools do not seem to have different effects from Catholic schools. The effect of attending a school in the 95th percentile of school-decade abuse proportions is insignificant in most cases. On the other hand, the impact of attending a residential school in a decade with abuse proportions in the 99th percentile has substantial effects on outcomes 30 The likelihood of employment is substantially decreased while the likelihood receiving government transfers increases substantially. Attending a school with a relatively abusive environment completely wipes out any positive economic effect of residential schooling. It should be noted that the reported specification includes only provincial fixed effects. Estimations of a full set of band fixed effects creates difficulties with convergence, so these results should be kept with this qualification in mind. However, it becomes clear from Table 12 that abusive environments and the religion of the school can have substantial effects on long run outcomes.

\section{Conclusion}

This is the first analysis to offer causal evidence on the long term consequences of forcible child removal and residential schools. To circumvent the non-random selection of children into residential schools, I use two connected sources of exogenous variation. The first source is geographic variation in the times of school opening, closing and changes in school distance. The second source uses a Bartik style instrument that exploits policy-driven national changes in residential school

\footnotetext{
${ }^{30}$ In the 99 th percentile there are approximately 70 observations. Thus, the results should be understood with this qualification in mind.
} 
attendance and its interaction with historic regional religious composition.

My results suggest that, on average, residential schools achieved their goals of economic and cultural assimilation. However, I find suggestive evidence that residential schooling was a less effective assimilation tool than the simultaneous removal of children from their homes and their placement in completely non-indigenous environments. These findings contribute to the literature on identity and peer group formation by providing the first evidence regarding the effects of partial and complete racial separation and aggressive attempts at assimilation.

The work here has mixed implications for the literature on the long term economic development of indigenous communities. The education and economic assimilation of indigenous peoples may aid in economic growth on reservations and may allow more effective interaction between indigenous people and the federal government. However, since indigenous cultural traditions were also been eroded, it may have been more difficult for communities to develop governance structures due to a lack of cultural common ground. Future work should investigate these possibilities.

Finally, this paper provides the first evidence regarding the long term effects of abuse on long run economic outcomes. While the results are merely suggestive and based on relatively small samples, there is evidence that attending a boarding school during a decade when there was a high level of abuse eliminates any economic integration generally associated with attendance at a residential school. 
Figure 1: Location of Residential Schools in 1930 and Aboriginal Settlements

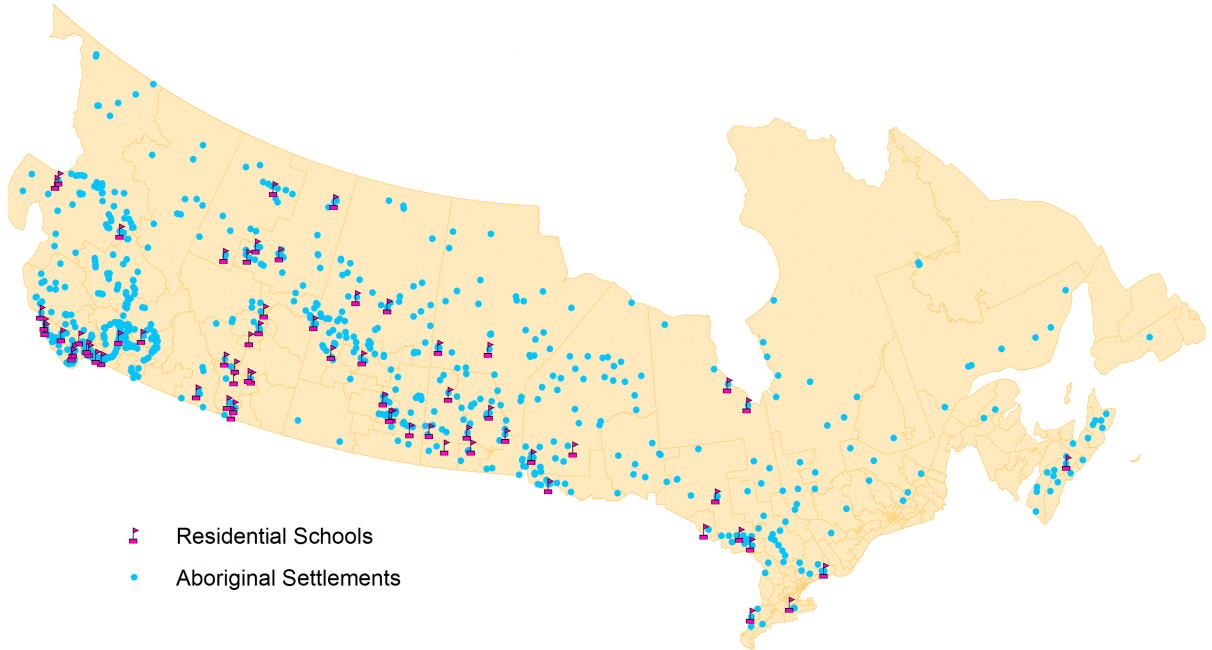

Notes: Data on Aboriginal settlements and positions of residential school locations compiled from geographic sources cited in the geographic references section. Data on resdiential schools compiled from "Where are the Children", by the Legacy for Hope Foundation. This source can be found at http://www.wherearethechildren.ca/. Last Accessed September 28, 2012.

\section{Tables and Figures}


Figure 2: The Percentage of Enrollment and Attendance Accounted for By Residential Schools

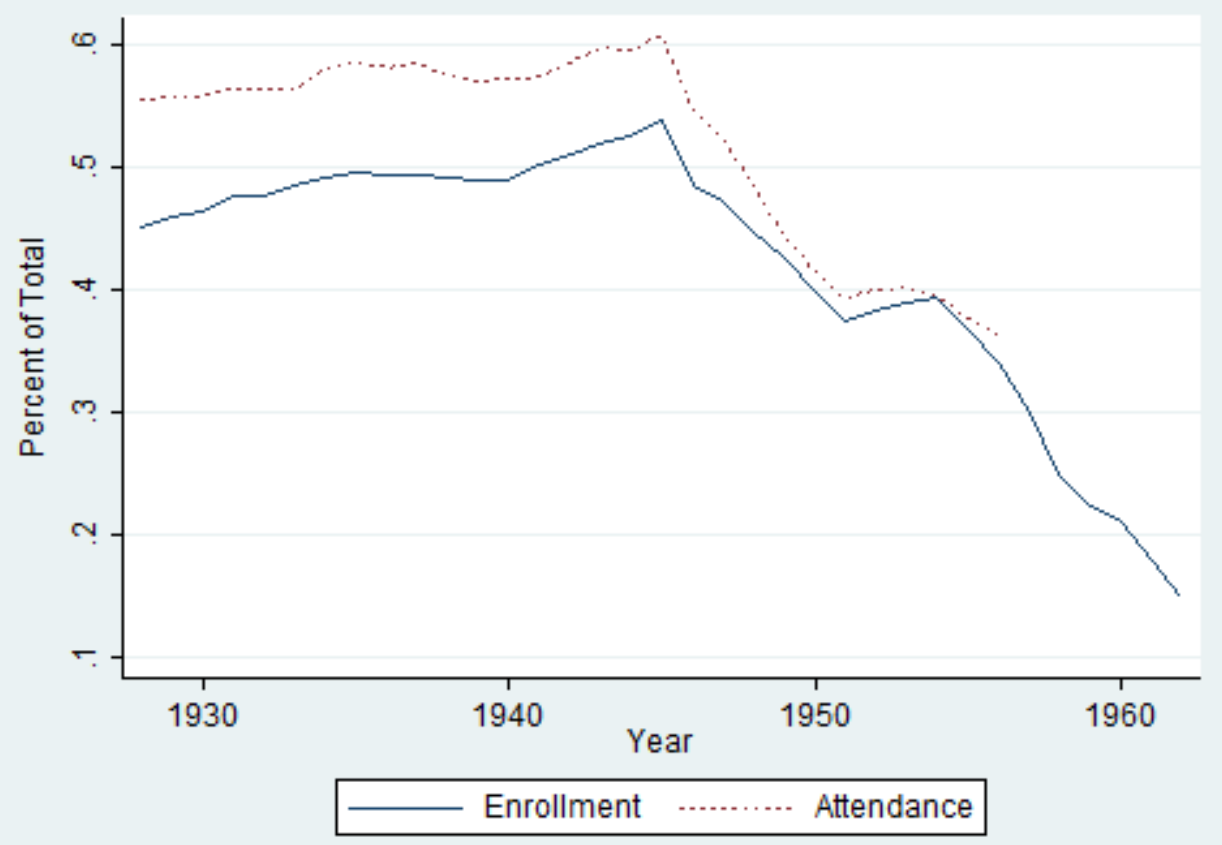

Notes: These calculations were made using the 1941 to 1980 Indian Affairs Reports. 
Table 1: Descriptive Statistics By Residential School Attendance

\begin{tabular}{|c|c|c|}
\hline & Attended & Did Not Attend \\
\hline \multirow{4}{*}{ Single Ethnicity } & 0.547 & 0.518 \\
\hline & $(0.012)$ & $(0.009)$ \\
\hline & 0.926 & 0.705 \\
\hline & $(0.007)$ & $(0.009)$ \\
\hline \multirow[t]{2}{*}{ Latitude } & 52.393 & 52.631 \\
\hline & $(0.060)$ & $(0.043)$ \\
\hline \multirow[t]{2}{*}{ Age } & 40.139 & 30.759 \\
\hline & $(0.286)$ & $(0.131)$ \\
\hline \multirow[t]{2}{*}{ Distance to City (KM) } & 109.19 & 116.85 \\
\hline & $(0.205)$ & 0.151 \\
\hline \multirow[t]{2}{*}{ High School Graduate } & 0.477 & 0.487 \\
\hline & $(0.012)$ & $(0.009)$ \\
\hline \multirow[t]{2}{*}{ At Least Grade 5} & 0.695 & 0.766 \\
\hline & $(0.011)$ & $(0.006)$ \\
\hline \multirow[t]{2}{*}{ Receive Government Transfers } & 0.372 & 0.274 \\
\hline & $(0.012)$ & $(0.007)$ \\
\hline \multirow[t]{2}{*}{ Employed } & 0.394 & 0.492 \\
\hline & $(0.012)$ & $(0.009)$ \\
\hline \multirow[t]{2}{*}{ In Aboriginal Community } & 0.559 & 0.348 \\
\hline & $(0.013)$ & $(0.006)$ \\
\hline \multirow[t]{2}{*}{ Participate in Traditions } & 0.147 & 0.068 \\
\hline & $(0.009)$ & $(0.004)$ \\
\hline Number of Observations & 5460 & 16999 \\
\hline Number of Schools & \multicolumn{2}{|r|}{62} \\
\hline
\end{tabular}

Notes: Standard errors are reported in parentheses. The variable labeled "Single Ethnicity" is a one if an individual claimed they only has Aboriginal ancestry and zero otherwise. The variable labeled "Participate in Traditions" equals one if an individual saw a traditional healer or participated in hunting, gathering, dancing and other traditional recreational and religious activities in the past year. 
Figure 3: How The Decline in Residential School Attendance in a Region Depends On The Local Proportion Catholic in 1941

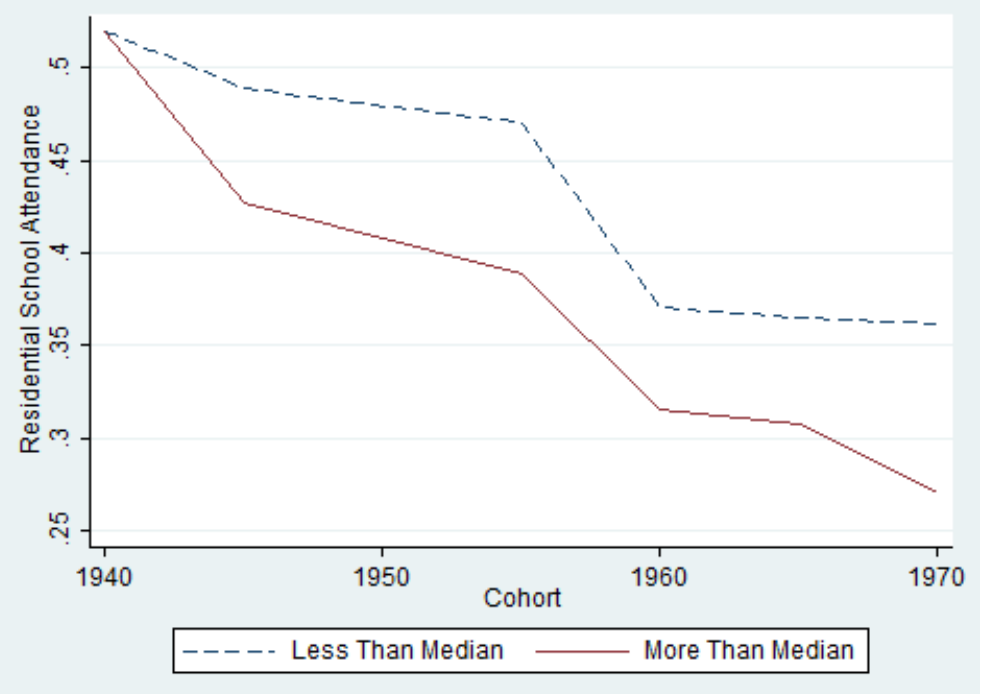

Notes: This figure uses data from the 1991 Aboriginal Peoples Survey in combination with data from the 1941 and 1991 Canadian Censuses. On the y-axis is average residential school attendance split whether the proportion Catholic was above or below the median proportion Catholic of non-indigenous people in a census division in 1941. These proportions are adjusted by gender, aboriginal ancestry, a fixed band effect, latitude and distance to closest major city. 
Table 2: What Determines Whether a School is Open When an Individual is of Schooling Age?

\begin{tabular}{lcccccc} 
& \multicolumn{5}{c}{ Dependent Variable } \\
\cline { 2 - 7 } Covariates & \multicolumn{2}{c}{ Open } & \multicolumn{7}{c}{ Open $\times$ Distance } & 1941 Prop Catholic $\times$ Trend \\
\hline Female & 0.126 & -0.034 & $-0.741^{*}$ & -0.280 & $-0.003^{*}$ & 0.001 \\
& $(0.074)$ & $(0.071)$ & $(0.312)$ & $(0.236)$ & $(0.001)$ & $(0.001)$ \\
Single Ethnicity & -0.025 & $0.395^{* *}$ & 0.104 & -0.148 & $-0.004^{*}$ & -0.003 \\
& $(0.125)$ & $(0.151)$ & $(0.565)$ & $(0.526)$ & $(0.002)$ & $(0.001)$ \\
non-aboriginal Emp Rate & -0.168 & $0.480^{*}$ & $1.585^{* * *}$ & $1.091^{* *}$ & 0.002 & 0.002 \\
& $(0.144)$ & $(0.196)$ & $(0.544)$ & $(0.397)$ & $(0.002)$ & $(0.001)$ \\
Latitude & $-0.157^{* * * *}$ & $-0.460^{* * *}$ & $2.388^{* * *}$ & $3.175^{* * *}$ & $0.002^{* * *}$ & 0.000 \\
& $(0.016)$ & $(0.132)$ & $(0.086)$ & $(0.476)$ & $(0.000)$ & $(0.001)$ \\
KM (10) to City & $0.038^{* * *}$ & 0.016 & $0.296^{* * *}$ & $0.203^{* *}$ & $0.001^{* * *}$ & $0.001^{* * *}$ \\
& $(0.004)$ & $(0.024)$ & $(0.026)$ & $(0.064)$ & $(0.000)$ & $(0.000)$ \\
1941 Prop Catholic $\times$ Trend & 0.232 & $-3.756^{* * *}$ & $-51.060^{* * *}$ & $-13.015^{* * *}$ & - & - \\
& $(0.717)$ & $(0.688)$ & $(3.859)$ & $(3.886)$ & - & - \\
\hline $\mathrm{N}$ & 11460 & 10271 & 11460 & 10271 & 11460 & 10271
\end{tabular}

Notes: Standard errors are reported in parentheses and are clustered by band and three year cohort.. Panel (1) is the full sample with province effects, while Panel (2) includes all bands with at least 40 people. The total number of bands in this specification is 108. Both specifications include a full set of cohort fixed effects. The reason for these restrictions with the various geographic controls regards convergence of the likelihood function and credible estimation of the time invariant effects. The dependent variable is indicator variable called "open" which is equal to one for an individual if the closest residential school to a community was open when they of the legally mandated schooling age (which depend on federal and provincial legislation). The asterisks indicate the level of significance: ${ }^{*} \mathrm{p}<0.10,{ }^{* *} \mathrm{p}<0.05,{ }^{* * *} \mathrm{p}<0.01$. 
Table 3: Residential School Attendance and High School Graduation: Coefficient Estimates from the Bivariate Probit Model

\begin{tabular}{|c|c|c|c|c|}
\hline & \multicolumn{2}{|c|}{ School Open and Distance } & \multicolumn{2}{|c|}{1941 Prop Catholic $\times$ Trend } \\
\hline & (1) & (2) & (1) & (2) \\
\hline \multicolumn{5}{|l|}{ High School Graduation } \\
\hline \multirow[t]{2}{*}{ Attendance } & $0.704 *$ & $0.604 * * *$ & 0.447 & $0.573^{* * *}$ \\
\hline & $(0.365)$ & $(0.191)$ & $(0.428)$ & $(0.207)$ \\
\hline \multirow[t]{2}{*}{ Female } & $0.257 * * *$ & $0.207 * * *$ & $0.269^{* * *}$ & $0.207 * * *$ \\
\hline & $(0.079)$ & $(0.055)$ & $(0.079)$ & $(0.057)$ \\
\hline \multirow[t]{2}{*}{ Latitude } & $-0.043 * * *$ & $-0.130^{*}$ & $-0.043 * *$ & $-0.128 *$ \\
\hline & $(0.016)$ & $(0.067)$ & $(0.017)$ & $(0.068)$ \\
\hline \multirow[t]{2}{*}{ KM (10) to City } & $-0.014 * * *$ & 0.006 & $-0.015 * * *$ & 0.006 \\
\hline & $(0.005)$ & $(0.011)$ & $(0.005)$ & $(0.012)$ \\
\hline \multirow[t]{2}{*}{ Single Ethnicity } & $-0.762 * * *$ & $-0.733 * * *$ & $-0.738 * * *$ & $-0.730 * * *$ \\
\hline & $(0.128)$ & $(0.126)$ & $(0.136)$ & $(0.131)$ \\
\hline \multicolumn{5}{|l|}{ Attendance } \\
\hline \multirow[t]{2}{*}{ Open } & $0.374 * * *$ & $0.684 * * *$ & & \\
\hline & $(0.102)$ & $(0.105)$ & & \\
\hline \multirow[t]{2}{*}{ Open $\times$ Distance } & $-0.036 * * *$ & $-0.041 * * *$ & & \\
\hline & $(0.007)$ & $(0.007)$ & & \\
\hline \multirow[t]{4}{*}{1941 Prop Catholic $\times$ Trend } & & & -1.573 & $-4.229 * * *$ \\
\hline & & & $(1.051)$ & $(1.011)$ \\
\hline & $0.140^{* *}$ & 0.045 & $0.147^{* *}$ & 0.064 \\
\hline & $(0.064)$ & $(0.047)$ & $(0.065)$ & $(0.049)$ \\
\hline \multirow[t]{2}{*}{ Single Ethnicity } & $0.521 * * *$ & $0.525 * * *$ & $0.493 * * *$ & $0.522^{* * *}$ \\
\hline & $(0.145)$ & $(0.126)$ & $(0.150)$ & $(0.128)$ \\
\hline \multirow[t]{2}{*}{ Latitude } & 0.011 & $-0.297 * * *$ & 0.001 & $-0.249 * * *$ \\
\hline & $(0.016)$ & $(0.077)$ & $(0.017)$ & $(0.077)$ \\
\hline \multirow[t]{2}{*}{ KM (10) to City } & 0.001 & $-0.029^{* *}$ & -0.005 & $-0.034 * * *$ \\
\hline & $(0.005)$ & $(0.019)$ & $(0.005)$ & $(0.012)$ \\
\hline Birth Cohort Fixed Effects & $\mathrm{X}$ & $\mathrm{X}$ & $\mathrm{X}$ & $\mathrm{X}$ \\
\hline Provincial Fixed Effects & $\mathrm{X}$ & & $\mathrm{X}$ & \\
\hline Band Fixed Effects & & $\mathrm{X}$ & & $\mathrm{X}$ \\
\hline \multirow[t]{2}{*}{ Correlation } & -0.254 & $-0.234 * *$ & -0.097 & $-0.222^{*}$ \\
\hline & $(0.237)$ & $(0.115)$ & $(0.256)$ & $(0.125)$ \\
\hline $\mathrm{N}$ & 11460 & 10271 & 11460 & 10271 \\
\hline
\end{tabular}

Notes: Standard errors are reported in parentheses and are clustered by band and three year cohort. Columns labeled (1) include the full sample with province effects. Columns lab§4t (2) includes all bands over sample size 40 with band fixed effects with a total of 108 bands. The reason for this restriction with the band fixed effects regards convergence of the likelihood function and credible estimation of the time invariant effects. All regressions include latitude, gender, distance from closest city, an only Aboriginal ancestry indicator, birth cohort fixed effects, the geographical effects specified. The first set of panels includes the open indicator and the distances to the school in the attendance equation while the second set of panels includes 1941 Proportion Catholic in individual's subdivision $\times$ (average attendance in that individual's cohort 
Table 4: The Impact of Residential School on Economic Outcomes

\begin{tabular}{|c|c|c|c|c|c|c|c|}
\hline & & & (1) & & & (2) & \\
\hline Outcomes & $\operatorname{ATE}(\rho=0)$ & $\operatorname{ATE}(\rho \neq 0)$ & ATET $(\rho \neq 0)$ & Correlation $(\rho)$ & $\operatorname{ATE}(\rho \neq 0)$ & ATET $(\rho \neq 0)$ & Correlation $(\rho)$ \\
\hline \multirow[t]{2}{*}{ HS Graduation } & $0.070^{* * * *}$ & $0.181 * * *$ & $0.179 * * *$ & $-0.222^{*}$ & $0.191^{* * * *}$ & $0.188 * * *$ & $-0.243^{* * *}$ \\
\hline & $(0.023)$ & $(0.044)$ & $(0.065)$ & $(0.125)$ & $(0.044)$ & $(0.066)$ & $(0.115)$ \\
\hline \multirow[t]{2}{*}{ Government Transfers } & 0.001 & $-0.158^{* * * *}$ & $-0.210^{* * * *}$ & $0.410^{* * * *}$ & $-0.117^{* * *}$ & $-0.153^{* * * *}$ & $0.289 * *$ \\
\hline & $(0.057)$ & $(0.042)$ & $(0.052)$ & $(0.134)$ & $(0.036)$ & $(0.045)$ & $(0.134)$ \\
\hline \multirow[t]{2}{*}{ Employed } & $-0.045^{* * *}$ & $0.121 * * *$ & $0.145 * * *$ & $-0.346 * *$ & $0.140 * * *$ & $0.172 * * *$ & $-0.398 * *$ \\
\hline & $(0.023)$ & $(0.043)$ & $(0.065)$ & $(0.175)$ & $(0.047)$ & $(0.070)$ & $(0.159)$ \\
\hline \multirow[t]{2}{*}{ In Aboriginal Community } & -0.021 & $-0.187 * * *$ & $-0.253^{* * * *}$ & $0.555^{* * * *}$ & $-0.085^{* * *}$ & -0.113 & 0.207 \\
\hline & $(0.019)$ & 0.062 & $(0.132)$ & $(0.196)$ & $(0.038)$ & $(0.073)$ & $(0.141)$ \\
\hline \multirow[t]{2}{*}{ Participate Traditional } & 0.008 & -0.078 & $-0.129^{*}$ & $0.552^{* * * *}$ & -0.057 & $-0.092^{*}$ & $0.412^{* * * *}$ \\
\hline & $(0.020)$ & $(0.064)$ & $(0.082)$ & $(0.147)$ & $(0.050)$ & $(0.066)$ & $(0.151)$ \\
\hline \multirow[t]{2}{*}{ Aboriginal Language } & $-0.021^{* * * *}$ & $-0.053 * *$ & $-0.076^{* *}$ & 0.141 & $-0.067^{* * *}$ & $-0.095 * *$ & $0.208^{*}$ \\
\hline & $(0.007)$ & $(0.030)$ & $(0.044)$ & $(0.136)$ & $(0.031)$ & $(0.045)$ & $(0.123)$ \\
\hline Source of Variation & & \multicolumn{3}{|c|}{1941 Prop Catholic $\times$ Trend $\left(\gamma_{t} w_{j t=1941}\right)$} & \multicolumn{3}{|c|}{ School Open $\left(z_{j t}\right)$ and Distance $\left(z_{j t} \delta_{j}\right)$} \\
\hline
\end{tabular}

$\mathrm{N}$

$\sim 10271$

Notes: The columns titled "ATE $(\rho=0)$ " contain the univariate probit marginal effects. The columns titled "correlation" contain the estimate of the correlation of the error terms between the outcome equations, whose dependent variable is listed on the left hand side, and the residential school attendance equation. Standard errors are reported in parentheses and are estimated by the Huber Sandwich Estimator. The columns titled "ATE" and "ATET" contain estimates of the average treatment effect and the effect of the treatment on the treated respectively. It can be understood as a summary statistic for the extent of unobservable selection bias. Both of their standard errors are calculated using the delta method, are reported in parentheses and are based off standard errors clustered at the band-and three year cohort level. The first panel used 1941 Proportion Catholic in an individual's census division $\times$ (average attendance in that individual's cohort - average attendance in cohort at peak 1934) in the attendance equation. The second panel includes the open indicator and the distances to the school in the attendance equation as the exclusion restriction. All regressions include latitude, gender, distance from closest city, an only Aboriginal ancestry indicator, birth cohort fixed effects, and band fixed effects with 108 bands in total. All bands included have a sample size of 40 . The sample size varies by the dependent variable and thus the number of observations, $N$, is approximate. The asterisks indicate the level of significance: $* \mathrm{p}<0.10, * * \mathrm{p}<0.05, * * * \mathrm{p}<0.01$. 
Table 5: Estimates of the Intent to Treat From the 1991 Census

\begin{tabular}{rcccc}
\hline Outcome & High School & Bachelor's Degree & Government Transfers & Employed \\
\hline \multirow{2}{*}{ Open } & $0.087^{* * *}$ & 0.008 & $-0.048^{* * *}$ & $0.052^{* * *}$ \\
& $(0.050)$ & $(0.005)$ & $(0.022)$ & $(0.024)$ \\
Open X Distance & $-0.018^{* * *}$ & -0.009 & $0.007 * *$ & $-0.006^{* *}$ \\
& $(0.004)$ & $(0.009)$ & $(0.003)$ & $(0.003)$ \\
$\mathrm{N}$ & 35574 & 35574 & 35440 & 35568 \\
\hline \multirow{2}{*}{ Outcome } & Total Ln Wages & Total Weeks Worked & On reserve & Aboriginal Language \\
\hline \multirow{2}{*}{ Open } & $0.140^{* * *}$ & 0.001 & -0.022 & $-0.042^{* *}$ \\
& $(0.065)$ & $(0.037)$ & $(0.034)$ & $(0.011)$ \\
Open X Distance & $-0.008^{*}$ & -0.004 & -0.005 & $0.012^{* * *}$ \\
& $(0.004)$ & $(0.003)$ & $(0.004)$ & $(0.004)$ \\
\hline \multirow{2}{*}{$\mathrm{N}$} & 19657 & 20400 & 34959 & 34787
\end{tabular}

Notes: The estimates reported are the probit marginal effects. Standard errors are reported in parentheses and clustered at the band-cohort level. All specifications include latitude, gender, distance from closest city, an only Aboriginal ancestry indicator, birth cohort fixed effects and band fixed effects with 458 bands in total. The asterisks indicate the level of significance: * $\mathrm{p}<0.10, * * \mathrm{p}<0.05, * * * \mathrm{p}<0.01$. 
Table 6: Estimates of the Intent to Treat For Those Who Are Ineligible: The Effect of Having the Closest School Open

\begin{tabular}{ccccccc}
\hline Outcome & High School & Bachelor's Degree & Gov't Transfers & Employed & Total Ln Wages & Total Weeks Worked \\
\hline \multirow{2}{*}{ Open } & $-0.059^{*}$ & -0.047 & -0.011 & -0.003 & 0.011 & -0.003 \\
& $(0.031)$ & $(0.035)$ & $(0.040)$ & $(0.032)$ & $(0.025)$ & $(0.011)$ \\
Open X Distance & -0.003 & -0.003 & 0.005 & 0.004 & $-0.007 * * *$ & 0.001 \\
& $(0.003)$ & $(0.004)$ & $(0.004)$ & $(0.003)$ & $(0.002)$ & $(0.001)$ \\
\hline \multirow{2}{*}{$\mathrm{N}$} & 41320 & 41320 & 59748 & 59740 & 46779 & 51033
\end{tabular}

Notes: The estimates reported are the probit marginal effects. Standard errors are reported in parentheses and clustered at the band-cohort level. All regressions include latitude,gender, distance from closest city, an only Aboriginal ancestry indicator, birth cohort fixed effects, and census division fixed effects. The indicator "open" is equal to one for an individual if the closest residential school to a community was open when they of the legally mandated schooling age (which depend on federal and provincial legislation). It is zero otherwise. "Open $\times$ Distance" is this indicator times the distance from the closest residential school. The asterisks indicate the level of significance: $* \mathrm{p}<0.10, * * \mathrm{p}<0.05, * * * \mathrm{p}<0.01$. 
Table 7: On and Off Reserve: Bivariate Probit Results

\begin{tabular}{|c|c|c|c|c|c|c|c|c|c|c|c|c|}
\hline \multirow[b]{3}{*}{ Outcomes } & \multicolumn{6}{|c|}{ on reserve } & \multicolumn{6}{|c|}{ off reserve } \\
\hline & \multicolumn{3}{|c|}{ (1) } & \multicolumn{3}{|c|}{ (2) } & \multicolumn{3}{|c|}{ (1) } & \multicolumn{3}{|c|}{ (2) } \\
\hline & ATE & ATET & $\rho$ & ATE & ATET & $\rho$ & ATE & ATET & $\rho$ & ATE & ATET & $\rho$ \\
\hline \multirow[t]{2}{*}{ HS Graduation } & $0.171^{* * *}$ & $0.167 * * *$ & -0.125 & $0.183^{* * *}$ & $0.179^{* * *}$ & -0.149 & $0.148 * * *$ & $0.177 * *$ & -0.221 & $0.168^{* * * *}$ & $0.199 * * *$ & -0.265 \\
\hline & $(0.028)$ & $(0.047)$ & $(0.135)$ & $(0.027)$ & $(0.047)$ & $(0.133)$ & $(0.055)$ & $(0.081)$ & $(0.254)$ & $(0.056)$ & $(0.083)$ & $(0.247)$ \\
\hline \multirow[t]{2}{*}{ Gov't Transfers } & $-0.084 * * * *$ & $-0.085^{* * * *}$ & 0.133 & $-0.060^{* * * *}$ & $-0.060^{* * * *}$ & 0.090 & -0.155 & $-0.221 * *$ & $0.647 * *$ & $-0.147^{*}$ & $-0.207 * *$ & $0.680 * * *$ \\
\hline & $(0.028)$ & $(0.031)$ & $(0.159)$ & $(0.027)$ & $(0.030)$ & $(0.152)$ & $(0.123)$ & $(0.134)$ & $(0.262)$ & $(0.114)$ & $(0.126)$ & $(0.255)$ \\
\hline \multirow[t]{2}{*}{ Employed } & $0.203^{* * * *}$ & $0.201 * * *$ & -0.335 & $0.171^{* * * *}$ & $0.171^{* * * *}$ & -0.278 & 0.032 & 0.041 & -0.399 & 0.053 & 0.066 & -0.444 \\
\hline & $(0.050)$ & $(0.070)$ & $(0.410)$ & $(0.040)$ & $(0.054)$ & $(0.313)$ & $(0.083)$ & $(0.101)$ & $(0.298)$ & $(0.089)$ & $(0.110)$ & $(0.283)$ \\
\hline \multirow[t]{2}{*}{ Traditional } & $-0.163^{*}$ & $-0.205^{* *}$ & $0.776 * * *$ & -0.032 & -0.037 & 0.149 & -0.043 & -0.071 & $0.612 * *$ & -0.069 & -0.118 & $0.396 * *$ \\
\hline & $(0.102)$ & $(0.113)$ & $(0.295)$ & $(0.037)$ & $(0.048)$ & $(0.201)$ & $(0.066)$ & $(0.096)$ & $(0.260)$ & $(0.108)$ & $(0.137)$ & $(0.201)$ \\
\hline \multirow[t]{2}{*}{ Aborig Language } & 0.004 & 0.004 & $-0.143^{*}$ & $-0.071 * * *$ & $-0.073^{* * *}$ & 0.062 & 0.008 & 0.012 & 0.011 & -0.009 & -0.014 & -0.154 \\
\hline & $(0.030)$ & $(0.043)$ & $(0.097)$ & $(0.027)$ & $(0.040)$ & $(0.114)$ & $(0.040)$ & $(0.070)$ & $(0.249)$ & $(0.038)$ & $(0.058)$ & $(0.196)$ \\
\hline Source of Variation & & $\gamma_{t} w_{j t=1941}$ & & & fit and $z_{j t} \delta_{j}$ & & & $\gamma_{t} w_{j t=1941}$ & & & $z_{j t}$ and $z_{j t} \delta_{j}$ & \\
\hline Birth Cohort FE & $\mathrm{x}$ & $\mathrm{x}$ & $\mathrm{x}$ & $\mathrm{x}$ & $\mathrm{x}$ & $\mathrm{x}$ & $\mathrm{x}$ & $\mathrm{x}$ & $\mathrm{x}$ & $\mathrm{x}$ & $\mathrm{x}$ & $\mathrm{x}$ \\
\hline Province FE & & & & & & & $\mathrm{x}$ & $\mathrm{x}$ & $\mathrm{x}$ & $\mathrm{x}$ & $\mathrm{x}$ & $\mathrm{x}$ \\
\hline Census Division FE & $\mathrm{x}$ & $\mathrm{x}$ & $\mathrm{x}$ & $\mathrm{x}$ & $\mathrm{x}$ & $\mathrm{x}$ & & & & & & \\
\hline F-Stat in First & & 34.71 & & & 25.24 & & & 4.50 & & & 0.63 & \\
\hline
\end{tabular}

$\mathrm{N}$

8789

2671

Notes: The columns titled "ATE" and "ATET" contain estimates of the average treatment effect and the effect of the treatment on the treated respectively. Both of their standard errors are calculated using the delta method, are clustered at the birth cohort-year level and are reported in parentheses. The columns titled " $\rho$ " contain the estimate the correlation of the error terms between the outcome equations, whose dependent variable is listed on the left hand side, and the residential school attendance equation. It can be understood as a summary statistic for the extent of unobservable selection bias. All regressions include latitude, gender, distance from closest city, an only Aboriginal ancestry indicator, birth cohort fixed effects, provincial fixed effects specified. The first set of panels that contain " $\gamma_{t} w_{j t=1941}$ " use the Bartik style variation for identification, while the panels that contain" $z_{j t}$ and $z_{j t} \delta_{j}$ " use the open indicator and the distances to the school in the attendance equation as the exclusion restriction. The asterisks indicate the level of significance: $*$ p $<0.10, * *$ $\mathrm{p}<0.05, * * * \mathrm{p}<0.01$. 
Table 8: Effect on High School Graduation Conditional on Obtaining At Least Grade 10: A Lower Bound on the Impact of Residential School on High School Graduation Rates

\begin{tabular}{|c|c|c|c|c|c|c|c|c|}
\hline & \multicolumn{8}{|c|}{ Sample Restriction: Conditional on Getting Grade 10} \\
\hline & \multicolumn{4}{|c|}{ Open and School Distance } & \multicolumn{4}{|c|}{1941 Prop Catholic $\times$ Trend } \\
\hline & \multicolumn{8}{|c|}{ (1) } \\
\hline \multirow{4}{*}{ HS Graduation } & Coefficient & $\operatorname{ATE}(\rho \neq 0)$ & ATET $(\rho \neq 0)$ & Correlation $(\rho)$ & Coefficient & $\operatorname{ATE}(\rho \neq 0)$ & ATET $(\rho \neq 0)$ & Correlation $(\rho)$ \\
\hline & $2.111 * * *$ & $0.135^{* * *}$ & $0.226^{* * *}$ & $-0.952 * * *$ & $1.871^{* * *}$ & $0.099 * *$ & $0.164 * * *$ & $-0.592 *$ \\
\hline & $(0.187)$ & $(0.024)$ & $(0.034)$ & $(0.228)$ & $(0.373)$ & $(0.059)$ & $(0.051)$ & $(0.334)$ \\
\hline & \multicolumn{8}{|c|}{ (2) } \\
\hline \multirow[t]{2}{*}{ HS Graduation } & $2.055^{* * *}$ & 0.112 & $0.185^{*}$ & $-0.846^{* * *}$ & $2.021 * * *$ & 0.108 & $0.179 * *$ & 0.890 \\
\hline & $(0.299)$ & $(0.141)$ & $(0.119)$ & $(0.366)$ & $(0.299)$ & $(0.114)$ & $(0.102)$ & $(0.600)$ \\
\hline
\end{tabular}

Notes: Standard errors are reported in parentheses and and clustered at the band-three year cohort level for the last set of panels and at the band-year cohort level for the first set of panels. The columns titled "ATE" and "ATET" contain estimates of the average treatment effect and the effect of the treatment on the treated respectively. Both of their standard errors are calculated using the delta method based off the standard errors clustered at the aforementioned levels above. The columns titled "correlation" contain the estimate the correlation of the error terms between the outcome equations, whose dependent variable is listed on the left hand side, and the residential school attendance equation. It can be understood as a summary statistic for the extent of unobservable selection bias. Panel (1) is the full sample with province effects. Panel (2) includes all bands over sample size 40 with fixed effects for band. The total number of bands in this specification is 108 . The reason for these restrictions with the various geographic controls regards convergence of the likelihood function and credible estimation of the time invariant effects. All regressions include latitude, gender, distance from closest city, an only Aboriginal ancestry indicator, birth cohort fixed effects, the geographical effects specified. All specifications include includes opening, closure and school distance in the attendance equation in the left hand panel and the 1941 Proportion Catholic in individual's census division $\times$ (average attendance in that individual's cohort - average attendance in cohort at peak 1934). The asterisks indicate the level of significance: $* \mathrm{p}<0.10, * * \mathrm{p}<0.05, * * * \mathrm{p}<0.01$. 
Table 9: Being Away from Home: The Effect of Residential School

\begin{tabular}{|c|c|c|c|c|c|c|}
\hline & \multicolumn{6}{|c|}{ Sample Restriction } \\
\hline \multirow[b]{2}{*}{ Outcome } & \multicolumn{3}{|c|}{$<49$} & \multicolumn{3}{|c|}{$<49$ \& Away } \\
\hline & ATE $(\rho \neq 0)$ & ATET $(\rho \neq 0)$ & Correlation $(\rho)$ & $\operatorname{ATE}(\rho \neq 0)$ & ATET $(\rho \neq 0)$ & Correlation $(\rho)$ \\
\hline \multirow[t]{2}{*}{ HS Graduation } & $0.225 * * *$ & $0.247 * * *$ & $-0.986 * * *$ & $-0.181^{*}$ & $-0.199 *$ & $0.308^{*}$ \\
\hline & $(0.007)$ & $(0.018)$ & $(0.765)$ & $(0.090)$ & $(0.101)$ & $(0.189)$ \\
\hline \multirow[t]{2}{*}{ Government Transfers } & $-0.229 * * *$ & $-0.281 * * *$ & $0.779 * * *$ & $0.089 *$ & 0.092 & -0.009 \\
\hline & $(0.001)$ & $(0.004)$ & $(0.158)$ & $(0.063)$ & $(0.079)$ & $(0.127)$ \\
\hline \multirow[t]{2}{*}{ Employed } & $0.148^{* * *}$ & $0.169^{* * *}$ & $-0.487 * * *$ & $-0.129^{*}$ & $-0.134 *$ & -0.049 \\
\hline & $(0.009)$ & $(0.023)$ & $(0.163)$ & $(0.083)$ & $(0.091)$ & $(0.222)$ \\
\hline \multirow[t]{2}{*}{ Participate Traditional } & $-0.079 * * *$ & $-0.109 * * *$ & $0.575^{* * *}$ & $-0.114^{* *}$ & $-0.048^{*}$ & 0.305 \\
\hline & $(0.006)$ & $(0.014)$ & $(0.181)$ & $(0.068)$ & $(0.033)$ & $(0.235)$ \\
\hline \multirow[t]{2}{*}{ Aboriginal Language } & $-0.218^{* * * *}$ & $-0.309 * * *$ & $0.875^{* * *}$ & $0.167 * * *$ & $0.177 * * *$ & $-0.450 *$ \\
\hline & $(0.001)$ & $(0.002)$ & $(0.157)$ & $(0.010)$ & $(0.020)$ & $(0.234)$ \\
\hline \multirow[t]{2}{*}{ In Aboriginal Community } & $-0.345^{* * *}$ & $-0.430 * * *$ & $0.845^{* *}$ & $0.034 * * *$ & $0.038^{* * *}$ & 0.145 \\
\hline & $(0.001)$ & $(0.001)$ & $(0.242)$ & $(0.011)$ & $(0.016)$ & $(0.237)$ \\
\hline
\end{tabular}

$\mathrm{N}$

9769

3899

Notes: The columns titled "ATE" and "ATET" contain estimates of the average treatment effect and the effect of the treatment on the treated respectively. Standard errors are reported in parentheses and are clustered at the birth cohort-band level and calculated using the delta method. The columns titled "correlation" contain the estimate of the correlation of the error terms between the outcome equations, whose dependent variable is listed on the left hand side, and the residential school attendance equation. It can be understood as a summary statistic for the extent of unobservable selection bias. The panel labeled " $<49$ " includes all people who were asked there they lived while attending schools, which is the less than 49 age group. The panel labeled " $<49$ and Away" includes only individuals who went to residential school, lived with a non-aboriginal family, or "somewhere else." All specifications include latitude, gender, distance from closest city, an only Aboriginal ancestry indicator, birth cohort fixed effects, provincial fixed effects. All specifications include includes open indicator and distance $\times$ open as excluded instruments. The asterisks indicate the level of significance: $* \mathrm{p}<0.10, * * \mathrm{p}<0.05, * * * \mathrm{p}<0.01$. 
Table 10: Does the Effect Vary by Era of Attendance?

\begin{tabular}{ccccccc}
\hline & \multicolumn{7}{c}{ Outcome } \\
\hline & High School & Government Transfers & Employed & Participate Traditional & Aboriginal Language & On Reserve \\
\hline \multirow{2}{*}{ ATE 1950-1965 } & $0.219^{* * *}$ & $-0.184^{* * *}$ & $0.147^{* * *}$ & $-0.075^{* * *}$ & $-0.232^{* * *}$ & $-0.384 * * *$ \\
& $(0.013)$ & $(0.006)$ & $(0.015)$ & $(0.013)$ & $(0.002)$ & $(0.001)$ \\
\multirow{2}{*}{ ATE Pre-1950 } & $0.137 * * *$ & $-0.258^{* * *}$ & $0.142^{* * *}$ & $-0.142^{* * *}$ & $-0.416^{* * *}$ & $-0.443^{* * *}$ \\
& $(0.033)$ & $(0.007)$ & $(0.041)$ & $(0.014)$ & $(0.002)$ & $(0.001)$ \\
\hline
\end{tabular}

Notes: Standard errors are reported in parentheses and are clustered at the birth cohort-band level. All regressions include latitude, gender, distance from closest city, an only Aboriginal ancestry indicator, birth cohort fixed effects, the provincial fixed effects. The attendance equation includes the open indicator and the distances to the school as the exclusion restriction. The columns titled "ATE 1950-1965" and "ATE Pre-1950" contain estimates of the average treatment effect for those who were aged seven after 1950 and those who were seven before, and the effect of the treatment on the treated, respectively. They were estimated using a bivariate probit which allowed the effect of residential school attendance to vary between these two eras. Both of their standard errors are calculated using the delta method. The asterisks indicate the level of significance: $*$ p $<0.10, * * \mathrm{p}<0.05$, $* * * \mathrm{p}<0.01$. 
Table 11: Descriptive Statistics Abuse

\begin{tabular}{|c|c|c|}
\hline Statistic & Using Sample of Abused Cases & Scaled Sample of Abused Cases \\
\hline Mean & 0.03 & $5 \%$ \\
Median & 0.02 & $3 \%$ \\
95th Percentile & 0.09 & $15 \%$ \\
99th Percentile & 0.21 & $36 \%$ \\
Max & 0.47 & $78 \%$ \\
\hline N & \multicolumn{2}{|c|}{434} \\
\hline
\end{tabular}

Notes: The proportion abused is calculated from data provided by Aboriginal Affairs and Northern Development on the number of individuals who attended each residential school in each decade. In addition, the Indian Residential School Adjudication Secretariat has provided the number of approved individuals who have applied for compensation for abuse under the Independent Assessment Process by school and by decade. If a school in a decade has five or less cases of abuse, the school is counted as having zero cases of abuse. The number of approved cases I have been given access to at this point include 8,960 cases, with total number expected to apply at 29,000. The Adjudication Secretariat predicts that this sample will be representative of the distribution of abuse cases among schools and decades, but the level of abuse is obviously an underestimate. To obtain a reasonable estimate of the level of abuse, I assume all decades and schools where abuse was not reported in my sample to have 5 individuals who were abused. Then I scale up all decades by 70 percent to arrive at the final estimates reported. This process will obviously entail error, but its ultimate effect on the estimates should not be affected since the measurements used in estimation are based on rank in the upper tail of the distribution rather than scale. The first column is the proportion abused by decade within the sample and the second column uses the scaled up numbers to construct the proportion. 
Table 12: Heterogeneity in the Effect of Residential Schooling: Religion and Abuse

ڤి

\begin{tabular}{|c|c|c|c|c|c|c|c|}
\hline \multirow[b]{2}{*}{ ATET of Interest } & \multicolumn{7}{|c|}{ Outcome } \\
\hline & HS Graduation & Government Transfers & Employed & on reserve & Participate Traditional & Aboriginal Language & Married \\
\hline \multirow[t]{2}{*}{ Attendance } & $0.234 * * *$ & $-0.184 * * *$ & $0.114^{* * * *}$ & $-0.383^{* * * *}$ & $-0.095 *$ & $-0.356^{* * * *}$ & $0.074 * * *$ \\
\hline & $(0.054)$ & $(0.044)$ & $(0.05)$ & $(0.163)$ & $(0.065)$ & $(0.286)$ & $(0.029)$ \\
\hline \multirow[t]{2}{*}{ Abuse 95 Perc } & -0.033 & 0.005 & $0.219^{* * * *}$ & 0.120 & -0.022 & 0.024 & $-0.097 * * * *$ \\
\hline & $(0.046)$ & $(0.065)$ & $(0.054)$ & $(0.152)$ & $(0.079)$ & $(0.431)$ & $(0.031)$ \\
\hline \multirow[t]{2}{*}{ Abuse 99 Perc } & -0.03 & $0.251 * * *$ & $-0.482 * * *$ & -0.145 & 0.101 & -0.038 & $-0.29 * * *$ \\
\hline & $(0.066)$ & $(0.077)$ & $(0.056)$ & $(0.253)$ & $(0.149)$ & $(0.652)$ & $(0.062)$ \\
\hline \multirow[t]{2}{*}{ Anglican } & -0.017 & 0.006 & 0.043 & 0.028 & 0.009 & 0.027 & -0.035 \\
\hline & $(0.044)$ & $(0.06)$ & $(0.050)$ & $(0.153)$ & $(0.084)$ & $(0.414)$ & $(0.032)$ \\
\hline \multirow[t]{2}{*}{ Methodist } & -0.073 & 0.024 & -0.011 & 0.026 & 0.004 & 0.011 & -0.032 \\
\hline & $(0.043)$ & $(0.062)$ & $(0.05)$ & $(0.154)$ & $(0.082)$ & $(0.403)$ & $(0.032)$ \\
\hline \multirow[t]{2}{*}{ Presbyterian } & $-0.33^{* * *}$ & 0.007 & $-0.168^{* * * *}$ & 0.176 & 0.041 & 0.195 & $0.093^{* *}$ \\
\hline & $(0.062)$ & $(0.07)$ & $(0.062)$ & $(0.17)$ & $(0.101)$ & $(0.526)$ & $(0.041)$ \\
\hline
\end{tabular}

Notes: The marginal effects are reported on residential school attendance (given in the row labeled "attendance"), whether the school had an abusive environment interacted with attendance, and whether the school was Anglican or Methodist, interacted with attendance. Standard errors are reported in parentheses, estimated by the delta method and clustered at the band-cohort level. All specification include latitude, gender, distance from closest city, an only Aboriginal ancestry indicator, birth cohort fixed effects and provincial fixed effects specified. The open indicator and distance $\times$ open are included in the attendance equation as excluded instruments and their interaction with abuse and the Anglican, Presbyterian and Methodist indicators. The asterisks indicate the level of significance: * $\mathrm{p}<0.10, * * \mathrm{p}<0.05, * * * \mathrm{p}<0.01$. 


\section{References}

[1] Aboriginal Healing Foundation. Response, Responsibility, and Renewal Canada's Truth and Reconciliation Journey. Ottawa: Aboriginal Healing Foundation, 2009. Accessed July 23, 2012. http://www.ahf.ca/downloads/trc2.pdf.

[2] Aboriginal Healing Foundation. The Healing Has Begun: An Operational Update from the Aboriginal Healing Foundation. Ottawa: Aboriginal Healing Foundation, 2002. Accessed May 14, 2013. http://www.ahf.ca/downloads/thehealing-has-begun.pdf.

[3] Adams, David W. Education for Extinction: American Indians and the Boarding School Experience, 1875-1928. Lawrence: University Press of Kansas, 1995.

[4] Acemoglu, Daron, and Tarek A. Hassan, and James A. Robinson. "Social Structure and Development: A Legacy of the Holocaust in Russia." The Quarterly Journal of Economics 126(2011): 895-946.

[5] Aghion, Philippe, and Peter Howitt. The Economics of Growth. Cambridge: MIT Press, 2009.

[6] Akee, Randall, Miriam Jorgensen, and Uwe Sunde. "Constitutions and Economic Development: Evidence from the American Indian Nations.” (2012): memo. 
[7] Akee, Randall. "Checkerboards and Coase: The Effect of Property Institutions on Efficiency in Housing Markets." Journal of Law and Economics 52(2009): 395-410.

[8] Akerlof, George A., and Rachel E. Kranton. "Economics and identity." The Quarterly Journal of Economics 115(2000): 715-753.

[9] Akerlof, George A., and Rachel E. Kranton. Identity Economics: How Our Identities Shape Our Work, Wages, and Well-being. Princeton University Press, 2010.

[10] Altman, Jon C. "The Economic Status of Indigenous Australians." Canberra: Centre for Aboriginal Economic Policy Research, 2000.

[11] Andersen, Thomas, Jack Kruse and Birger Poppel. "Survey of Living Conditions in the Arctic: Inuit, Saami and the Indigenous Peoples of Chukotka (SLICA)." Artic 55(2002): 310-315.

[12] Austen-Smith, David, and Roland G. Fryer. "An Economic Analysis of "Acting White"." The Quarterly Journal of Economics 120(2005): 551-583.

[13] Barman, Jean. "Separate and Unequal: Indian and White Girls at All Hallows School, 1884-1920" Indian Education in Canada Volume 1: The Legacy. edited by Jean Barman, Yvonne Hebert and Don McCaskill. Nakoda Institute Occasional Paper No. 2. (Vancouver: University of British Columbia Press, 1986).

[14] Bartik, Timothy J. "Who Benefits from Local Job Growth: Migrants or the Original Residents?” Regional Studies 27(1993): 297-311. 
[15] Blanchard, Oliver, and L. F. Katz. "Regional Evolutions." Brookings Papers on Economic Activity 23(1992): 1-76.

[16] Canada Department of Mines and Resources. (1945-1965). Canada Department of Mines and Resources Report of Indian Affairs Branch. Ottawa. Accessed November 4, 2012. http://www.collectionscanada.gc.ca/databases/indianaffairs/001074-119.03e.php?page_id_nbr=33668\&PHPSESSID=albnefemvhkcbdt3di3v523ek7.

[17] Canada, The Education Division, The Department of Citizenship and Immigration. The Education of Indian Children in Canada. A Symposium Written by Members of Indian Affairs Education Division, with Comments by the Indian Peoples. The Canadian Superintendent. Toronto: The Ryerson Press, 1965.

[18] Canada. Royal Commission on Aboriginal Peoples. Report of the Royal Commission on Aboriginal Peoples. Vol. 1: Looking Forward Looking Back. Part Two: False Assumptions and a Failed Relationship. Paper 10: Residential Schools [CD-ROM]. Ottawa: Libraxus, 1997.

[19] Card, David. "Using Geographic Variation in College Proximity to Estimate the Return to Schooling." In Aspects of labour Market Behavior: Essays in Honour of John Vanderkamp, ed, by Louis N. Christofides, E. Kenneth Grant, and Robert Swidinsky, 201-222. Toronto: University of Toronto Press, 1995.

[20] Cariboo Tribal Council. The Impact of the Residential School. Williams Lake: Cariboo Tribal Council, 1991. 
[21] Carino, Joji. "Poverty and Well-being." State of the World's Indigenous Peoples. 14-49. New York: The Secretariat of the United Nations Permanent Forum on Indigenous Issues, 2010.

[22] Carr-Stewart Sheila. "A Treaty Right to Education." Canadian Journal of Education, 26(2001): 125:143.

[23] Cassidy, Julie. "The Canadian Response to Indian/Aboriginal Residential Schools: Lessons for Australia and the United States?" Murdoch University Electronic Journal of Law 16(2009): 38-71.

[24] Cornell, Stephen, and Joseph. P. Kalt. "Where's the Glue? Institutional and Cultural Foundations of American Indian Economic Development." The Journal of Socio-Economics 29(2000): 443-470.

[25] Cornell, Stephen, and Joseph. P. Kalt. "American Indian Self-Determination: The Political Economy of a Policy that Works." John F. Kennedy School of Government, Harvard University, 2010.

[26] Riddell, W. Craig and Song, Xueda. "The Impact of Education on Unemployment Incidence and Re-Employment Success: Evidence from the U.S. Labour Market." Labour Economics 18(2011): 453-463.

[27] Crey, Ernie, and Suzanne Fournier. Stolen from Our Embrace: The Abduction of First Nations Children and the Restoration of Aboriginal Communities. Madeira Park: David Neel D\&M Publishers Inc, 1998. 
[28] Curto, Vilsa. E., and Roland G. Fryer. "The Potential of Urban Boarding Schools for the Poor: Evidence from SEED," Journal of Labour Economics forthcoming (2014).

[29] Curry, Bill. "Cost to Redress Native Residential School Abuse Set to Pass \$5-Billion." The Globe and Mail, November 14, 2011. Accessed September 6, 2012. http://m.theglobeandmail.com/news/politics/costto-redress-native-residential-school-abuse-set-to-pass-5billion/article2242226/?service=mobile.

[30] Davin, Nicolas. F. "Report on Industrial Schools for Indians and Half-Breeds [The Davin Report]." Sir John A. Macdonald Papers. 91(1879): 35428-35445. Accessed March 31, 2012. http://www.canadianshakespeares.ca/multimedia/pdf/davin_report.pdf.

[31] Dawson, Alexander S. "Histories and Memories of the Indian Boarding Schools in Mexico, Canada, and the United States." Latin American Perspectives 39(2012): 80-99.

[32] Dippel, Christian. "Forced Coexistence and Economic Development: Evidence from Native American Reservations." (2011) memo.

[33] Duflo, Ester. "The Medium Run Effects of Educational Expansion: Evidence from a Large School Construction Program in Indonesia." Journal of Development Economics 74(2004): 163-197.

[34] The Economist. "Tales Out of School." The Economist. October 26, 2000. Accessed October 1, 2012. http://www.economist.com/node/404059. 
[35] Evans, William. N., and Julie. H. Topoleski. "The Social and Economic Impact of Native American Casinos.” Working Paper No. W9198, National Bureau of Economic Research, 2002.

[36] Fryer, Roland G., and Steven D. Levitt. "The Causes and Consequences of Distinctively Black Names." The Quarterly Journal of Economics 119(2004): 767-805.

[37] Fryer Jr, Roland G., and Paul Torelli. "An Empirical Analysis of "Acting White'." Journal of Public Economics 94(2010): 380-396.

[38] Glenn, Charles L. American Indian/First Nations Schooling: From the Colonial Period to Present. New York: Palgrave MacMillian, 2011.

[39] Gover, Kevin. 2000. "Remarks of Kevin Gover, Assistant Secretary Indian Affairs: Address to Tribal Leaders." Journal of the American Indian Education 39(2000): 4-6.

[40] Grant, Anges. No End of Grief: Indian Residential Schools in Canada. Winnipeg: Pemmican Publications, 1996.

[41] Gresko, Jacqueline. “White 'Rites' and Indian 'Rites': Indian Education and Native Responses in the West." In Shaping the Schools of the Canadian West, edited by David C. Jones, Nancy M. Sheehan, and Robert M. Stamp, Calgary: Detselig, 1979.

[42] Haig-Brown, Celia. Resistance and Renewal: Surviving the Indian Residential School. The Secwepemc Cultural Education Society. Vancouver: Tillacum Library, 1988. 
[43] Hall, Gillette. H., and Harry A. Patrinos, eds. Indigenous Peoples, Poverty, and Development. Cambridge: Cambridge University Press, 2012.

[44] Hamilton, Willis D. The Federal Indian Day Schools of the Maritimes. Fredericton: The Micmac-Maliseet Institute, 1986.

[45] Harper, Stephen. "Prime Minister Harper offers full apology on behalf of Canadians for the Indian Residential Schools System." Stephen Harper: Prime Minister of Canada. 2008.

[46] Hawthorn, Harry B. A Survey of the Contemporary Indians of Canada: Economic, Political, Educational Needs and Policies. Indian Affairs Branch, Ottawa. Volume III, 1967.

[47] Indian Residential Schools Resolution Canada [IRSRC]. 2006. Indian Residential Schools Settlement Agreement. Accessed December 3, 2008. http://www.residentialschoolsettlement.ca/settlement. html.

[48] Jacobs, Eva, and Lavina White. Liberating Our Children Liberation Our Nations, Report of the Aboriginal Committee. Community Panel Child Protection Legislation Review in British Columbia. Victoria: Queen's Printer, 1992.

[49] Johnston, Patrick. Native Children and the Child Welfare System. Canadian Council on Social Development Series. Toronto: Jame Lorimer Ltd, 1983.

[50] Kuhn, Peter, and Arthur Sweetman. "Aboriginals as Unwilling Immigrants: Contact, Assimilation and Labour Market Outcomes." Journal of Population Economics 15(2002): 331-355. 
[51] Macdonald, Donald, and David Wilson. "The Income Gap Between Aboriginal Peoples and the Rest of Canada." Canadian Centre for Policy Alternatives. April 2010. Accessed November 14, 2013. http://www.policyalternatives.ca/sites/default/files/uploads/publications/reports/docs/Aboriginal\%20

[52] McFarlane, Kimberly. A. "Educating First-Nation Children in Canada: The Rise and Fall of Residential Schooling.” M.A. Thesis. Queen's University, 1999.

[53] Miller, James R. Shingwauk's Vision: A History of Native Residential Schools. Toronto: University Toronto Press, 1996.

[54] Miller, James R. Lethal Legacy: Current Native Controversies in Canada. Toronto: McClelland and Steward Ltd, 2004.

[55] Milloy, John S. A National Crime The Canadian Government and the Residential School System, 1879 to 1986. Winnipeg: Manitoba Studies in Native History XI The University of Manitoba Press, 1999.

[56] Neal, Derek. "The Effects of Catholic Secondary Schooling on Educational Attainment." Journal of Labour Economics 15(1997): 98-123.

[57] Neyman, Jerzy, and Elizabeth L. Scott. 1948. "Consistent Estimates Based on Partially Consistent Observations." Econometrica: Journal of the Econometric Society, 16(1948): 1-32.

[58] Nunn, Nathan. “The Long-Term Effects of Africa's Slave Trades.” The Quarterly Journal of Economics 123(2008): 139-176. 
[59] Nuu-Chah-Nulth Tribal Council. Indian Residential Schools: The Nuu-chahnulth Experience. Port Alberni: Nuu-chah-nulth Tribal Council, 1996.

[60] Oreopoulos, Philip. "Estimating Average and Local Average Treatment Effects of Education when Compulsory Schooling Laws Really Matter." American Economic Review, 96(2006): 152-175.

[61] Psacharopoulos, George, and Harry. A. Patrinos. Indigenous People and Poverty in Latin America: An Empirical Analysis. World bank, 1994.

[62] Reimer, Gwen. 2010. "The Indian Residential Schools Settlement Agreement's Common Experience Payment and Healing: A Qualitative Study Exploring Impacts on Recipients." Ottawa: Aboriginal Healing Foundation. Accessed 27, 2011. http://Indigenouspeoplesissues.com/attachments/article/4655/4655_cephealing.pdf.

[63] Reyhner, Jon, and Jeanne Eder. American Indian Education: A History. Norman: University of Oklahoma Press, 2004.

[64] Rudd, Kevin. "Apology to the Stolen Generations of Australia. Part 1." ABC 1: $13-22$.

[65] Smith, Andrea. Indigenous Peoples and Boarding Schools: A Comparative Study. New York: Permanent Forum on Indigenous Issues Eighth session, 2009. 
[66] Stock, James H., and Motohiro Yogo. "Testing for Weak Instruments in Linear IV Regression.” Working Paper No. 0284. National Bureau of Economic Research, 2002.

[67] Szaz, Margaret C. "Through a Wide Angle Lens: Acquiring and Maintaining Power, Position, and Knowledge through Boarding Schools.” In Boarding School Blues: Revisiting American Indian Educational Experiences. Omaha: U of Nebraska Press, 2006.

[68] The Boarding School Healing Project. "Reparations and American Indian Boarding Schools: A Critical Appraisal." Accessed April 15, 2012. http://www.boardingschoolhealingproject.org/files/ A_Critical_Appraisal_of_Reparations_final.pdf.

[69] The Truth and Reconciliation Commission of Canada. "They Came for the Children: Canada, Aboriginal Peoples, and Residential Schools.” Winnipeg: Library and Archives Canada Cataloguing, 2012.

[70] Tyler, Brian S. "An Analysis of Public and Catholic Secondary Education and the Earnings of Men.” Ph.D. diss., University of Chicago, 1994.

[71] UN Secretariat. Permanent Forum on Indigenous Issues, Divison for Economic and Social Affairs and Division for Social Policy and Development. State of the World's Indigenous Peoples. New York, 2009. (ST/ESA/328). (U.N. sales No. 09.VI.13).

[72] UN General Assembly. United Nations Declaration on the Rights of Indigenous Peoples : Resolution / Adopted by the General Assembly. New York, 
2007. (A/RES/61/295). http://www.refworld.org/docid/471355a82.html. Last retrieved 26 September 2013.

\section{FOR ONLINE PUBLICATION}

\section{A More Detail On The Decisions of Aboriginal Families}

Here I further elabourate on decision problem of Aboriginal parents and how it interacts with government enforcement to generate the demand for residential schools. I also further discuss the outcome equations.

Remember that government enforcement is given by

$$
E_{i j t}=\lambda^{\prime} x_{i j t}+B_{j}+C_{t}-e\left(z_{j t}, \delta_{j}\right)+\rho_{\kappa} \kappa_{i j t}+\rho_{h} h_{i j t}+v_{i j t} .
$$

where $\lambda$ is a parameter vector.

Substituting in for $E_{i j t}$ in Equation 1 gives:

$$
A_{i j t}=\left\{\begin{array}{ccc}
1 & \text { if } & \lambda^{\prime} x_{i j t}+B_{j}+C_{t}-e\left(z_{j t}, \delta_{j}\right)-\psi_{i j t}^{*}>-\varepsilon_{i j t} \\
0 & \text { if } & \text { otherwise }
\end{array}\right.
$$

where $A_{i j t}$ is an indicator of whether a child attends a residential school or not and $\varepsilon_{i j t}=\rho_{\kappa} \kappa_{i j t}+\rho_{h} h_{i j t}+v_{i j t}$.

Aboriginal parents know that the government will enforce attendance according to Equation 4, but do not observe $\varepsilon_{i j t}$. They choose their level of resistance, $\psi_{i j t}^{*}$, accordingly. I assume that parents care about two things for their children: cultural 
capital and human capital. Let $\bar{\kappa}_{i j t}$ represent total cultural capital and $\bar{h}_{i j t}$ total human capital. Human capital accumulates for each individual according to the total amount of time they spend in school, given by $\tau_{s}$, where $s$ indexes the type of school ( $s=d$ for day school and $s=b$ for residential school), multiplied by the quality of the schooling given by $q$. Note that the time in boardings school will be greater than the time spent in a day school so $\tau_{b}>\tau_{d}$. The individual also inherits an idiosyncratic level of human capital given by $h_{i j t}$. The amount of cultural capital accumulated is given by the amount of time a child spends with their family over the course of their schooling years, which is assumed to be the amount of time they are not in school. This is given by $\bar{\tau}-\tau_{s}$ where $\bar{\tau}$ is the total time available during their schooling years. The accumulation rate of cultural capital is given by $\boldsymbol{l}$. Again, students inherit some level of cultural capital, $\kappa_{i j t}$. The human and cultural capital accumulation equations are given respectively as:

$$
\bar{h}_{i j t}=q \tau_{s}+h_{i j t}, \text { and } \bar{\kappa}_{i j t}=\imath\left(\bar{\tau}-\tau_{s}\right)+\kappa_{i j t} .
$$

The utility of the parents for their child attending each type of schooling is given by:

$$
\begin{array}{cl}
\text { Day School: } u_{i j t}^{d} & =\imath\left(\bar{\tau}-\tau_{d}\right)+q \tau_{d}+\kappa_{i j t}+h_{i j t} \\
\text { Residential School: } u_{i j t}^{b} & =\imath\left(\bar{\tau}-\tau_{b}\right)+q \tau_{b}+\kappa_{i j t}+h_{i j t} .
\end{array}
$$

Parents choose the human and cultural capital of their child indirectly by choosing how strongly to resist their child being taken to a residential school. With knowledge of Equation 5 parents choose their optimal amount of resistance by solving: 


$$
\max _{\psi_{i j t}}\left\{\Phi\left(\psi_{i j t}\right)\left(u_{i j t}^{b}\right)+\left(1-\Phi\left(\psi_{i j t}\right)\right)\left(u_{i j t}^{d}\right)-\psi_{i j t}\right\}
$$

subject to Equation 5, where $\Phi$ is the probability that a parents' resistance will surpass government enforcement. ${ }^{31}$ An important assumption is that parents can exert negative resistance. Resistance surpassing enforcement is only probabilistic because parents cannot observe the idiosyncratic enforcement level for their child until resistance is exerted. Resistance is assumed to be costly to parents and thus enters their utility function negatively. This also could be modeled as the parents valuing some consumption good and resistance being financially costly. To get further I assume that $\varepsilon_{i j t}$ in Equation 5 is normally distributed with mean zero and variance equal to one $\mathrm{e}^{32}$ and explicitly solve for the optimal choice of parental resistance $\psi_{i j t}^{*} \cdot{ }^{33}$ Substituting in for $u_{b}, u_{d}$, and $\psi_{i j t}^{*}$ into 5, yields

$$
A_{i j t}=\left\{\begin{array}{ccc}
1 & \text { if } & \beta_{1}+\beta_{2}^{\prime} x_{i j t}-e\left(z_{j t}, \delta_{j}\right)+B_{j}+C_{t}+\varepsilon_{i j t}>0 \\
0 & \text { if } & \text { otherwise }
\end{array}\right.
$$

where $\beta_{1}=\sqrt{\ln \left(\frac{2}{\sqrt{2 \pi}}\right)+\ln \left((q-\imath)\left(\tau_{b}-\tau_{d}\right)\right)}$, and $\beta_{2}=\lambda$. Note that for $\beta_{1}$ to be a real number, $(q-\imath)\left(\tau_{b}-\tau_{d}\right)$ must be positive. This will be true as long as the rate of accumulation of human capital is greater than of cultural capital. Equation 7

\footnotetext{
${ }^{31}$ I assume the distance to a day school is zero. Differences in travel time to day schools would translate into differences in time with family and time in school. It could also show up in the enforcement equation of the government where distance from a day school would be subtracted from distance to a residential school. In the actual estimations, distance to the closest city is intended to absorb distance to the closest day school.

${ }^{32} \mathrm{~A}$ sufficient condition for this is that $\rho_{h} h_{i j t}, \rho_{\kappa} \kappa_{i j t}$ and $v_{i j t}$ are mean zero and their variances sum to one.

${ }^{33}$ This yields $\psi_{i j t}^{*}=\sqrt{\ln \left(\frac{2}{\sqrt{2 \pi}}\right)+\ln \left((q-\imath)\left(\tau_{b}-\tau_{d}\right)\right)}+\lambda x_{i j t}+B_{j}+C_{t}-e\left(z_{j t}, \delta_{j}\right)$.
} 
summarizes the selection of children into residential school.

In the model, parents care whether their children attend a residential school or a day school because it will influence their child's final human and cultural capital accumulation. Parents care about both human capital and cultural capital because they contribute differently into their child's later life outcomes. Children who grow up with high amounts of traditional cultural capital will receive higher returns from living with those who share their culture and thus will be more likely to live in Aboriginal communities. Since the cost will be lower for those individuals who have high cultural capital they will also be more likely to use their Aboriginal language in their homes and participate in traditional activities. Those with high human capital will be more likely to graduate high school, receive high returns to market activities and thus be employed, be less likely to receive government transfers, and receive higher income.

Assume there exists a set of cultural outcomes, each given by $\kappa_{i j t k}$ and market outcomes, $e_{i j t m}$, whose return is given by $\alpha_{k} \bar{\kappa}_{i j t}+\tilde{B}_{j k}+\tilde{C}_{t k}+\alpha_{k 2}^{\prime} x_{i j t}$ and $\alpha_{m} \bar{h}_{i j t}+$ $\tilde{B}_{j m}+\tilde{C}_{t m}+\alpha_{m 2}^{\prime} x_{i j t}$ respectively. 34 The subscript $m$ indexes market outcomes and $k$ indexes cultural outcomes. The parameters $\tilde{B}_{j k}, \tilde{C}_{t k}$, and $\alpha_{k 2}^{\prime} x_{i j t}$, allow the return to a given cultural activity $k$ to vary by community, birth cohort and a set of individual characteristics such as gender and ethnic origins. Parameters specific to market activities are defined similarly. Whether an individual chooses to engage in each type of activity will depend on their return to that activity. If the return to that activity is positive they will engage in it, and if negative they won't. Substituting for $\bar{h}_{i j t}$ in the return to market activity $m$ implies the decision to engage in that

\footnotetext{
${ }^{34}$ Given that most of the outcomes I have access to are binary I focus on zero/one outcomes here, but a similar intuition follows for continuous variables.
} 
activity can be given by

$$
e_{i j t m}=\left\{\begin{array}{ccc}
1 & \text { if } & \alpha_{m 1}+\alpha_{m 2}^{\prime} x_{i j t}+\alpha_{m 3} A_{i j t}+\tilde{B}_{j m}+\tilde{C}_{t m}+\eta_{m i j t}>0 \\
0 & \text { if } & \text { otherwise }
\end{array}\right.
$$

where, $\alpha_{m 1}=\alpha_{m} q \tau_{d}, \alpha_{m 3}=\alpha_{m} q\left(\tau_{d}-\tau_{b}\right)$, and $\eta_{m i j t}=\alpha_{m} h_{i j t}$. On the other hand, substituting in for $\bar{\kappa}_{i j t}$ in the returns to cultural activity $k$ implies the decision to engage in a particular cultural activity is given by

$$
\kappa_{i j t k}=\left\{\begin{array}{ccc}
1 & \text { if } & \alpha_{k 1}+\alpha_{k 2}^{\prime} x_{i j t}+\alpha_{k 3} A_{i j t}+\tilde{B}_{j k}+\tilde{C}_{t k}+\eta_{k i j t}>0 \\
0 & \text { if } & \text { otherwise }
\end{array}\right.
$$

where $\alpha_{k 1}=\alpha_{k} \imath\left(\bar{\tau}-\tau_{d}\right), \alpha_{k 3}=\alpha_{k} \imath\left(\tau_{d}-\tau_{b}\right)$, and $\eta_{m i j t}=\alpha_{k} \kappa_{i j t}$.

Note that the error between the outcome and residential school attendance equations are correlated as a result of government selection on unobservable endowments of human and cultural capital: $\eta_{k i j t}$ and $\varepsilon_{i j t}$ by $\alpha_{k} \rho_{\kappa}$ and $\eta_{h i j t}$ and $\varepsilon_{i j t}$ by $\alpha_{e} \rho_{h}$. This implies the outcome equation cannot be estimated consistently without jointly estimating the attendance equation. To evaluate the causal effect of residential school attendance on outcomes, an additional parameter - the correlation of the errors terms - must be estimated. For the model above to be identified independent of functional form restriction long term life outcomes and which varies over both cohorts and communities ${ }^{35}$ The cost of enforcement for the government depends on how far the closest residential school is from a community which varies over

\footnotetext{
${ }^{35}$ The variable must vary over both cohorts and communities or it will be collinear with the cohort or community fixed effects.
} 
Figure 4: Composition of Enrollment

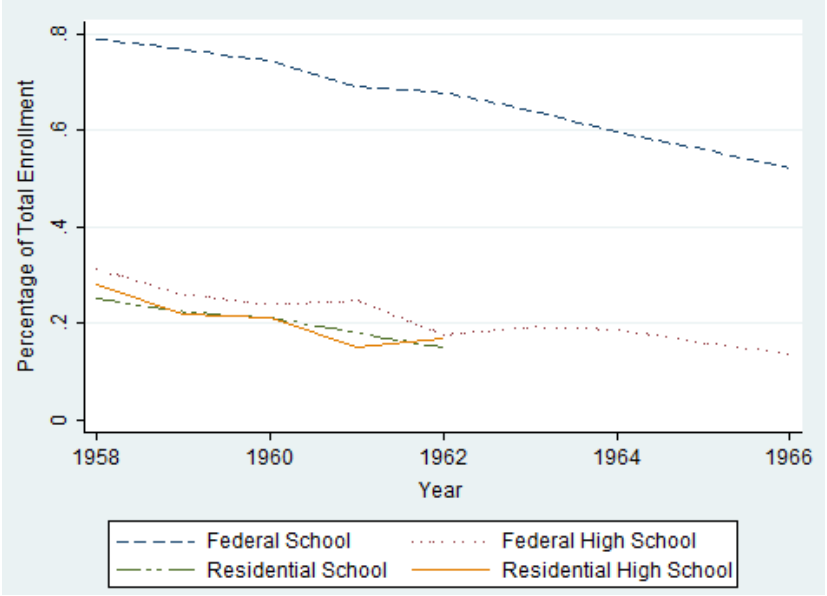

Notes: These data were compiled from the 1960-1970 Canada Year Book.

time and place via the opening and closing of residential schools. This can be excluded from the outcome equations as it determines residential school attendance, but not human and cultural capital directly. It is important to note that this is conditional on a time invariant set of community characteristics such as distance to the closest major city. Whether or not this is reasonable depends on the nature of the missionaries' decisions.

\section{B Appendix Tables and Figures}


Table 13: Linear Probability Model First Stage Results: The Effect of the Instruments on Residential School Attendance

\begin{tabular}{|c|c|c|c|c|}
\hline & \multicolumn{2}{|c|}{ (1) } & \multicolumn{2}{|c|}{ (2) } \\
\hline & (a) & (b) & (a) & (b) \\
\hline Open & $0.114 * * *$ & $0.182^{* * * *}$ & & \\
\hline & $(0.035)$ & $(0.034)$ & & \\
\hline Open $\times$ Distance & $-0.012 * * *$ & $-0.012 * * *$ & & \\
\hline & $(0.002)$ & $(0.002)$ & & \\
\hline \multirow[t]{2}{*}{1941 Prop Catholic $\times$ Trend } & & & $-0.517 * *$ & $-1.222 * * *$ \\
\hline & & & $(0.252)$ & $(0.306)$ \\
\hline \multirow[t]{2}{*}{ Female } & $0.035 * *$ & 0.014 & $0.039 * *$ & 0.019 \\
\hline & $(0.016)$ & $(0.014)$ & $(0.017)$ & $(0.014)$ \\
\hline \multirow[t]{2}{*}{ Single Ethnicity } & $0.123 * * *$ & $0.111^{* * *}$ & $0.121^{* * *} *$ & $0.110^{* * *}$ \\
\hline & $(0.028)$ & $(0.026)$ & $(0.029)$ & $(0.026)$ \\
\hline \multirow[t]{2}{*}{ Latitude } & 0.002 & $0.066^{* * * *}$ & -0.001 & $0.055^{* * *} *$ \\
\hline & $(0.004)$ & $(0.017)$ & $(0.004)$ & $(0.017)$ \\
\hline \multirow[t]{2}{*}{ KM (10) to City } & 0.001 & $-0.006 *$ & -0.002 & $-0.008 * *$ \\
\hline & $(0.001)$ & $(0.003)$ & $(0.001)$ & $(0.004)$ \\
\hline Birth Cohort FE & $\mathrm{X}$ & $\mathrm{X}$ & $\mathrm{X}$ & $\mathrm{X}$ \\
\hline Provincial FE & $\mathrm{X}$ & & $\mathrm{X}$ & \\
\hline Band FE & & $\mathrm{X}$ & & $\mathrm{X}$ \\
\hline F-Statistic & 12.60 & 15.93 & 4.22 & 17.69 \\
\hline Hansen J Statistic & 8.998 & 0.362 & - & - \\
\hline $\mathrm{N}$ & 11460 & 10271 & 11460 & 10271 \\
\hline
\end{tabular}

Notes: Standard errors are reported in parentheses and are clustered at the three year birth cohort-band level. Panel (a) is the full sample with province effects, while Panel (b) includes all bands with at least 40 people. The total number of bands in this specification is 108 . The reason for these restrictions with the various geographic controls regards convergence of the likelihood function and credible estimation of the time invariant effects. The indicator "open" is equal to one for an individual if the closest residential school to a community was open when they were of the legally mandated schooling age (which depends on federal and provincial legislation). It is zero otherwise. "Open $\times$ Distance" is this indicator times the distance from the closest residential school. The row labeled "1941 Prop Catholic $\times$ Trend" is the coefficients on 1941 Proportion Catholic in individual's census division $\times$ (average attendance in that individual's cohort - average attendance in cohort at peak 1934). The F-statistic on the excluded instruments is given in the row labeled "F-Statistic". The row labeled "Hansen J Statistic" is the test statistic from the Sargan (1958) and Hansen (1982) tests of over-identifying restrictions. The asterisks indicate the level of significance: $* \mathrm{p}<0.10, * * \mathrm{p}<0.05, * * * \mathrm{p}<0.01$. 


\section{The Log-Likelihood Function}

The notation and set up below is from Greene (2002) p.710-711. Let $X_{2}=$ $\left[1, x_{i j t}, z_{j t}, \delta_{j}, b_{t}, c_{j}\right]$ and $X_{1}=\left[1, a_{i}, b_{t}, c_{j}, x_{i j t}\right]$, where $b_{t}$ is a vector of band dummies and $c_{j}$ is a vector of cohort dummies. The bivariate normal cdf is given by

$$
\operatorname{Prob}\left(X_{1}<x_{1}, X_{2}<x_{2}\right)=\int_{-\infty}^{x_{2}} \int_{-\infty}^{x_{1}} \phi_{2}\left(z_{1}, z_{2}, \rho\right) d z_{1} d z_{2},
$$

which I will denote $\Phi_{2}\left(x_{1}, x_{2}, \rho\right)$. The density is

$$
\phi_{2}\left(z_{1}, z_{2}, \rho\right)=\frac{e^{-1 / 2\left(x_{1}^{2}+x_{2}^{2}-2 \rho x_{1} x_{2}\right) /\left(1-\rho^{2}\right)}}{2 \pi\left(1-\rho^{2}\right)^{1 / 2}} .
$$

To construct the log-likelihood, let $q_{i j t 1}=2 y_{i j t}-1$ and $q_{i j t 2}=2 A_{i j t}-1$. Now let

$$
z_{i 1}=\tilde{\alpha}_{0}+\tilde{\alpha}_{1}^{\prime} x_{i j t}+\tilde{\alpha}_{2} A_{i j t}+\tilde{B}_{j} b_{j}+\tilde{C}_{t} c_{t} \text { and } z_{i 2}=\beta_{1}+\beta_{2}^{\prime} x_{i j t}+\beta_{3} z_{j t}+\beta_{4} z_{j t} \delta_{j}+B_{j} b_{j}+C_{t} c_{t}
$$

and $w_{i 1}=q_{i 1} z_{i 1}$ and $w_{i 2}=q_{i 2} z_{i 2}$ and $\rho_{i *}=q_{i 1} q_{i 2} \rho$.

Then the log likelihood function is given by

$$
\log L=\sum_{i=1}^{n} \ln \operatorname{Prob}\left(Y_{1}=y_{i j t}, Y_{2}=A_{i j t} \mid x_{1}, x_{2}\right)=\sum_{i=1}^{n} \ln \Phi_{2}\left(w_{i 1}, w_{i 2}, \rho\right) .
$$

\footnotetext{
${ }^{36}$ The only away in which the likelihood differs when $w_{j t}$ is used as exogenous variation is the omission of $z_{j t}$ and $\delta_{j}$ by $w_{j t}$.
} 
Which I estimate using maximum likelihood. The marginal effects of each independent factor on final outcomes can be computed as well. Let $g_{i 1}=\phi\left(w_{i 1}\right) \Phi\left[\frac{w_{i 2}-\rho_{i *} w_{i 1}}{\sqrt{1-\rho_{i *}^{2}}}\right]$. Note that there are several "marginal effects" one might want to evaluate in the bivariate probit model (See Green 1996b). For convenience in evaluating them, we will define a vector $x_{1}=x_{1} \cup x_{2}$ and let $x_{1}^{\prime} \beta_{1}=x^{\prime} \gamma_{1}$. Thus, $\gamma_{1}$ contains all the nonzero elements of $\beta_{1}$ and possibility some zeros in the positions of variables in $\mathrm{x}$ that appear on in the other equation; $\gamma_{2}$ is defined likewise. The bivariate probability is

$$
\operatorname{Prob}\left[y_{1}=1, y_{2}=1 \mid x\right]=\Phi_{2}\left(x^{\prime} \gamma_{1}, x^{\prime} \gamma_{2}, \rho\right) .
$$

The marginal effects of changes in $\mathrm{x}$ on this probability are given by

$$
\frac{\partial \Phi_{2}}{\partial x}=g_{1} \gamma_{1}+g_{2} \gamma_{2}
$$




\section{A History of Residential Schools}

In 2006 approximately 4 percent of the Canadian population self-identified as Aboriginal (Statistics Canada 2008a). Aboriginal people are the youngest and fastest growing ethnic group in Canada and have notably lower annual earnings than the average Canadian. Estimates of how much lower varies substantially depending on the sample, gender and how an Aboriginal person is defined. Estimates of the "earnings gap" vary from 7 to 63 percent for men and 2 to 15 percent for women (Mueller 2004). Samples that include only full-time/full-year workers such as DeSilva (1999) and George and Kuhn (1994) produce much smaller estimates of the earnings gap then samples that include all workers (such as Pendakur and Pendakur 2002). In 2006, 40 percent of Aboriginal people lived in government defined communities known as reservations or reserves, which have varying degrees of self-governance. Those eligible to live in these areas are known as North American Indians or First Nations. Those First Nations members who live on-reserve typically have significantly lower earnings than their off-reserve counterparts. Drost and Richards (2003) estimate the median on-reserve income penalty to be approximately 40 percent in 1995. George and Kuhn (1994) have estimated the mean on-reserve earnings penalty to be about 14 percent for men using the 1986 Census. They find the on-reserve penalty is only about 8 percent for women.

There are three commonly recognized groups of Aboriginal peoples in Canada: First Nations (or North American Indians), Métis, and Inuit. R v Powley (2003), the primary and landmark case in defining Métis rights under the 1982 Constitution, specifies the term "Métis" as distinctive peoples who, in addition to having 
mixed Indian and European ancestry, developed their own customs, and recognizable group identity separate from their Indian or Inuit and European forebears More generally, the Métis are understood to be of mixed American Indian and European ancestry that are not eligible for registered Indian Status. For a discussion of the definition of Métis see Sawchuk (2001). The Inuit are Indigenous people who live in the Northern, Artic in Canada and the United States. While all three populations had experiences with the residential school system, the experiences of North American Indian children are most well-known and will be focused on here. Although Métis children attended residential schools, the system was not designed for them. The explicit policy outlining admission of Métis students was created in a 1911 contract between the Federal government and the churches. Clause 4(b) of the contract stated that Métis children were not to be admitted unless Indian children did not fill the residential school authorized admission level. If this was the cause, the Superintendent General could provide authorization for a Métis child to be admitted, but was not allowed to fund his education in any dimension. This policy was maintained throughout the rest of the history of the system (RCAP, 1996). The Inuit had very little contact with formal schooling in general and were subject to residential school policy much later than most of Canada. For a discussion of the Métis' experience with Indian Residential schools see Chartrand, Logan and Daniels (2006) and for a discussion of the Inuit's experience see King (2006) and Milloy (1999, 239-259).

Residential schooling is a phenomenon that has touched a large fraction of the First Nations population and weighs heavily in the popular conscience. It is estimated that about 150,000 Aboriginal children passed through these schools, with 
80,000 former students living today (TRC 2012). During the system's peak from 1930 to 1945,50 percent of registered Indian students attended a residential school and in 2001, over 44 percent of North American Indian children had a family member who attended residential school. Although 139 residential schools are officially recognized, many more may have existed (TRC 2012). The government did not embrace the residential school model as formal policy until the 1880 s when more centralized accounting began to take place (Miller 1996). In addition, the Indian Residential School Settlement Agreement does not cover any residential school that operated without federal government support. Religious organizations and provincial governments have often operated residential schools independently of the federal government.

Residential schools operated in every territory and province with the exception of Newfoundland and Prince Edward Island. Figure 1 shows the distribution of residential schools across the country during the peak of the system in 1930. The flags represent the locations of residential schools and the dots indicate the centroid of Aboriginal communities included in the 1991 Census. It can be seen from this figure that residential schools existed throughout the country, but they were more prevalent in the western provinces. The reasons for the pattern are a matter of historical debate and discussed further in Section $\mathrm{A}$.

The system involved three main actors: the missionaries (who opened, closed and operated the schools for most of their history); the federal government (who funded, regulated and enforced attendance); and the Aboriginal families (whose children could be compelled to attend these schools).

Missionary involvement with residential schooling predates any federal govern- 
ment involvement in Aboriginal education. Missionaries were creating both residential and day schools as both a conversion and humanitarian effort in the new world as early as the 1500s. The first residential schools were formed by missionaries in New France in the 1600s but they quickly disappeared, partly because the Aboriginal peoples had no interest and partly because powerful forces on the French side saw little purpose in them (Miller 2004, 222). The later experiments in British Canada took a stronger hold with the creation of one of the first and longest lasting residential institutions in 1834: the Mohawk institute (General Synod Archives, 2008; Miller 1996). Arguably, the success of the British in establishing schools rather than the French was due to the shift in the economic motivations of the colonists. Early relationships established with Aboriginal people were based on the fur trade and military alliances. Later, the colonists' interests shifted to settlement. The period where it was profitable for the Aboriginal people to continue with their traditional lifestyles was coming to a close. The close of the War of 1912 also began to limit the use of military alliances with the Aboriginal people (Miller 2004, 226).

Table 15 describes the religious patterns among 139 schools included in the Indian Residential School Settlement. Approximately 50 percent or more of the schools were operated by the Catholic Church. Only much later did non-denominational schools begin to open by the federal and provincial governments: primarily as hostels and in the Northern areas of the country. The Anglican Church was the second biggest religious player, followed by the United Church. Fifteen of the total 70 Catholic orders were involved in the operation and creation of the residential school system (Canadian Conference of Catholic Bishops 2012). 
The federal government's formal involvement in the system began with confederation in 1867. Confederation brought with it self-proclaimed fedal government responsibility for the lives of the Aboriginal and in 1868 legislation authorized funds to be used for their education. This spurred the growth of the residential school system. The federal government assumed the funding of some 57 schools already in existence. Only two were residential schools. By 1879 that number was four and then it grew to 71 in 1923. Part of the government's decision to pursue the residential school model was inspired by a complimentary report published by Nicholas F. Davin in 1879. After visiting industrial schools in the United States, Davin promise in the institutions and recommended the Canadian government to support the model (The Davin Report 1879).

The federal government provided per capita grants and funds to establish schools, but the Churches were the ones to propose the schools location and their willingness was essential in determining whether a residential school was constructed. Milloy (1999) reports that the pattern of rapid growth of residential schools was not based on any Department strategy, but by federal reactions to missionary requests and persistent lobbying by the Churches.

The Church's perceptions were often paternalistic: some seemed to believe that they were more capable of determining a community's needs than the community itself. For example, the Anglican Church believed that "the Church represents in many of these developing areas the appropriate voice of peoples slowly emerging into community consciousness," (Anglican Church of Canada, Joint Committee, 1960, 796). These sorts of attitudes and the lack of involvement and control of the Aboriginal population in their education system suggest that the existence of resi- 
dential schools was due to supply, rather than demand concerns. The government showed a surprising lack of direction and control in the construction and location of residential schools and rarely ever rejected a missionary's request for school funding (Milloy 1999, 56-58). The locations of these schools seemed to be organized mostly due to personal causes, the connections of missionaries, and competition among Churches for souls (Miller 2001, King 1964). An example of personal causes includes the opening of Carcross Residential schools in the Yukon. In the late 1890s a pioneer Anglican Bishop was becoming increasingly disturbed at the turmoil and social upheavals caused the immigrants flooding to his headquarters in Dawson as a result of the gold rush and he began looking for a more secluded, yet still convenient headquarters to continue his missionary work. "Bishop Bompass had already been in the Yukon for over thirty years. He had come from England as a young minister and had become a Bishop as a result of his dedicated service in the north. For a dozen or more years he had maintained a sort of school and orphan care in his own home in Dawson, and had envisioned a permanent residential school for Indian children but had never found the right location. He had never before been to Carcross and Lake Bennett. As soon as he made the trip the town became his "See City" as well as the location of the school of which he had dreamed so long," (King 1964, 40).

Analysis of confidential government records indicates requests for residential schools were rarely rejected. There is some evidence that government did show a slight preference for residential schools closer to urban settlements if two denominations proposed schools for the same band (Milloy 1999, 56-58). Figure 5 shows the opening of these schools visually. Many of the last openings occurred in the in 
the north and northern western provinces in align with the later time of settlement. Schools continued to open into the 40s, 50s and even into the late 60s although the number of openings were much smaller as government policy shifted away from residential schools. However, Church political influence and passion extended the system far past the date the government believed it was optimal policy and were actively attempting to close the residential schools.

For most of the system's history, the government had very little direct involvement in its operation and relied on missionary passion, knowledge and involvement. The federal government provided per capita grants and funds to establish schools, but the churches were the ones to propose the schools location and their willingness was essential in determining whether a residential school was constructed. The government played no role in the management of the system until 1911 when it set out a regulatory framework for the churches (Milloy 1999, 52). The government increased its role in the system over time, tightening regulations regarding the operation of the schools in the 1950s and eventually forcing the churches out of the official operation of the schools in 1969. However, the role of the church was never fully eliminated: until the end of the system's life many of the school's employees were originally hired by the churches.

In addition to providing funding, and eventually regulations, for the residential schooling system, the federal government also enforced attendance at residential schools. In the early history of the system attendance at school was voluntary and many of the students that attended residential schools were orphans or came from families that were unable to care for them (Sealey 1980; Barman 1986). Principals of residential schools were told "orphans and children without any persons to look 
after them should be first selected" (Milloy 1999, 31). But in 1920, an amendment to the Indian Act made school attendance mandatory for all Indian children between the ages of seven and fifteen. Section A10(1) of the 1920 Indian Act states that "every Indian child between the ages of seven and fifteen years who is physically able shall attend such day, industrial or boarding school as may be designated by the Superintendent General...Provided, however, that such school shall be the nearest available school of the kind required," (Indian Act 1920, Emphasis added). Section 10 also outlines the mechanics of enforcement: truant officers, and, "on summary conviction," penalties of fines or imprisonment for non-compliance.

It should be noticed that the Act did not clearly define what determined the type of school that is "of the kind required" and left a substantial amount of discretion to the Superintendent General for student selection. This discretion resulted in residential schools being operated for "orphan children, children from broken homes and those who because of isolation or the migratory way of life of their families, are unable to attend day schools," (The Administration of Indian Affairs 1964, 44). This selection of children also predominated before the 1960s. For example, in 1923 the deputy minister of Indian Affairs told an Oblate bishop that Ottawa was directing its agents on reservations to give preference to children from neglectful or destitute homes when vacancies occurred at residential schools (Miller 1996, 313). Even before the 1920s those who could not attend school on a regular basis were often shipped to residential schools (Sealy 1980). In addition, the only residential school to ever exist in Atlantic Canada was opened in 1930 explicitly to service "underprivileged" Aboriginal children (Miller 1996, 313-314).

After 1951, the welfare role of the residential schools became even more pre- 
dominant as provinces began to provide child welfare services on reserves and to use residential schools as a resource (Milloy 1999). A survey completed in 1953 reported that approximately 40 percent of the students fell into the category of neglected. A 1961 analysis of residential schools in British Columbia calculated that 50 percent of the students enrolled were from undesirable homes and the report suggested that this was representative of national circumstances. By 1966, a confidential report suggested that 75 percent of the students were in this category. By the mid-1970s, the estimates from a number of schools suggest that more than 80 percent of those in attendance at residential schools were there because of perceived neglect (Milloy 1999). This uptake of welfare services by the provinces led to what is known as the "sixties sweep": a large increase in rate of children being removed from their homes and placed into foster care and non-aboriginal homes. Much of this massive increase was due cultural differences between provincial welfare authorities and Aboriginal families (Johnston 1983, 23; Jacobs and White 1992). It was not uncommon for children to be removed if their homes did not abide by typical western family structure (Jacobs and White 1992). For example, Indian Affairs had to send out notice that parents being "separated, divorced, or unmarried is not sufficient grounds for addition of the child to a student residence" (Indian Affairs 1969). Welfare agents also assumed children to be living in poverty when they were merely living in accordance to traditional values: while no food in the house implied hunger in the average Canadian home, it may have only have implied there was food outside in an Aboriginal one.

If no other schooling options were available, children were forced to attend residential schools in order to comply with federal legislation. How strictly this 
legislation was enforced came down to the discretion of the government agent on reserve (the Indian Agent). If the Indian Agent desired to enforce the law to its full extent, children could be forcefully removed from their home by truancy officers and their parents subject to fines or imprisonment (Section 10, Indian Act 1920). Some attempted to fight the system but were punished or threatened into submission (Haig-Brown 1991, 95-96; Haig-Brown 1991, 109). In addition, after 1945, parents would not receive a monthly income supplement issued to parents by the federal government if they did not comply with provincially legislated schooling ages (Milloy 1999, 205). If Aboriginal children wanted to attend high school, the only option was often to attend a residential school or to board in a residential school while attending public school in a non-aboriginal community.

The federal government's enforcement of attendance at residential schools varied over time. In 1945, government policy began to shift away from the residential schooling system after harsh critiques presented by Aboriginal peoples and members of the Indian Affairs department before the Re-establishment and Reconstruction Commission which was established to review the state of Canadian affairs after the Second World War, (Leslie 2002). The federal government began to view residential schooling as a relic of the past. The government promoted the system's closure and started integrating children into public day schools with the assistance of the provinces. Figure 2 shows this sharp change in government enforcement of attendance at residential schools. While residential schools accounted for over 50 percent of enrollments in schools in 1945, they accounted for less than 20 percent by 1965 . Later, the federal government began to tighten the grounds for admission to residential schools and to put more stringent specifications on when removal of 
children from their homes was warranted. This further decreased the proportion of children attending residential schools (Milloy 1999, 219).

In 1969 the director of the Indian Affairs Operations Branch, W.E. Armstrong sent out clarification to Chiefs, Band Councils, Regional Directors and all Superintendents of Indian Agencies regarding the admission of Aboriginal children in to residential schools. It stated only students who met 1 of 6 requirements could be admitted to a residential school: "1) Home is isolated and removed from day school services; 2) Parents or guardians are migratory; 3) Problems in the home; 4) The handicapped student who has a chronic condition, but can live in a student residence and obtain regular medical follow-up which would be difficult to obtain in the home area; 5) Students who require a period of adjustment to urban living through living in a residence with peers who share his culture - that is, a student who requires a gradual orientation to urban living before he can manage in a private boarding home in the community; 6) No suitable private boarding home is available in the area in which the appropriate school is located." Categories 1, 2, 3 and 4 applied to students up to 14 years of age while categories $3,4,5$ and 6 applied to students 15 year of age and over. The sixties sweep came as the department began to firmly lay out the conditions for which a child could be placed in a residential school (Indian Affairs 1969). In addition, "there may be cases where a family is so large that the parents are unable to provide a proper home where the children can continue school. In such cases, consideration can be made to have older children admitted to student residences," (Indian Affairs 1969).

Not until the late 1960s and early 1970s did Aboriginal parents have any active choice in the education of their children. Before then, "Indians took no part 
in the processes of education," (Hawthorn 1967, 40) ${ }^{37}$ However, even before the official attempt at inclusion Aboriginal families were another important actor in the residential schooling system - largely one of resistance. Although there is significant evidence that Aboriginal people desired education, demanding it in the form of residential schools was not the common pattern. For example, when First Nations negotiated treaties with the federal government they demanded clauses obligating the federal government to provide education to some extent for their children. When the treaties demanded schools, they required them to be built on reserve. Parents are frequently described as resistant to the residential schooling system, attempting to prevent their children from attending these schools both indirectly and overtly (Furniss 1995). Some parents attempted to fight the system. A Shuswap mother reports attempting to send her children to public school in order to keep her children out of residential school but was prohibited by the Department of Indian Affairs (Haig-Brown 1991, 95-96).

\section{The Intentions of the System and School Location}

It is the prevailing view that the primary intention of the residential schooling system was cultural assimilation and education. Perhaps the most politically and morally neutral description of the residential schooling system was given by King (1964). He describes the residential schooling as serving "a unique social purpose. It serves as the institutionalized means by which a dominant society seeks to transmit a body of information, including both formalized subject matter content and

\footnotetext{
${ }^{37}$ Although by 1967 the Indian Affairs Department was making an effort to employ and train Aboriginal teachers and develop Indian Home and School Associations and Indian School Committees these initiatives were only embryonic (Hawthorn 1967).
} 
social norms" (King 1964, 1).

Three motivations are frequently cited for the creation of residential schooling system. The first are feelings of moral obligation to the Aboriginal people. Missionaries and the government felt it was their duty to improve the quality of life of the Indigenous population through Christianity, literacy, skill building and modern health practices (Miller 1996). Residential schools also existed partially as welfare institutions for orphans, destitute children and children that were from homes that were perceived as neglectful.

However, the second motivation often suggested is less benevolent. Numerous authors argue the Residential schooling system was an attempt by the government to eradicate the Indian way of life and possibility even the Indian himself. Chrisjohn, Young and Maraun (2006) argue that "residential schools were one of many attempts at the genocide of the Aboriginal Peoples," $(2006,21)$. The term survivor is commonly used dialogue about residential schools (Aboriginal Healing Foundation 2010). Some academics have concluded that terms like "cultural genocide" and "ethnocide" are appropriate in the Canadian case (Hudson and MacDonald 2012). Hudson and MacDonald assert that "the essence of what the IRS system was about" was "the attempted destruction of Aboriginal languages, religions, and cultures in Canada" (Hudson and Donald 2012, 4). The Assembly of First Nations asserts that all the characteristics of the IRS system meet the UN convention of cultural genocide (Assembly of First Nations 2002).

The third motive, less frequently cited, was to help prevent rebellion. On more than one occasion there was violence between the Aboriginal population and the colonists and the bloodshed that characterized the American experience was unde- 
sirable. The potential for it to erupt increased with the beginning of settlement in the west, the diminution of the buffalo, the return of the smallpox epidemic, and the Riel rebellion in 1869-70. The Indians were seen as a threat to be neutralized through education and assimilation (Milloy 1999).

However, portraying the system has having uniform objectives throughout its history may be overly simplistic. Initially, the goal of the residential school system was to prepare children to integrate into western society. However, this policy ended in 1910 and was replaced with the intention of preparing children for a "civilized life" on-reserve (Barman 1986, 120). Policy seemed to fall half way between assuming Indians were incapable of being integrated into the majority and that it was undesirable to have them integrate. Either way the "civilization" effort continued through residential schools attempting to endow a knowledge of English, western culture and manual labour and homemaking skills (Glenn 2011, 29). Policy again shifted after the Second World War when integration into public schooling became the preferred policy. During this last shift in policy, the residential schooling system was largely seen as undesirable, but a necessary institution in order to smooth the transition to full integration and to care for children who had "undesirable" home conditions.

The motivations above for the residential schooling system provide some insight to the reason residential schooling was more prevalent in the western provinces. The first plausible explanation is that western Aboriginal people were viewed as less "socially advanced," (Sealey 1980; Miller 2004, 245). For example, as early as 1869 and 1884 the Indian Act and the Indian Advancement Act allowed the federal government to grant a reasonable level of self-government for "the more progressive 
bands." However, by 1946 with very few exceptions, no bands in Western Canada were granted this privilege. On the other hand, practically all the bands in Ontario, Quebec, and the Maritime Provinces were under the elective system (MacInnes 1946, 392-394).

Another plausible explaination for residential schools being more prominent in the western provinces regards the simulatenous increase in funding for residential schools, the decline of the bufflo and the treaty making process (Glenn 2011). Each of the treaties signed in the 1870 s contained some clause regarding a government obligation to provide schooling. Each treaty differed in the exact wording of the education provision and thus brought slightly different obligations. The most frequently cited example is Treaty One, 1871 which required the government to maintain a school on each reserve 'whenever the Indians of the reserve should desire it' (Glenn 2011, 29-39). However, most of the treaties' wording allows the Government to circumvent the wishes of the band by the provision that a school would be provided whenever the band desires it and "be it advisable to her Majesty." Treaties Seven through Eleven have much different wording and do not require schools on reserve or at the behest of the community. Carr-Stewart (2001) suggests that the government did not meet its obligations to establish schools on reserves when the band desired it. On the other hand, church willingness to establish schools was a convenient method through which the government could partially meet their treaty obligations with little active engagement (Milloy 1999). Since there was more funding for the residential school system than before churches may have been relatively more willing to establish residential schools than day schools. The decline of the bufflo and the increased reliance on the government on the part of the western First 
Nations may have resulted in less resistance.

\section{Previous Literature on the Effects of Residential School}

Many authors have suggested that the residential schooling system was unsuccessful as an academic institution and as a care facility (Milloy 1999, Miller 1996; RCAP 1996; AFN 2002; Nuu-chah-nulth Tribal Council 1996; Cariboo Tribal Council 1991). Residential schools have been accused of failing to protect and provide for the children that attended (Claes and Cliffton 1998) and of damaging families (Stonefish 2007).

Through the history of the system children who attended these schools, their families and Aboriginal and non-aboriginal commentators alike described the children who came back home as "trapped between two worlds." An unnamed mother of children who attended residential school recalled: "When they came home I was so happy, but they acted so strange...Before they would always hunt, set rabbit snares, and haul wood, but after they didn't want to listen and they'd call me names like 'Old Indian,,', (Aboriginal Healing Foundation 2002, 26-27). Reporting to government officials, the Pas band stated a that "child who returns from a residential school at the age of 16 or 17 is inenviably unable to fit into the life of the reserve...while inadequate training in the schools and racist attitudes in EuroCanadian society made it impossible for them to find jobs" (SJC Minutes 1947, Benson "Different Visions," The Pas band brief 32-33).

These effects are suspected to persist in generations unaffected directly by residential schools. The Canadian Truth and Reconciliation Commission on Indian Residential School's asserts that “...[residential school's] impact has been transmit- 
ted from grandparents to parents to children. This legacy from one generation to the next has contributed to social problems, poor health, and low educational success rates in Aboriginal communities today," (TRC 2010, 1).

However, some academics have argued that the residential schooling system generated an educated elite with a strong Aboriginal identity that spent their careers fighting for Indigenous legal rights and cultural preservation (Glenn 2011; Gresko 1979; Szaz 2006; Miller 1996; Reyhner and Eder 2004), rather than generating a culturally stranded, uneducated population.

At this point the statistical literature on the effects of residential school is sparse and does not rely on what most economists would understand as causal methodology. The Cariboo Tribal Council's study on their members finds significant negative impacts of attendance at IRS and abuse on mental health, but not final educational outcomes or employment status. A study by the Nuu-Chah-Nulth Tribal Council finds similar results. The Australian Bringing Them Home Report (1997) conducted on the impact of removal of Aboriginal children from their homes found that there were no improvements in schooling or employment for the group taken away from their homes relative to the group that remained. In addition, those taken from their homes were three times as likely to have acquired a police record and were twice as likely to use illicit drugs. They also earned higher incomes due to a greater degree of urbanization and thus greater access to welfare payments. The only study I am aware of on the intergenerational effects of residential school is by Bougie and Senécal (2000) who demonstrate a negative association between parental residential school attendance and child school performance. The negative association the authors find is completely accounted for by family income and other factors. 
Although the existing literature on the effect of residential school is informative, economists would generally not consider the methodolgoy to be informative regarding the causal effects of residential school. Given the above description of student selection and the geographic distribution of residential schools, a comparison of mean outcomes between those that attend residential school and those that do not will not be informative regarding causal effects.

\section{The Environments in Residential Schools and Their Alternatives}

Residential schools were located both within Aboriginal communities and as far as hundreds of kilometers away. Although children were permitted to return home for summer vacation starting in 1920, children were often taken extraordinary distances to attend a residential school and many didn't see their family for years (Miller 1996, 311-312; Aboriginal Healing Foundation, 2002; McFarlane 1999). Miller stated that "the sheer difficulty and expense of sending children home for summer holidays often accounted for the protracted separation from family for which residential schools were notorious," (Miller 1996, 311).

Unlike schools attended only during the day (day schools) the residential schooling system operated on a half day system for much of its history. Half the day was spent in academics and religion and the other half in skills such as shoe-making and other trades. However, by 1910, the half day system did not involve as much instruction in trades as it did manual labour (Gresko 1986, 94). Although the half day system officially ended in 1951 (Milloy 1999, 227) it was abolished in Anglican schools in the mid-1940s and it continued in some schools until the late 1950s (Miller 1996, 530). Until that time, student labour was used to make up for school 
budgetary short falls. Regimes at these schools tended to be much more regulated than a student's life at home (Gresko 1986, 33). Gresko (1986, 92-93) gives an idea of the weekday schedule of Qu'Appelle Industrial School during the earliest era in Table 16.

Schooling also involved cultural learning such as ethics, music, differences between white and Indian ways of life, and gender roles. Children were only permitted to speak English and were either punished for speaking their native language or rewarded for not. Some of these punishments were reported to have been severe. Examples of such severe punishment include being beaten to the point of permanent scarring (Crey and Fournier 1998, 62) and having needles being inserted into one's tongue (Aboriginal Healing Foundation 2002, 6). However, not all principals and teachers submitted to government preferences regarding English language usage and the restriction of parental visits (Barman 1986; Gresko 1986). Gresko (1986) finds that the principal of Qu'Appelle from 1884 to 1917, Father Hugonnard, failed to inform the department about the Cree and Sioux catechism classes he held. He also neglected to mention in his reports to the department that he asked the sisters some of whom had learned to speak Cree - to teach new pupils first in Cree, than in English. Hugonnard also did not yield to the department in its desire to keep children away from their parents. He tended to promote parental visits in a conversion effort (Gresko 1986, 93).

Over and above child labour and removing children from their families, residential schools were notorious for their early health conditions. One of the most infamous publications on the conditions in residential schools was a pamphlet published in 1922 by Dr. Peter Bryce, the former Chief Medical Officer of the Depart- 
ment of Indian Affairs. Dr. Bryce was instructed by the Indian Affairs department to conduct a special investigation of 35 residential schools in the Prairie Provinces. In his report he highlighted the high death rates among children who had attended these schools. One of the most extreme cases he described was the File Hills reserve's school - 75 percent of all individuals to attend the school in its 16 year life span were dead at the time of Bryce's survey (Bryce 1922, 4).

The inspection of the schools in 1907 and 1909 was repeated by Dr. F.A. Corbett in 1920 and 1922. The Doctor found as many as 75 percent of children were infected with tuberculosis. What concerned Dr. Corbett even further were the signs of neglect. The discovery that 60 percent of students at Old Sun in Alberta had "scabies or itch...in an aggregated form" which was easily remedied and commonly found in children in crowded and unhygienic living conditions (Milloy 1999, 99).

Miller states that "regulations that were supposed to ensure a healthy student body were tightened following the overhaul of schooling arrangements in 1911, with more precise directions from Ottawa and more supervision. However, neither the provision of medical care nor the enforcement of regulations improved until the more affluent days of the later 1950s and they were never comprehensive and effective in their application," (Miller 1996, 301-302). The epidemics of influenza and tuberculosis that ravaged the Aboriginal population were not well managed by the schools (Miller 1996, 301-305; Milloy 1999; Bryce 1922) and the death toll was relatively high even in the 1957 influenza outbreak (Miller 1996, 304). Miller discusses the lack of commitment of the government to give adequate provisions for students until after the 1950s. For example, in 1946 students were reduced to brushing their teeth with soap (Milloy 1996, 307). 
However, while residential schools were inadequate in many respects, the situations in many students' home communities were often less than ideal. Overcrowding, poor medical care, poor sanitation, poor diet and inadequate clothing were present in both the schools and in many of the students' homes (Lux 2001, 107). In addition, regular contact between community members and the schools in some regions may have facilitated the spread of disease and made the health conditions in the two impossible to separate (Stoops, 2006).

On top of forced labour, isolation from families, and poor health conditions, the quality of education received at the residential schools has also been repeatedly questioned over the history of the system. However, the small amount of academic literature on early federal day schools suggests education received at these schools was also poor (Hamilton 1986, 17-18). In fact, day schools in Aboriginal communities were often operated by the same religious denominations that ran the residential schools and suffered many of the same challenges. Both types of institutions suffered from significant staff turn-over, employed unqualified teachers, and were chronically underfunded (The Department of Citizenship and Immigration 1965).

Difference in funding arrangements however may have resulted in differences in school quality however. Until 1957 the residential schools operated on a per-capita funding basis from the government. After 1957 the schools were funded according to a cost based scheme (RCAP 1996). Additional costs had to be made up either by the Church's own funds or by student labour (The Department of Citizenship and Immigration 1965; Milloy 1996). On the other hand, the federal government took responsibility of teacher's salaries directly in day schools. Prior to September 1, 1949 the government did not pay the salaries of teachers in any Indian residen- 
tial school. On that date, the government took over payment of teacher's salaries in three residential schools. In 1961 the government owned 61 of the residential schools and entered into operating agreements with the religious authorities (expect for one which is operated directly by the federal government). In 1965 there were four Church-owned residential schools to which per-capita grants were still given: Albany (Fort Albany, Ont), Fort George (Fort George, P.Q), Notre Dame (Norway House, Manitoba), Holy Angels (Fort Chipewyan, Alta.), and Christie (Kakawis, B.C.) (The Department of Citizenship and Immigration 1965, 32-33).

In the early 1950s the Department of Indian Affairs (called the Department of Citizenship and Immigration at the time) began to integrate Aboriginal children into the public school system. The rise of public schooling gave Aboriginal children a third schooling option to residential schooling or attending a community day school. At the time of integration, Aboriginal children received no special treatment in public schools and there was no separate program to attend to their needs. After an expensive review of Aboriginal education it was determined that this was problematic: "the child on entry and the teacher do not implicitly share as many values and expectations as do the teacher and the typical middle-class white child," (Hawthorn 1967, 13). Socio-economic differences between middle-class white children and Aboriginal children made keeping up in public schools difficult. Children were often sent home because they were "dirty" or "improperly dressed." This was difficult to remedy since many Aboriginal homes did not provide bathing facilities common in non-aboriginal homes. On top of the fact children were also confounded with a lack of places to study at home (Hawthorn 1967, 19), many children upon entering school still did not speak English or French as their first language. This made 
keeping up at school even more difficult.

Children who attended a public school from home could face as long as a two hour bus commutes each way (Educational Task Force 1975, 33). Not only did this increase the incentive to not attend classes, but those that did were "unable to participate in extra-curricular activities or receive additional tutoring because of tight bus schedules" (Educational Task Force 1975, 33). On the other hand, in residential schools, some children could engage in extra-curricular activities such as brass bands, Cubs, Brownies, Scouts, Girl Guides and Cadets (Miller 2004, 246; Persson 1986). If students were too far from any school to commute on a daily basis and if they did not attend a residential school then they would stay in private, predominately white, boarding homes. These boarding homes became the prevailing option for small isolated Aboriginal communities after the closure of the residential schools. In Ontario in 1975, parents had no choice in the boarding home their child was assigned too and an evaluation of these homes found they were often overcrowded, under-supervised with poor communication between boarding home and native parents (Educational Task Force 1975, 31).

Most interactions between the parents and the school board at this time involved the school board informing parents of the inadequacy of their children. In addition, despite efforts by the department, textbooks continued to include material about Aboriginal people that "was inaccurate, overgeneralized and even insulting" (Hawthron 1967, 19). In addition, because Indians did not pay school taxes due to their special status, they were not permitted to be elected on school boards. As a consequence, "Indians feel completely dissociated from decisions taken, and too often consider them harmful to the welfare of their children" (Hawthron 1967, 69). 
On the other hand, beginning in the 1970s residential schools had school committees Aboriginal parents could be involved in - although evidence seems to suggest the school committees were dysfunctional (Hawthron 1967, 82).

\section{The Ultimate Closure of the System}

Due to the creation of the Family Allowance in 1945 and the rapidly increasing Aboriginal population (which was rebounding from the tuberculosis epidemic), there was a dramatic rise in the enrollment rates of Aboriginal children in school from 1945 to 1955 (Indian Affairs Department 1945-1955). Ottawa projected that in order to accommodate the growing numbers of students they needed 60 new classes a year by 1960 (General Synod Archives 2008).

Rising enrolment rates coincided with changing political attitudes toward racially segregated education and the rapid aging of residential school buildings. All these factors would contribute to the decision to end the residential schooling system. The political motivation to end the system was established starting in 1943 during the hearings of the Re-establishment and Reconstruction Commission. The Commission was formed to review the state of Canadian affairs during the Second World War and provided a stage for the critics of the residential schooling system to voice their concerns. The commission ultimately recommended a review of the Indian Act and their findings eventually lead to the closure of the residential schooling system (Leslie 2002). Instrumental to the change was the Indian Affairs Superintendent of Welfare and Training Robert Hoey. He brought to the attention of the Committee the increasing costs of the residential school system and his serious doubts about its efficacy in general. Hoey had been shocked by a visit he made to the Mount Elgin 
School in 1942 when he discovered the severely neglected sanitary conditions at the school. A report he commissioned afterward (the Simes report) found similar conditions at a number of other schools across the country (Milloy 1999, 192).

However, the desire for closure was not enough to lead to a speedy end of the system. The process of closure was long and difficult. It took over forty years for the system to fully shut down. In fact, the rapidly increasing size of the Aboriginal population, educational demands, and the persistent lobbying of the Catholic Church required a mild expansion of the system before the desires for closure could be fully realized. However, integration into provincial public schools became the preferred policy and was to be conducted as quickly as possible with the residential schools subsequently closed. Other schools where built in order to provide access to education for the new large population of Aboriginal school aged children. Dilapidated schools that did not meet current regulations of health or safety standards were closed where possible and students integrated into the provincial system (Milloy 1999). In 1945 the Indian Affairs Departmental reports show there were 76 residential schools in operation with 8,865 on roll with average attendance of 8,006 . The majority of schools were in Alberta with nineteen. In both residential and day schools, there were no mention of any students past grade 9. In total there were 7,480 students roll, with an average attendance of 5,092. The largest number of day schools was in Ontario, with the smallest number in Alberta with one. There were only six integrated schools in the country with only 67 students in Quebec, Ontario, Manitoba and Saskatchewan (Indian Affairs 1945, 190-192). Within 10 years, after the end of the war, these numbers looked dramatically different. Alberta still had 18 residential schools, but now had 30 day schools. BC still had 13 residential schools, 
but now 65 day schools, Manitoba had the same nine residential schools and 64 day schools. Ontario had 11 residential schools but now 97 day schools. Patterns in other provinces looked similar.

When the decision to shut down the residential school system was taken, Indian Affairs started a substantial drive to integrate Aboriginal children into public schools. The first joint agreement was signed in 1950 (South Indian Lake, Le Pas) in Manitoba (Hawthorn 1967, 67). By 1952 there were fourteen more completed and on the basis of that experience a set of procedures was drawn up for the Negotiated Integrated School Programs and Joint Agreements. The government tried to induce local school boards and provincial governments to admit students by offering to cover "the costs of educating Indian children in provincial schools by paying a per capita amount based on the general operating costs when education services already exist. Where new buildings have to be built, the sharing of expenses is based on the relative size of the Indian student population compared with the total student population. If the proportion is a quarter or a third or a half, the federal government will pay the same proportion of the total construction costs," (Hawthorne 1967, 68). The willingness of the federal government to support local public school boards in integrating Aboriginal children into their schools did not mean that agreements to take in new Aboriginal students were easily reached. The integration period took over twenty years due to political disputes, consultation and disagreements on "what was best" for the Aboriginal population.

There was major opposition to public integration and the closure of residential schools from the Catholic Church in western Canada. In Ontario and Quebec, where children could be easily integrated into Catholic day-schools, there was no 
opposition mounted (Milloy 1990, 220). After extensively reviewing confidential department of Indian Affairs files, Milloy concluded that "it was not study, nor quiet rational consideration and discussion, that dominated the discourse on the western schools over the next decade but political struggles over the fate of each school...the Department saw the church's hand behind every incident of opposition" and the fight took on a greater character of "who would control Indian communities" (Milloy 1999, 231). There was even a suspicion that the various religious denominations and sympathetic officials were admitting children who were not neglected in any sense to residential schools simply to keep the schools open (Milloy 1991, 219).

Where schooling agreements could be made, children were integrated into public schools immediately. However, in areas where integration was delayed, the residential schooling system was used to facilitate children's integration into public schools. Children from isolated communities who did not yet have schools in their communities and were too far to be transported to the closest public school, resided at the closest residential school in order to attend public school during the day. In fact, many residential schools ceased to be schools and eventually acted as hostels. By 1967, public school integration had practically reached its saturation point in Manitoba and Saskatchewan (and largely Alberta) ${ }^{38}$ By the late 60s and early 70 s, the residential schools remaining primarily acted as hostels and increasingly as welfare institutions (Presbyterian Archives 2010).

A turning point in the entire Indian education system took place after the publication of the Federal government's "White Paper" which promoted the end of all legal distinction between Aboriginal and non-aboriginal people and the abolition of

\footnotetext{
${ }^{38}$ Hawthorn (1967. 66) asserts that the public schools in these regions were superior to the government's own and thus they felt integration was justified.
} 
the Department of Indian Affairs (The Government of Canada, 1969). The white paper induced an up-roar from Aboriginal leaders throughout the country. When the government attempted to close Blue Quill's Residential School in Alberta in 1970 (Persson 1986), the people of the Saddle Lake-Athabaska district rose up and took control of the school, protesting and physically controlling the building. Eventual transfer of the school to the band was made marking the beginning of the transition of the last remaining residential schools to the control of the bands (Royal Commission of Aboriginal People 1995, 325). This event is taken as one of the largest signs of resistance to federal government policy and marking the beginning of "Indian Control of Indian Education" (National Indian Brotherhood, 1972). Although 23 proposals for transfers of residential schools to bands existed, ultimately only 5 followed Blue Quills, all in Saskatchewan (Milloy 1999, 237). By the 1980s only a dozen residential schools operated by bands were left in existence with one school operated by government at band request. The last government-run school closed in 1996, and the last band-run in 1998 (Aboriginal Healing Foundation 2009, 176). 39

Although it took nearly 40 years, the residential system was fully shut down. I investigate how the composition of education changed as a result of this shift in

\footnotetext{
${ }^{39}$ The final year of closure of the last residential school is a matter of debate. The Aboriginal Healing Foundation has used the dates 1892 to 1969 to designate the time period of the official residential schooling system (King, Napier and Kechego 2004). Although residential schools existed long before then, it was not until then a formal order-in-council established the federal government joint partnership with the missionaries and a set of regulations governing the schools. The 1969 date is used as a date of closure because it marks the formal end of Church involvement in residential schools and in government's formal residential school system. However, it should be noted that the government continued to run a number of the schools until 1996 with emphasis on band involvement and ultimate control. Some of these schools we directly transferred to the band for operation with no government involvement (King, Napier and Kechego 2004). Miller (1996) on the other hand claims the system ended in the 1970s, while Milloy (1999) asserts 1986. The Truth and Reconciliation Commission, uses the date of closure of Gordon Residential in 1996 as the formal date of closure (TRC 2012).
} 
government policy at the end of World War Two by compiling data from the Canada Year Book 1941-1970 and the Department of Indian Affairs Annual reports. Figure 2 shows that residential schools accounted for a large fraction of enrollment from 1928 to 1945 and an even greater fraction of attendance. Then, as policy shifted and children were integrated into public schools or day schools were built in their communities, residential schools rapidly began to play a much smaller role.

Figure 4 shows the proportion of total and high school enrollment that federal day schools accounted for since 1958. We can see from this figure that public integration continued systematically over this period. In addition, most federal day schools were not at the high school level. Those that were, were residential schools. This indicates that if an individual attended high school, they likely either attended a public school or residential school.

Figure 6 demonstrates regional variation within provinces and time also exists. Notice the eastern provinces have a systematically different pattern than western Canada of both openings and closures. This may be the result of the different views of the federal government toward the western Aboriginal people and the timing of settlement. Notice in terms of closure times, Manitoba and British Columbia are extraordinary similar. This may partially be due to the fact that both provinces reached early agreements with the federal government regarding child welfare provision. This is also true for Ontario, but the patterns there do not comply with the other two provinces. Figure 7 gives the conditional probability distribution of each school being open by each western province. This figure demonstrates that the times of closure varied across many cohorts in the west. Taken together these figures imply there is substantial variation in the type of schooling received by In- 
dian students over this time period and that the timing of residential school closure varies significantly across the country over time. 


\section{Table 14: On and Off Reserve: Bivariate Probit Results}

\begin{tabular}{|c|c|c|c|c|c|c|}
\hline & \multicolumn{3}{|c|}{ On Reserve } & \multicolumn{3}{|c|}{ Off Reserve } \\
\hline Outcomes & ATE & ATET & $\rho$ & ATE & ATET & $\rho$ \\
\hline \multirow[t]{2}{*}{ HS Graduation } & $0.183^{* * *} *$ & $0.179 * * *$ & -0.149 & $0.168 * * *$ & $0.199 * * *$ & -0.265 \\
\hline & $(0.027)$ & $(0.047)$ & $(0.133)$ & $(0.056)$ & $(0.083)$ & $(0.247)$ \\
\hline \multirow[t]{2}{*}{ Gov't Transfers } & $-0.060 * * *$ & $-0.060 * * *$ & 0.090 & $-0.147^{*}$ & $-0.207^{* *}$ & $0.680^{* * * *}$ \\
\hline & $(0.027)$ & $(0.030)$ & $(0.152)$ & $(0.114)$ & $(0.126)$ & $(0.255)$ \\
\hline \multirow[t]{2}{*}{ Employed } & $0.171 * * *$ & $0.171^{*} * *$ & -0.278 & 0.053 & 0.066 & -0.444 \\
\hline & $(0.040)$ & $(0.054)$ & $(0.313)$ & $(0.089)$ & $(0.110)$ & $(0.283)$ \\
\hline \multirow[t]{2}{*}{ Traditional } & -0.032 & -0.037 & 0.149 & -0.069 & -0.118 & $0.396^{* * *}$ \\
\hline & $(0.037)$ & (0.048) & $(0.201)$ & $(0.108)$ & $(0.137)$ & $(0.201)$ \\
\hline \multirow[t]{2}{*}{ Aborig Language } & $-0.071 * * *$ & $-0.073^{* *}$ & 0.062 & -0.009 & -0.014 & -0.154 \\
\hline & $(0.027)$ & $(0.040)$ & $(0.114)$ & $(0.038)$ & $(0.058)$ & $(0.196)$ \\
\hline Province FE & & & & $\mathrm{X}$ & $\mathrm{X}$ & $\mathrm{X}$ \\
\hline Census Division FE & $\mathrm{X}$ & $\mathrm{X}$ & $\mathrm{X}$ & & & \\
\hline F-Stat in First & & 25.24 & & & 0.63 & \\
\hline $\mathrm{N}$ & & 8789 & & & 2671 & \\
\hline
\end{tabular}

Notes: The columns titled "ATE" and "ATET" contain estimates of the average treatment effect and the effect of the treatment on the treated respectively. Both of their standard errors are calculated using the delta method, are clustered at the birth cohort-year level and are reported in parentheses. The columns titled " $\rho$ " contain the estimate the correlation of the error terms between the outcome equations, whose dependent variable is listed on the left hand side, and the residential school attendance equation. It can be understood as a summary statistic for the extent of unobservable selection bias. All regressions include latitude, gender, distance from closest city, an only Aboriginal ancestry indicator, birth cohort fixed effects, and geographic fixed effects specified. This table uses the open indicator and the distances to the school in the attendance equation as the exclusion restriction $\left(z_{j t}\right.$ and $\left.z_{j t} \delta_{j}\right)$. The asterisks indicate the level of significance: $* \mathrm{p}<0.10, * * \mathrm{p}<0.05$, *** $\mathrm{p}<0.01$. 
Table 15: Number and Religion of Total Residential Schools that Ever Existed

\begin{tabular}{|c|c|c|}
\hline Religion & Number & Percent of Total \\
\hline \hline Anglican & 30 & 21.58 \\
Catholic & 69 & 49.64 \\
Mennonite & 3 & 2.16 \\
Non-Denominational & 20 & 14.39 \\
Protestant & 4 & 2.88 \\
United Church & 13 & 9.35 \\
\hline Total & 139 & 100 \\
\hline
\end{tabular}

Notes: These calculations were done from the information provided by the Truth and Reconciliation Commission of Canada and can be found at www.trc.ca.

Table 16: School Schedule (Gresko 1986, 93)

\begin{tabular}{|l|l|}
\hline Time & Activity \\
\hline 5:30 & Rise \\
6:00 & Chapel \\
6:30-7:15 & Bed making, milking and pumping \\
7:15-7:30 & Inspection to see children are well \\
7:30 & Breakfast \\
7:30-8:00 & Fatigue [Chores] for small boys \\
8:00 & Trade boys at work \\
9:00-12:00 & School, with a 15 minute morning recess \\
12:40 & Dinner \\
12:40-2:00 & Recreation \\
2:00-4:00 & School and trades for older pupils \\
4:45-6:00 & Fatigue [Chores], sweeping, pumping, and so forth \\
6:00-6:10 & Preparing for supper \\
6:10-6:40 & Supper \\
6:40-8:00 & Recreation \\
8:00 & Prayer and retire \\
\hline
\end{tabular}


Figure 5: Opening Of Residential Schools Across the Country
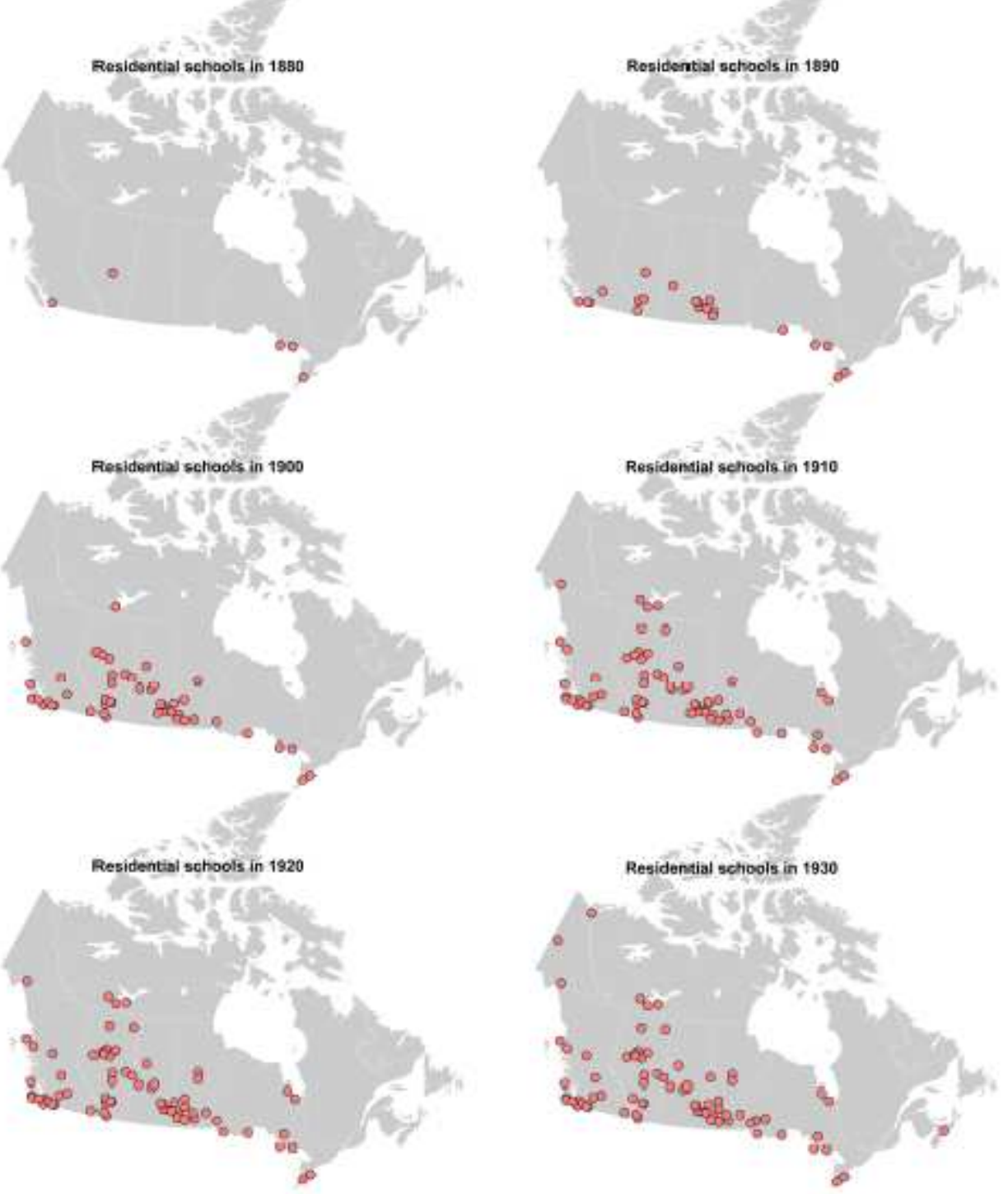

Notes: These figures were generated using the times of government involvement from Aboriginal Affairs and Northern Development. 
Figure 6: Opening and Closing from 1930 to 1990
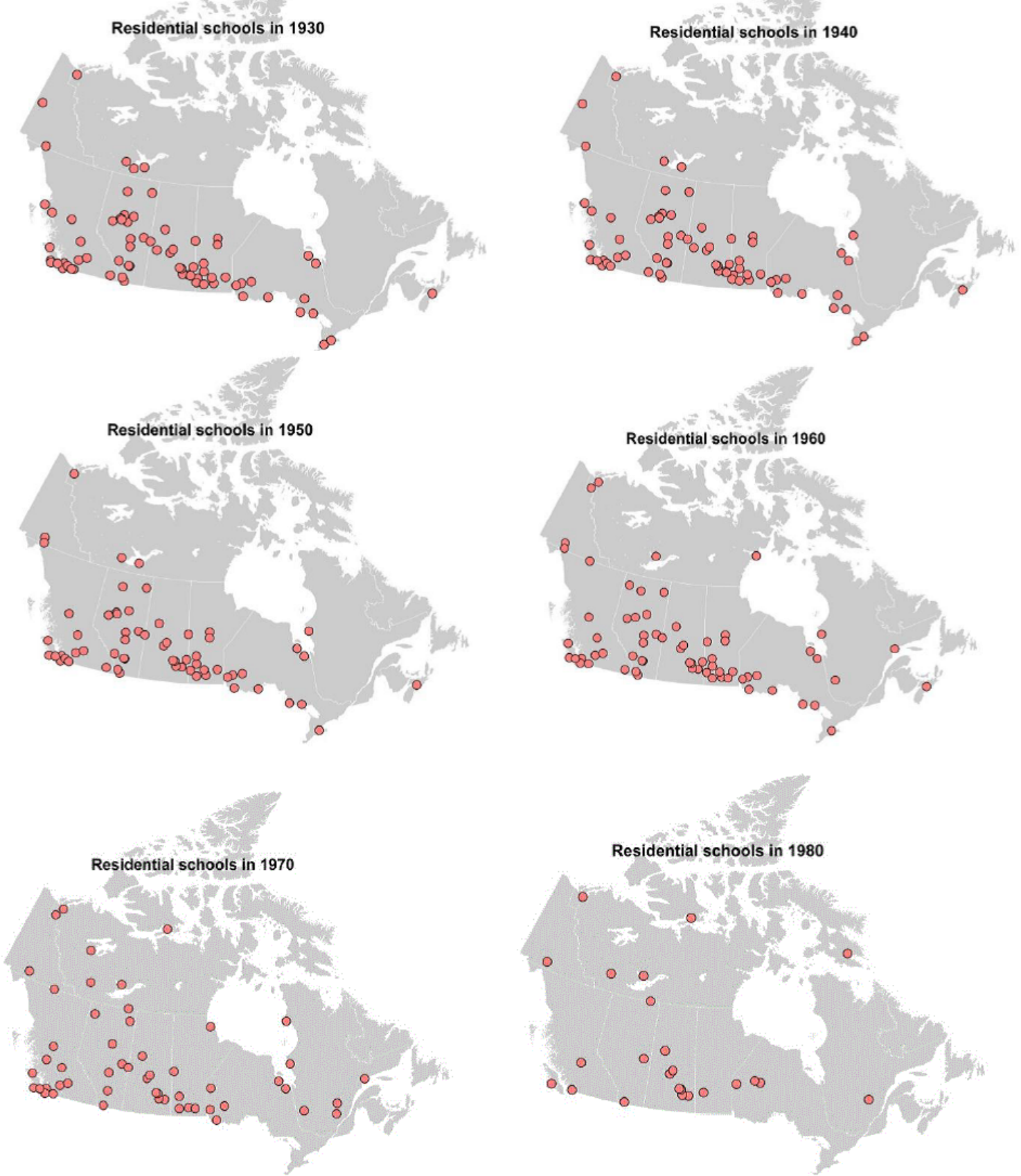

Notes: These figures were generated using the times of government involvement from Aboriginal Affairs and Northern Development. 
Figure 7: Cumulative Probability of School Opening and Closing

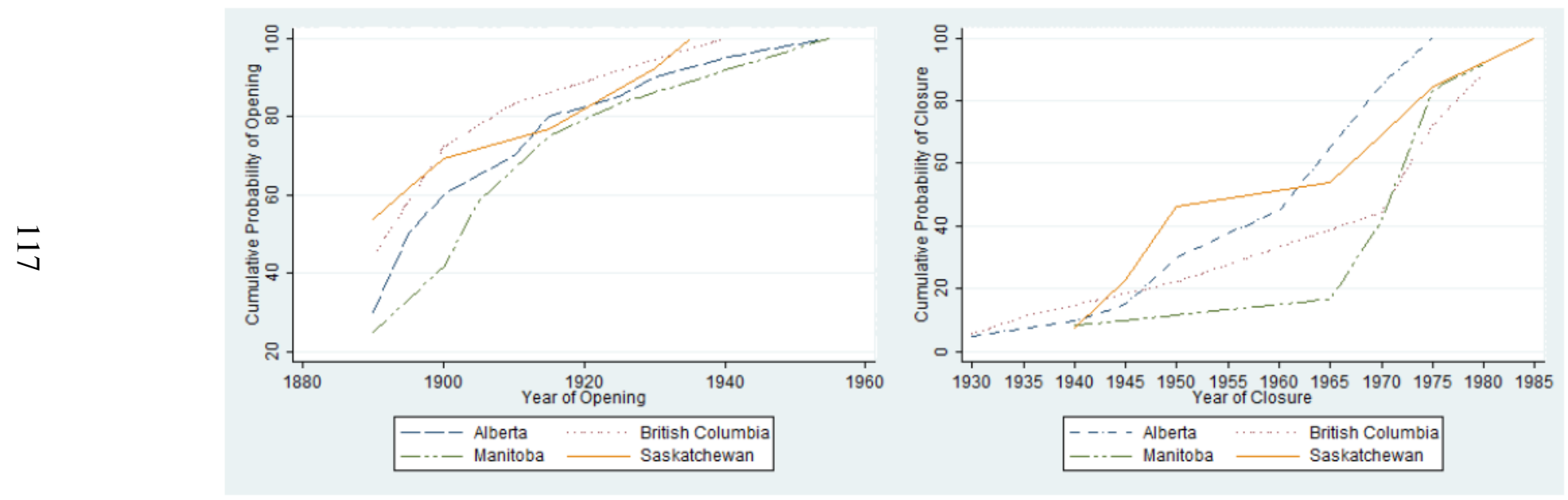

Notes: The calculations for this figure were made using the information available from www.wherearethechildren.ca. 
Detailed academic work on the reasons for the timing of residential school closure is relatively limited. The most in-depth discussions are given by Miller (1996) and Milloy (1999). After going through public documentation, Miller found very limited evidence of any pattern in closure, calling the process "ad hoc." Milloy's description is more thorough because of his access to Northern and Indian Affairs confidential records. His account gives several reasons for the differential times of closure across the country, but he largely attributes it to differential strength of vested interests across the country such as the Catholic Church (predominately the Oblates of Mary Immaculate) as described above. If this variation in school opening and closure was relatively random it can be used as a source of exogenous variation with which to identify the effect of Indian residential schools on long term outcomes. If Milloy was right, and the Catholic church based its decision to fight to keep residential schools open because of their relative ability to "keep the souls" of the Aboriginal children in different locations and the timing of school closure should be exogenous to differences in outcomes between cohorts of Aboriginal children over time. In combination with detailed band and cohort fixed effects, and changes in government policy this type of variation is a credible way to identify variation the effect of residential school. This will be used as the main source of identifying variation.

\section{Public Revelation of Abuse}

In 1990, Phil Fontaine, then head of the Association of Manitoba Chiefs, later 
Grand Chief of the Assembly of First Nations, came forward with his experiences of sexual abuse at the residential school in Fort Alexander, Manitoba. He claimed physical, sexual and psychological abuse was commonplace in the residential school system and called for a national inquiry to what occurred at the residential schools.

Although allegations of abuse had existed since the origins of the system, until Fontaine spoke out, the criticisms were largely ignored (TRC 2012). In 1994 the Assembly for First Nations released the report "Breaking the Silence: An Interpretive Study of Residential School Impact and Healing as Illustrated by the Stories of First Nation Individuals." In 1991 the Cariboo Tribal Council published their study on the impact of residential schools on their members and in 1994 the Nuu-ChahNulth Tribal Council did the same. All three of the studies recounted stories of deprivation, neglect and abuse. The 1991 Royal Commission on Aboriginal people concluded, after hearing professional historical testimony and speaking with former students, that despite department efforts to establish guidelines for punishment in federal schools, abusive treatment existed through the history of the system. ${ }^{40}$ Lawsuits and criminal charges began to occur throughout the country, captured international attention (Economist 2000), and eventually ended in the largest class action lawsuit in Canadian history: The Indian Residential Schools Settlement Agreement (Reimer, 2010).

The settlement agreement consisted of four main components. The first is the 40

The directives regarding strapping, which first were implemented in 1949 and were tightened in 1953 and 1962, did not prohibit other forms of punishment such as confinement, public beatings, and deprivation of food, all of which continued to be commonly applied well past 1950 (Report of the Royal Commission of Aboriginal People 1996, p.275). 
Common Experience Payment. This payment is given to every individual who attended a residential school. Individuals are compensated ten thousand dollars for their first year of attendance, and three thousand for every year after. Approximately 80,000 children who attended these schools received compensation. The Independent Assessment Process was the second component of the settlement, which was designed to provide additional compensation to students who suffered physical, sexual assaults or any other wrongful acts committed by adult employees of the government or church while attending a residential school. Currently, the assessment process expects 29,000 people to apply (Curry 2012). The third component of the settlement required the establishment of a "Truth and Reconciliation Commission" in order to acknowledge residential school experiences, the impacts and the consequences of the residential schooling system. The commission was also required to promote public awareness about the Indian residential schooling system and to create a as complete as possible historical record of the system. Finally, it set aside funds for the Aboriginal Healing Foundation whose mandate is to assist in healing from the residential school experience (Indian Residential Schools Settlement Agreement, 2006). Students who attended day schools are now launching their own lawsuit for the treatment they received (CBC, 2012).

\section{B Data Appendix}

\section{B.1 The 1991 Aboriginal Peoples Survey}

The 1991 Aboriginal Peoples Survey is a post-Census survey that derives its population from those that either claimed Aboriginal ancestry or Indian Status under 
the Indian Act in the Census. Those in the APS sample were further required to "identify" with their Aboriginal origins ${ }^{41}$ The long form was given to 20 percent of households off reservation and 100 percent of people on reservation. The data was collected by personal interviews with respondents, and in 17 percent of cases the survey was conducted through another household member on the behalf of the respondent if they were absent at the time of interview. The data was collected in June 1991 and response to the survey was voluntary. The response rate was 79 percent. Contact could not be made with 14 percent of the sample and 7 percent refused to be interviewed. If an individual did not answer a question used to construct a specific dependent variable or if they were missing any of the primary dependent variables, they were excluded from that part of the analysis.

It is important to note that the survey does not include the institutional population (such as those in prisons) nor does it include the homeless. To the extent that residential schooling increases incarceration rates or homelessness, the results here will be biased. This issue is explored further in the online data appendix. To get a sense of how important this could be, I form an estimate of the Canadian Aboriginal homeless population. According to the 2011 Vancouver Homeless Count (2012), there were approximately 2,650 people either visibly homeless or in shelters. I focus on Vancouver because it has a high proportion of homeless and a relatively large Aboriginal population. Twenty-seven percent of these individuals self-identified as

\footnotetext{
${ }^{41}$ The identification question was: "With Which Aboriginal group do you identify? North American Indian, Inuit, Métis, Another Aboriginal group?" If they didn't identify with an Aboriginal group they asked if they were "a registered Indian under the Indian Act of Canada"? If they said no, they were asked one final question and were then excluded from the survey. If residential schools were extraordinarily effective at integration and out-marriage, then people may not identify as Aboriginal and as a consequence my estimates will be a lower bound on the assimilation resulting from residential schools.
} 
Aboriginal. Extrapolating this number to the other four cities over one million people in Canada, and weighting by their population sizes (Statistics Canada 2013), yields an estimate of approximate 5,000 Aboriginal homeless. Adding the number of federally incarcerated Aboriginal people, approximately 3,400 (CBC 2013), yields a final number of approximately 8,400 Aboriginal people not observed. An estimated 150,000 Aboriginal people attended residential school. If all of these 8,400 individuals attended residential school, it implies they would make up 5.6 percent of the residential schooling population. It should also be kept in mind that this research inherently looks at individuals who are still living. Many of the children who attended residential school did not live until adulthood (Milloy 1999). To the extent that this fraction is higher than for children that did not attend residential school, the results will be biased.

A notable disadvantage to the 1991 APS is that separate residential schooling questions were asked to those between the ages of 50 and 64 and for those between 15 and 49. The question asked to those between 50 and 64 was, "Did you ever attend a residential school?". The question to those less than the age of 49 asked first whether an individual attended a single elementary school or multiple elementary schools. Then they were asked subsequently, "Where did you live while attending school: a) lived with family while at school; b) lived with a non-aboriginal family while at school c) lived at a residential school d) lived somewhere else." This process was then repeated for high school education if attendants ever made it to high school. All of these sub-questions were used to create a single indicator of whether an individual ever attended a residential school. The empirical model was run on both samples separately and comparability does not seem to be an issue. Anyone 
over the age of 65 was not asked any questions regarding their education.

The Métis and Inuit were excluded from the analysis in order to avoid overgeneralizing. Although the Métis were affected by the residential schooling system, their experiences were unique and I do not include them here due to the risk of over-generalizing. The explicit policy outlining admission of Métis students was drawn up in a 1911 contract between the Federal government and the churches. Clause 4(b) of the contract stated that Métis children were not to be admitted unless Indian children did not fill the residential school authorized admission level. If this was the case, the Superintendent General could provide authorization for the child to be admitted, but the school would bare the full cost of the admission. This policy was maintained throughout the rest of the history of the system (RCAP, 1996). For a discussion of the Métis and Indian Residential schools see Chartrand, Logan and Daniels (2006). I restrict the location of residence to the western provinces because residential schooling serviced a greater proportion of individuals than in the Eastern provinces; these bands are more uniform in their pre-settlement contact and educational alternatives, and this avoids dealing with the unique circumstances of the Inuit. The Inuit had very little contact with formal schooling in general and were subject to Indian Residential Schools much later than most of Canada. For a discussion of the Inuit experience see King (2006). Aboriginal peoples in the West faced substantially different circumstances than those in the East in ways that might violate the assumptions of the framework outlined in this paper. The first, western Aboriginal people were viewed as less "socially advanced," than those in the Eastern provinces (Sealey 1980; Miller 2004, 245); as early as 1869 and 1884 the federal government began granting a considerable levels of self-government for 
"the more progressive bands," and by 1946 with very few exceptions, all bands in Ontario Quebec, and the Maritime Provinces were under the elective system, while no bands in Western Canada were (MacInnes 1946, 392-394). In addition western Canada did not have long standing day schools like in the Eastern provinces by the early 1900s there were 28 Aboriginal day schools in the Atlantic provinces alone (Hamilton 1986) and over one hundred in the Eastern provinces. Residential schools were also more prominent in the western provinces as a result of the treaty making process during the $1870 \mathrm{~s}$, in an attempt to avoid violence and the decline of the buffalo (Glenn 2011). All of these facts could heavily influence the ability of Aboriginal communities to drive the opening and closure of residential schools, and resulted in substantially different time patterns than in the Eastern provinces. Restricting the sample to the western provinces also clarifies the counter-factual environment faced by the Indigenous population. The sample is restricted to those older than 20 in order to ensure individuals are given a chance to complete their high school education, and it is restricted to those younger than 65 , since anyone older was not asked schooling questions in the 1991 APS.

\section{B.2 Dates of School Closure}

I use information from the Aboriginal Healing Foundation on the dates of closure, opening, and location of different residential schools across the country 42 These are certainly not the only dates of opening and closure of residential schools that

\footnotetext{
${ }^{42}$ These dates and locations can be found at http://wherearethechildren.ca/en/about/ahf.html. Last Retrieved September 29, 2012.
} 
could be used. For example If the school was transferred to a band or group of bands before the school was ultimately closed, the date of transfer was given instead of the date of closure. To obtain actual dates of closure of the schools, I use records compiled by the General Synod Archives of the Anglican Church. I have also run specifications which use the dates of federal government involvement used in the Residential Schools Settlement Agreement. These last two sets of dates are not used as the main specifications because many of the dates extend well past the time when the schools resembled the historical residential schooling system; however, similar results are found using either set.

A total of sixty-two schools are included in the main analysis. This is approximately half of all the residential schools that existed. The other schools are not used either because they were in the territories or the Eastern provinces or closed before the time the individuals in my sample were of schooling age. In addition, many schools are often listed separately but are in fact geographic and religious continuations of each other and thus I do not count them as different entities. Finally, at times schools of different religious affiliations existed in the same area and I choose only the closest school. The sample of schools is further restricted beyond the sixty-two schools because I limit attention to those communities with residential schools that closed before 1965.43

For each cohort in each community $z_{j t}=1$ if a school was open when a given cohort would have been affected by the compulsory school attendance laws. Oth-

\footnotetext{
${ }^{43}$ Past 1965 the federal government began to take over residential schools from the churches and the Aboriginal people began to acquire more authority in the education of their children and residential schools began to become more ambiguous in nature with some acting solely as hostels rather than schools. Restricting the analysis to schools that closed pre-1966 makes understanding what it means to attend residential school more straight forward and does not have a qualitative impact on the results.
} 
erwise, $z_{j t}=0$. Before 1945, the mandatory school attendance ages for Aboriginal children were defined through the Indian Act. In 1920, the mandatory ages for school attendance were seven to fifteen. In 1930, there was an amendment to the Indian Act to extend the mandatory ages to sixteen. To be eligible for the Family Allowance implemented in 1945, parents had to comply with provincial schooling laws. Thus, mandatory ages are defined to comply with both federal and provincial legislation after 1945. The provincial schooling ages and their changes over time after 1945 is taken from Riddell and Song (2011). Riddell and Song (2011) expand upon the initial data collected by Oreopoulos (2006).

It is important to understand what the closure of the closest residential school implies. If the closest school to a community closes $-z_{j t}$ changes from one to zero - it implies that the cost of enforcement has increased for the federal government. This also implies the government will have a weaker incentive to enforce attendance at residential school and thus fewer children will attend. However, there still may be a subset of children who are forced to attend residential school despite its increased cost to the government. These children will attend a residential school further away. In addition, if the closest residential school was Catholic and a child's parents were Anglican, the closure of the closest residential school would not affect their attendance. As a consequence, the closure of the closest residential school does not induce attendance to drop to zero. Tests for a structural break in residential school attendance suggests the decrease in attendance after closure is 21.4 percent with a standard error of 6 percent. Tests indicate that there is no statistical trend in attendance before school closure, with the pre-closure slope coefficient of attendance equal to -0.01 with a standard error of 0.01 . 


\section{B.3 Mapping Individuals to Communities}

The communities that are matched are all areas defined as Indian reserves, settlements, or unorganized regions that contain Aboriginal communities that can be linked to a band. In some cases, villages or towns are included if they are associated with a particular Aboriginal band identified in the 1991 Census. Note here that the way I am defining communities is based on census subdivisions which are municipalities or areas that are deemed to be equivalent to a municipality for statistical reporting purposes such as an Indian reserve (Statistics Canada). The reader should note that there are technically many more reservations than Census subdivisions. There are 2,675 reserves Canada wide, but only 615 bands. Over half of these reservations are in British Columbia (http://www.gov.bc.ca/arr/reports/facts/overview.html). Census Subdivisions often aggregate many smaller settlements into larger statistical areas.

Once the sample is weighted using the population weights, nearly 50 percent of registered Indians who are in my sample do not currently live in one of the specified Aboriginal communities that have been linked to a school. Unweighted, this proportion of the population is a much less important part of the sample. Although the APS does not specify where an individual was born, it does specify what band an individual belongs to. More than half of these bands have a legally defined land base. A large fraction of these land bases link uniquely to only one or two CSDs. Using Aboriginal Affairs and Northern Development Canada's (AANDC) legal-linkage files of bands to CSDs, I can reconstruct an individual's "origin" communities. The draw-back of these files are that they define bands only by their 2006 names and their 2006 CSD. These differ substantially in some cases from their 1991 names 
and definitions. I convert the 2006 CSD using the correspondence tables proved by Statistics Canada to link the 2006 CSD to the 2001 CSD, then the 2001 divisions to the 1996 CSD and finally back to the 1991 CSD. Codes are aggregated when necessary to produce reasonably consistent geographic regions.

Neither Statistics Canada nor AANDC provides a correspondence table between the 2006 band definitions and the 1991 band definitions. I construct a correspondence using sources such as the Canadian encyclopedia or band websites which often provide band histories. A total of 420 out of the 660 bands in 2006 either had the same name in both years or were incorrectly spelled in 1991 and thus were straightforward. A total of 196 bands experienced name changes. Approximately 44 of the bands were difficult to match, either because they had been dissolved, reformed, or had no legal land base and needed to be matched based on their traditional locations.

Another limitation of the band listings in the 1991 APS is that some individuals did not list their band but instead listed their tribal council or the ethnic group they belonged to (for example, instead of saying Bigstone Cree or Chapleau Cree, they would just list Cree). In these cases, I link the tribal council or ethnic group to a large subset of possible CSD.

If a band is linked to more than one possible sub-division, I use the 1991 Confidential Long Form Census files to estimate the probability of being from each of these divisions, given each band. I then match individuals who currently reside outside one of the previously specified Aboriginal communities to one of these divisions using these estimated probability distributions. If a community has no legal land base, or if there are no individuals in the communities predicted given their 
band's legal land base, I estimate the probability distribution of their location based on where they actually are.

Note that using the 1991 probabilities rather than the probabilities at the time the individuals were in school is a matter of practicality. I have been unable to find a statistical resource that would allow me to calculate these probabilities for earlier time periods. What do exist are the number of "Indians" in a particular census division in 1921, 1931, 1941, and 1951, and every five years thereafter. Theoretically, these broader regions could be linked to bands using the 1991 geographic distribution of First Nations. However, given the reliance on the 1991 distributions, this route would add little over what aggregation of the 1991 distributions would provide.

\section{B.4 Abuse Data}

The data used in this section was acquired through Aboriginal Affairs and Northern Development Canada and the Indian Residential School Adjudication Secretariat. The data were generated as a consequence of the Indian Residential Schools Settlement Agreement.

The settlement agreement consisted of four main components. The first is the Common Experience Payment. This payment is given to every individual who attended a residential school. Individuals are compensated ten thousand dollars for their first year of attendance, and three thousand for every year after. Approximately 80,000 children who attended these schools received compensation. The third com- 
ponent of the settlement required the establishment of a "Truth and Reconciliation Commission" in order to acknowledge residential school experiences, the impacts and the consequences of the residential schooling system. The Independent Assessment Process was the second component of the settlement, which was designed to provide additional compensation to students who suffered physical, sexual assaults or any other wrongful acts committed by adult employees of the government or church while attending a residential school. Currently, the assessment process expects 29,000 people to apply (Curry 2012).

The number of approved abuse cases I have access to is 8,960 . This sample distribution of abuse cases used here may inaccurately represent the final distribution if some threshold number of victims in a cohort and community making an abuse claim is required before all victims claim. However, as long as reaching the threshold number of abuse claims is not correlated with the socioeconomic outcomes of interest, then this would only result in attenuation bias. If an effect of abuse is found, then we can assume it is a lower bound. It should be noted that the process of filing an abuse claim is completely confidential and all claims undergo an examination process regarding their plausibility. Thus, it is feasible that individual abuse claims are not inherently correlated with each other within a cohort or community. In addition, the process of needing to validate claims acts as a disincentive to filing a false claim. If anything, the application process and extensive examination of the claims would result in under-reporting.

In addition, two things should be noted regarding the possible cohort patterns in abuse reporting. First, one might suspect that older generations would be less likely to report any abuse (or even recognize some forms of physical maltreatment as 
abuse - such as being hit with a leather strap) even if there was more abuse present during the era they attended school. In the data, there does appear to be a correlation between the number of abuse cases and the decade of attendance: individuals who attended residential schools in later decades are more likely to claim severe forms of sexual abuse. However, any cohort trends that may be correlated with the socioeconomic outcomes of interest are taken into account by cohort specific fixed effects in all of the specifications. Second, the main results presented in the last sections were only for a sub-sample of schools that closed relatively early. To the extent that staff in schools that closed before 1965 date were more abusive than staff in schools that closed after, the estimates in the last section will under-estimate the positive economic effects of residential school. In this section, I include all schools that I have abuse information for.

\section{Geographic Data Sources}

1. ESRI ArcCanada 3.1. csd_1991.shp [1991 Census Subdivisions - Canada] [computer file]. (2005) Redlands, CA: Environmental Systems Research Institute.

2. Canadian Atlas Map Bundle. BCmdppn.shp [British Columbia mid-sized population points] [computer file]. 2010. Markham, ON: DMTI Spatial. Available:

3. Canadian Atlas Map Bundle. BCmjppn.shp [British Columbia major popula- 
tion points] [computer file]. 2010. Markham, ON: DMTI Spatial. Available: $\mathrm{UBC}$

4. Canadian Atlas Map Bundle. BCmnppn.shp [British Columbia minor population points] [computer file]. 2010. Markham, ON: DMTI Spatial. Available: $\mathrm{UBC}$

The last three sources are the exact same except "British Columbia" is replaced with all other provinces and "BC" with the appropriate provincial abbreviation. 